\title{
BERYLLIUM DIFFUSION OF RUBY AND SAPPHIRE
}

John L. Emmett, Kenneth Scarratt, Shane F. McClure, Thomas Moses, Troy R. Douthit, Richard Hughes, Steven Novak, James E. Shigley, Wuyi Wang, Owen Bordelon, and Robert E. Kane

\begin{abstract}
Over the past two years, the heat treatment of corundum involving lattice diffusion of beryllium (Be) at temperatures over $1800^{\circ} \mathrm{C}$ has become a major issue in the gem trade. Although initially only orange to orangy pink ("padparadscha"-like) sapphires were seen, it is now known that a full range of corundum colors, including yellow and blue as well as ruby, have been produced or altered by this treatment. An extension of the current understanding of the causes of color in corundum is presented to help explain the color modifications induced by Be diffusion. Empirical support is provided by Bediffusion experiments conducted on corundum from various geographic sources. Examination of hundreds of rough and faceted Be-diffused sapphires revealed that standard gemological testing will identify many of these treated corundums, although in some instances costly chemical analysis by mass spectrometry is required. Potential new methods are being investigated to provide additional identification aids, as major laboratories develop special nomenclature for describing this treatment.
\end{abstract}

arly in 2002, it became apparent that corundum treated by a new technique in Thailand had been filtering into the marketplace unannounced, particularly in Japan. It was subsequently learned that these stones had been traded for at least six months prior to this discovery, perhaps longer. The first announcement of this situation-an alert issued by the American Gem Trade Association (AGTA) on January 8, 2002-prompted substantial activity in gemological laboratories worldwide. Quite rapidly it was demonstrated that this new process involved diffusion of the light element beryllium (Be) into a wide variety of corundum types to alter their color.

The diffusion of beryllium into corundum creates yellow, orange, or brown color components. The effectiveness of this process in turning pale-colored or nearly colorless corundum into vibrant yellows and oranges is dramatic. No less dramatic is the alteration of pink sapphire to a "padparadscha" appearance or a vivid orange, as well as the conversion of bluish rubies to a fine red color. It also can reduce the amount of blue in dark blue sapphires, rendering them a more attractive color (figure 1).
Our initial interpretation-that this color alteration was caused solely by the diffusion of beryllium into the stone in an oxidizing atmosphere-was denied by those involved with the treatment process, and was questioned by other gemologists. Their arguments hinged primarily on observations that apparently similar starting materials could emerge from this process as a variety of colors, or completely unchanged. We believe that those observations are correct, but their interpretation is not. To understand the unusual behavior of beryllium in this material, we will have to examine far more closely the origin of color in corundum.

In addition to their changes in color, these stones exhibit many other features-both internal and on the surface - that indicate very high-temperature heat treatment and/or long periods of treatment. Taken together, these features indicate that a new treatment regime has been introduced into the jewelry trade.

See end of article for About the Authors and Acknowledgments. Gems \& Gemology, Vol. 39, No. 2, pp. 84-135.

(C) 2003 Gemological Institute of America 


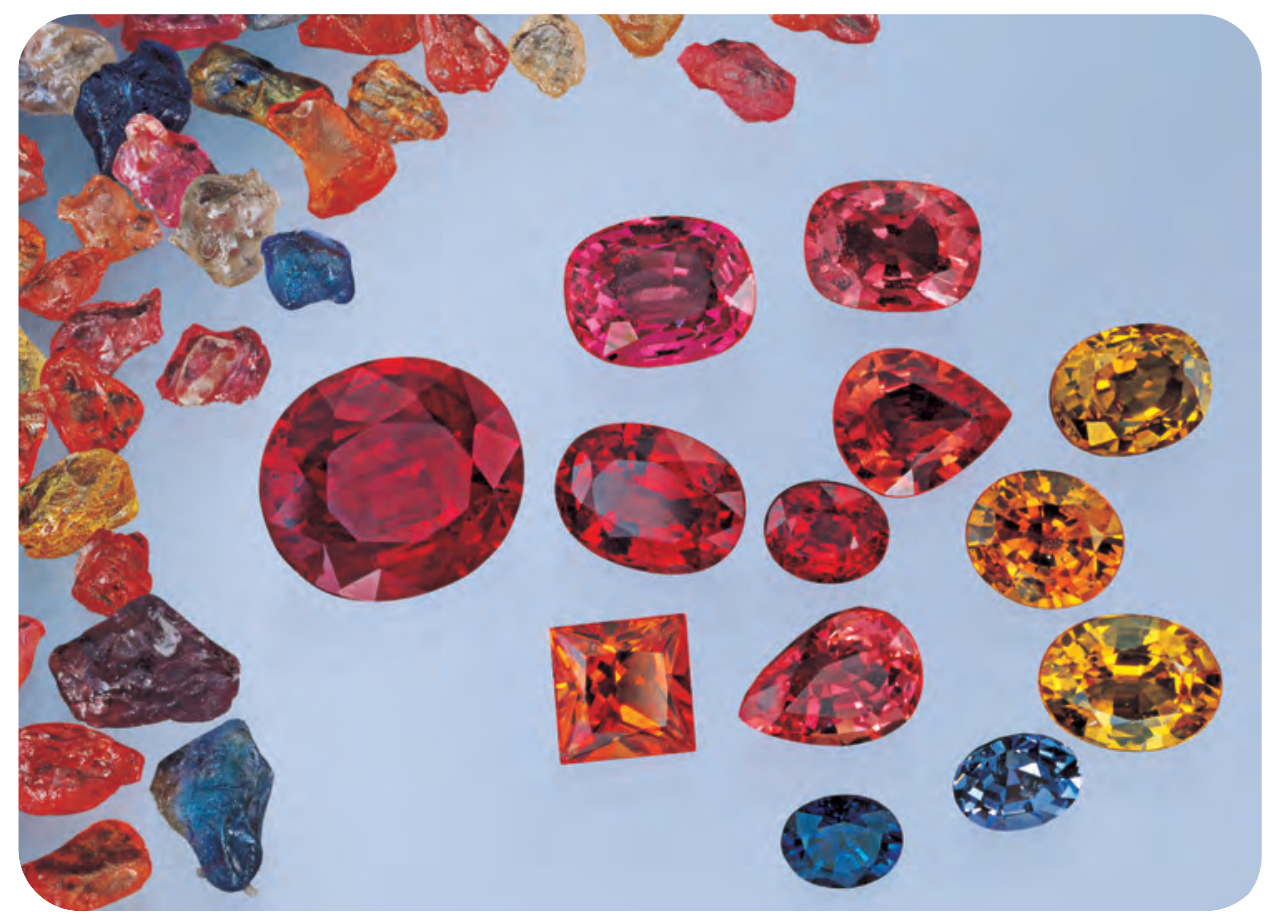

Figure 1. The beryllium diffusion process can affect many colors of corundum, including ruby and blue sapphire. The Be-diffused stones shown here range from 0.40 to 5.05 ct. Photo by Harold $巴$ Erica Van Pelt.

We start this discourse with a short historical discussion of corundum heat treatment and the connection of this new treatment to previous processes. That is followed by a summary of recent progress on beryllium diffusion. Next we delve deeply into the causes of color in corundum, extending the current understanding, to elucidate how a minute amount of this light element can cause such a variety of dramatic color alterations. To this end, we performed a series of Be diffusion experiments in one of our laboratories. We also studied a large number of Be diffusion-treated sapphires (some, both before and after treatment), untreated sapphires, and sapphires treated only by heat, using a variety of gemological and analytical methods. On the basis of the examinations and testing conducted, we present criteria for determining if stones have been Be diffused-some are quite simple, and some require advanced analytical instrumentation.

Finally, we note that this new treatment process has caused gemological laboratories to re-evaluate their thinking about corundum treatments in general, and the manner in which the treated stones should be described on laboratory reports and other documents in particular. Current descriptive language used on reports issued by the AGTA Gemological Testing Center and the GIA Gem Laboratory is presented.

Before we proceed, let us take a moment to explain the nomenclature that we will use in this article. The original diffusion process in which titanium was diffused from the outside of a piece of corundum into the bulk of the stone, producing a blue layer under the surface, was called "surface diffusion" by some gemologists (see, e.g., Hughes, 1997, pp. 121-124). However, the term surface diffusion is used in many other disciplines to mean a process by which a material moves over a surface, rather than through the surface into the interior. As recommended by the International Union of Pure and Applied Chemistry (Kizilyalli et al., 1999|, the scientifically correct term for the process by which a foreign material moves into and through a solid is lattice diffusion, previously referred to in the scientific literature as bulk diffusion. For the purposes of this article, we will use the term lattice diffusion or (in its shortened form) diffusion to describe this process.

\section{BACKGROUND}

Corundum has been heat treated with moderate color improvement since antiquity. However, today's modern heat-treatment techniques produce dramatic results when compared with the subtle changes of the past. The historic turning point was the discovery, apparently in the 1960s (see Crowningshield, 1966, 1970; Beesley, 1982), that the translucent milky white to yellow to brown and bluish white sapphire from Sri Lanka, known as geuda, could be transformed to a fine 
transparent blue by atmosphere-controlled hightemperature heating. This discovery was made possible by the availability of simple furnaces capable of reaching temperatures in the $\geq 1500^{\circ} \mathrm{C}$ range. The striking color change in the geuda material was caused by the dissolution of rutile inclusions in the stone, and by the inward diffusion of hydrogen from the reducing atmosphere. The importance of hydrogen diffusion was not recognized until much later (Emmett and Douthit, 1993). Eventually, tons of previously worthless geuda corundum were converted to marketable transparent blue sapphire.

The benefits of this process with geuda sapphire led to successful experimentation with many types and colors of sapphire (e.g., Crowningshield and Nassau, 1981; Keller, 1982; Themelis, 1992; Emmett and Douthit, 1993) as well as off-color ruby. As a result, the vast majority of rubies and sapphires traded today have been heat treated.

Initially these gems entered the market without any form of disclosure. By the time buyers did learn they were treated, the stocks of gem merchants were full of stones with color created by a high-heat process. In the mid-1980s, international regulatory bodies such as CIBJO decided that, because the heat treatment of sapphire was a "traditional trade practice," such a treatment need not be declared in the course of trade. The concept that turning unattractive corundum into a gem by heating it in an atmosphere-controlled furnace should be regarded as "traditional" was questionable from the outset, but the situation had reached a stage where something had to be done to allow trading to continue. Thus, the heat-treated geuda sapphires were placed in the same category as the far milder historic corundum heat treatments.

Diffusion-treated corundum first appeared on the world market in the late 1970s (Crowningshield, 1979). This process marked a radical departure from all earlier corundum heat treatment in that it produced a thin outer layer of saturated blue coloration in otherwise colorless or pale-colored sapphire by diffusing titanium into the stone from the outside. As such, it represented the first successful attempt to add color to sapphire from an external source. The technology was developed by Union Carbide Corp. and then sold to Golay Buchel. Eventually, treaters in Thailand also used this process (Kane et al., 1990; Hughes, 1991a,b). Nearly all sapphires produced by this method were blue, but a few orange stones also were seen (Scarratt, 1983). In
1993, GIA researchers reported on the experimental production of red "diffusion-treated" corundum (McClure et al., 1993).

In October 2001, Australian gemologist Terry Coldham informed one of the authors that a treater in Chanthaburi, Thailand, had developed a new method to transform bluish red Songea (Tanzania) stones to a fine orange to red-orange (Coldham, 2002; Hughes, 2002). Shortly thereafter, several other sources confirmed this information. The stones were to be marketed under a variety of new color names, such as "Sunset Sapphire" ("Treated Songea sapphires ...," 2002).

During a visit to Bangkok in November/ December 2001, another author saw the new treated orange sapphires in the gem market, as well as a large volume of orangy pink treated stones similar in color to traditional "padparadscha" sapphires. He later obtained samples for study. When staff members at the AGTA Gemological Testing Center (AGTA-GTC) examined these samples in New York, they found that all showed evidence of exposure to a high-temperature treatment (Scarratt, 2002a). When these stones were immersed in methylene iodide, many displayed unusual yellowto-orange rims surrounding pink cores, which suggested that a yellow colorant was being diffused into pink sapphire.

On December 28, 2001, Ken Scarratt reported his observations to Richard Hughes, who then examined faceted sapphires just purchased in Bangkok by Pala International. He found yellow-toorange rims on most pieces (see, e.g., figure 2). In early January 2002, AGTA and Pala International issued Internet warnings to their extensive mailing lists (Scarratt, 2002b).

Initially, the cause of these yellow-to-orange rims surrounding pink cores (with the overall color of the gems being orange to pinkish orange) was unknown. One of the authors (JLE) suggested in January that the features resulted from lattice diffusion of light elements, producing what are called "trapped-hole color centers" in the crystal lattice of the corundum. While the color produced and the elements added were different, the process was essentially identical to that used more than a decade earlier to produce a blue rim on sapphire by the diffusion of titanium. However, gemologists at Bangkok's Gem Research Swisslab (GRS) and the Gem and Jewelry Institute of Thailand (GIT) suggested that the color enhancement in this orange to orangy pink corundum was due to a 


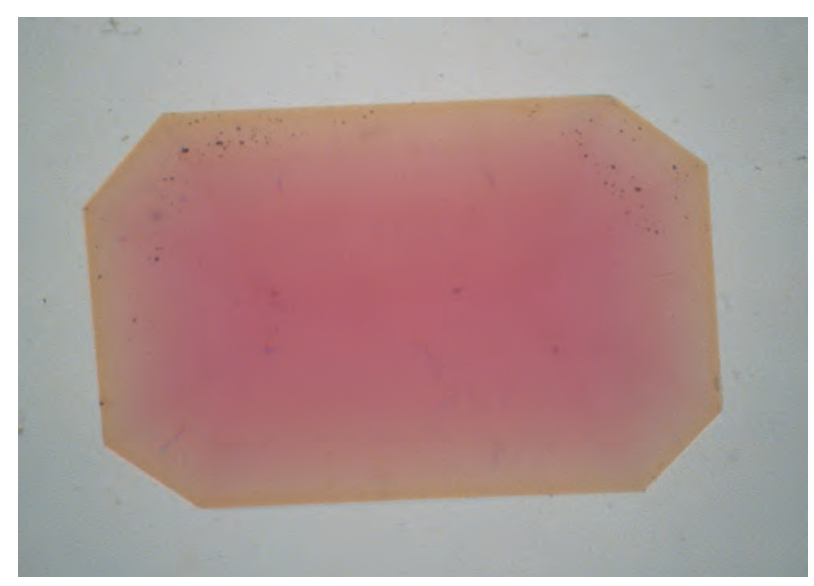

Figure 2. Most of the Be-diffused stones seen early on, particularly in the pink-orange color range, showed distinct yellow-to-orange surface-conformal layers when viewed in immersion. Photomicrograph by Shane F. McClure; magnified 10x.

change in the oxidation state of iron brought about by simple heat treatment (GIT, 2002; Proust, 2002; Weldon, 2002).

At the same time the orange color rims were observed, other unusual features were seen in these stones. Significant overgrowths of synthetic corundum were noted on rough stones (Scarratt, 2002b). In addition, remnants of these synthetic overgrowths were seen in stones re-cut and polished, raising the issue of what portion of the faceted stone was natural (McClure, 2002a). These features, plus unusual inclusion damage, suggested that an entirely new form of heat treatment had been initiated in Thailand.

Toward the end of January 2002, the GIA Gem Laboratory engaged one of the authors (SN) to analyze the treated stones using secondary ion mass spectrometry (SIMS, see Box A). During the AGTAsponsored Gemstone Industry and Laboratory Conference held in Tucson in early February 2002, another of the authors presented the SIMS data, which showed that not only did these stones contain beryllium, but there also was a direct correlation between the depth of color penetration and the depth of Be penetration (McClure et al., 2002). At the time, no standards for chemically analyzing the amount of beryllium in sapphire were available, and thus the absolute magnitude of the Be concentration was incorrect in these data (Wang and Green, 2002a); however, the relationship between beryllium content and the color-altered zone was very clear. Specifically, the concentration of Be decreased from the edge toward the center of suspected treated orangy pink sapphires, and the highest Be con- centrations occurred in the yellow-to-orange surface-related color zones. These results, combined with the surface-conformal nature of the rims, proved that beryllium had been diffused into the stones from an external source for the purpose of creating the observed color.

Following the discovery that Be was the element being diffused into the sapphires, two of the authors began a series of experiments designed to replicate the treatment being used in Thailand (see "Beryllium Diffusion into Corundum: Process and Results" section below). They guessed that the Thai treaters would use chrysoberyl, since it was commonly recovered with pink sapphire in Madagascar. Therefore, they heated Madagascar sapphires in the presence of crushed chrysoberyl $\left(\mathrm{BeAl}_{2} \mathrm{O}_{4}\right)$ to provide the beryllium, and found they could produce all the color modifications seen with the Thai treatment (Emmett and Douthit, 2002a). Simultaneously, scientists at D. Swarovski in Wattens, Austria, were carrying out similar experiments (McClure, 2002b). By May 2002, both the Swarovski and Emmett/ Douthit teams had independently reproduced the results of the Thai process.

After the 2002 Tucson Show, many gemologists began studying this material, which was available in abundance. On May 4, 2002, a meeting was held in Carlsbad, attended by several of the present authors, Dr. George Rossman of the California Institute of Technology, and representatives of the SSEF Swiss Gemmological Institute and the Gemological Institute of Thailand. At this meeting, the results of GIA and AGTA studies and those of Emmett and Douthit were presented and debated. Subsequently, many contributions to the understanding of these stones have appeared in the literature (Coldham, 2002; Hänni, 2002; Hänni and Pettke, 2002; PisuthaArnond et al., 2002; Qi et al., 2002; Peretti and Günther, 2002; Fritsch et al., 2003).

On February 7, 2003, at the Tucson Show, AGTA held a panel discussion on this new process; presentations were given by several of the present authors and others (Shor, 2003). While Thai processors and dealers were still denying that the sapphires were being treated by Be diffusion ("Thailand . . ., "2002), the information presented by this panel was indisputable. Don Kogen, president of Thaigem.com, attended this and other Tucson meetings on Be diffusion as the representative of the Chanthaburi Gem and Jewelry Association (CGA). He vowed to return to his CGA colleagues with this information to help resolve the situation. 


\section{BOX A: SIMS ANALYSIS}

SIMS (secondary ion mass spectrometry) allows us to measure the trace-element concentrations in gems down to ppm (parts per million), a capability never before needed by gemologists. SIMS is one of two commercially available techniques that can measure a wide range of elements down to ppm levels or below-the other is LA-ICP-MS (laser ablation-inductively coupled plasma-mass spectrometry)—without requiring special preparation or significant damage to the gem. It is the remarkable color alteration produced by as little as 10 ppma of beryllium in ruby and sapphire that has forced us to embrace such sophisticated analytical instrumentation. Embracing it has not been easy, as SIMS instruments cost $\$ 750,000-\$ 2,000,000$ each and LA-ICP-MS is more than $\$ 400,000$, well beyond the financial capability of most gemological laboratories. Thus, gem labs typically send samples to major analytical laboratories, recognizing that the cost of a single SIMS analysis can be several hundred dollars.

The first commercial SIMS instrument was developed to analyze the moon rocks brought back by the Apollo astronauts in 1969, and the technique has been used by mineralogists and petrologists ever since. Today SIMS is also indispensable to the semiconductor industry for analysis of semiconductor wafers. SIMS operates by focusing a beam of oxygen ions onto the sample in a vacuum chamber. Ions of the sample material are knocked off the surface of the sample by the oxygen ion beam and drawn into a mass spectrometer, which then sorts the ions according to their atomic weight and charge. Once sorted, the ions are counted, and the counts are converted into a quantitative analysis of the sample (for more information, see Hervig, 2002). Figure A-1 shows a SIMS instrument in operation.

As material (ions) must be removed from the stone, an important question is how much damage is done to the gem during this kind of analysis. The oxygen ion beam itself is very small, and is scanned over a square 150 by $150 \mu \mathrm{m}$ in area, with material removed to a depth of about $200 \mathrm{~nm}$. This shallow depression on a polished gemstone is nearly impossible to see with the unaided eye, but can be observed with a gemological microscope if light is reflected off the surface at certain

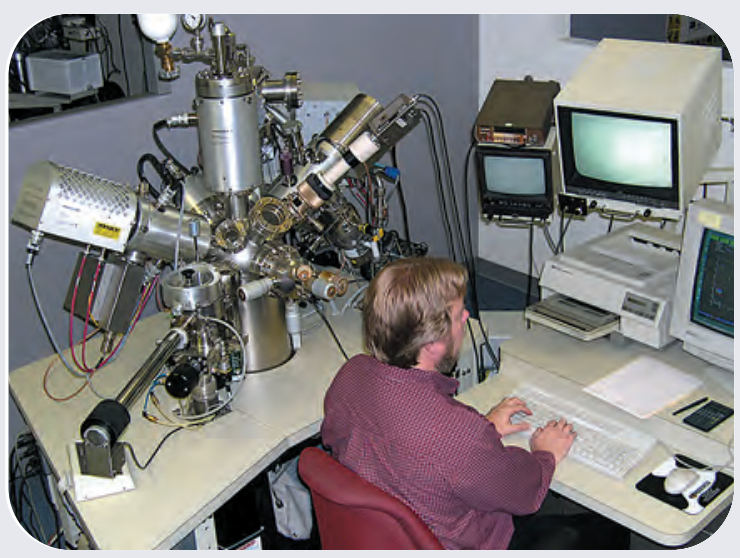

Figure A-1. Shown here is a SIMS instrument in use at Evans East. This PHI 6600, manufactured by Physical Electronics, employs a quadrupole mass spectrometer to detect and sort ions from the corundum sample.

angles (figure A-2). Although generally unnecessary, a light polishing can remove this very small depression.

As with all sophisticated analytical instruments, achieving accurate calibration is a primary issue for SIMS. Having a calibration standard made out of the same type of material as the one being analyzed is by far the best method. (Standards made from other materials can, at best, provide relative concentrations.) One of the authors (SN) has prepared synthetic sapphire standards for the analyses reported in this article, by ion implantation. Widely used in the semiconductor industry, this technique can place a broad variety of elements into sapphire with a concentration accuracy of a few percent or better (Leta and Morrison, 1980). Thus, we can achieve an overall measurement accuracy of better than $25 \%$ an impressive level when one considers that we are trying to measure only 5 to 50 atoms out of a million.

LA-ICP-MS has also been used successfully for this purpose by other researchers. SIMS was chosen for our research because several authors had experience with this instrument in detecting light elements in corundum.

Figure A-2. The ruby in these images was tested with SIMS and then examined at $25 \times$ magnification. In standard darkfield illumination, no mark is visible (left).

With reflected light, however, the mark left behind by the SIMS instrument can be seen (right). The mark is only visible with careful illumination. It would be extremely difficult to find with a hand loupe. Photomicrographs by Shane F. McClure.
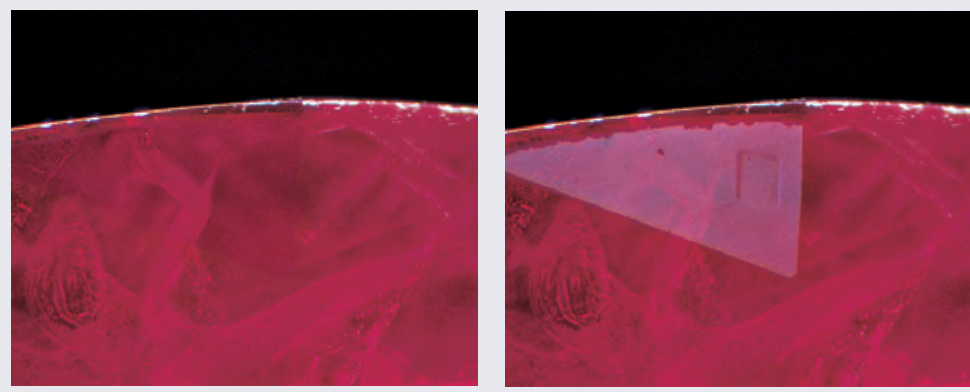
Shortly thereafter, on February 20, 2003, the Chanthaburi Gem and Jewelry Association issued a press release (CGA, 2003) in which they reported that their members had been introducing beryllium into corundum by adding chrysoberyl to the crucibles in which the stones were heated. They further stated that these Be-diffused stones would now be sold separately from other heat-treated corundum.

The Be-diffusion process is, without question, the most broadly applicable artificial coloration of natural corundum ever achieved (see figures 1 and 3). Analyses have indicated that the beryllium concentration in the diffused region is only about 10 to 35 parts per million atomic $\left(\mathrm{ppma}^{1}\right)$ or 4.4 to 15.5 ppmw (see table 1 for a comparison of ppma to ppmw for selected elements). That such minute concentrations of a foreign element could result in such a wide variety of colors and color modifications in corundum is truly unique. To understand how this occurs, we need to examine the causes of color in corundum much more closely than gemologists have done in the past. Much of the information in the following section has appeared in the scientific literature over the past 40 years, or is the result of studies by one of the authors (JLE) over the past 15 years.

\section{COLOR IN CORUNDUM}

The range of color in natural corundum is very extensive, with nearly all colors being represented (figure 4). Pure corundum is comprised only of aluminum and oxygen, and is colorless. Moreover, its spectrum exhibits no absorption (i.e., the material is transparent) from $160 \mathrm{~nm}$ in the ultraviolet to $5000 \mathrm{~nm}$ in the infrared. Gem corundum owes its many colors to impurities (typically trace elements) that have replaced aluminum in the crystal lattice. These impurities can be the direct cause of color, or they can chemically interact with one another to cause color, or to modify the strength (saturation) of a color. For the purpose of

\footnotetext{
1 The more commonly used units for trace-element analyses are ppmw (parts per million by weight), usually written as ppm. One ppm means that there is one microgram of impurity in one gram of crystal. In this article we choose to use the units ppma (parts per million atomic) to state trace-element concentrations. One ppma means that there is one trace-element atom for each million atoms (for corundum, i.e., $400,000 \mathrm{Al}$ atoms $+600,000 \mathrm{O}$ atoms). These units are chosen because it is the concentration of trace elements that determines how they chemically interact, not their relative weights.
}

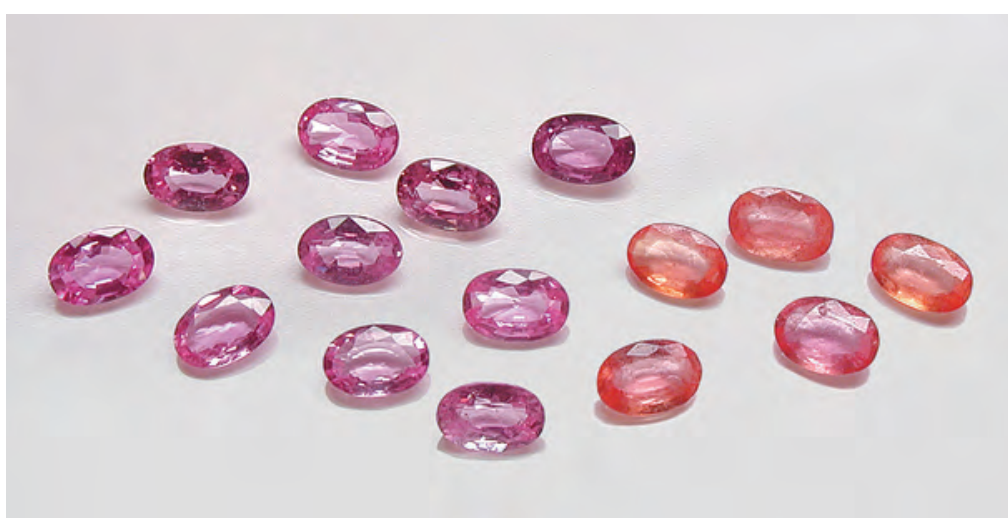

Figure 3. The Be-diffusion process is capable of causing dramatic changes in the color of corundum, such as altering pink sapphire (left, before treatment) to pinkorange (right, after treatment). The samples weigh approximately $1 \mathrm{ct}$ each; photo by Sriurai Scarratt.

this section, we will limit the discussion to colorants of natural corundum and will ignore the additional colorants used in the production of synthetic corundum.

The causes of color in corundum are manifold and have been addressed in many publications. A good general review is provided by Fritsch and Rossman (1987, 1988); Häger (2001) recently reviewed the colors of corundum extensively in the context of heat treatment. The basic causes of color (also referred to as chromophores) are well known: $\mathrm{Cr}^{3+}$ produces pale pink through deep red as concentrations increase, $\mathrm{Fe}^{3+}$ produces a pale yellow, $\mathrm{Fe}^{2+}$ $\mathrm{Ti}^{4+}$ pairs produce blue, and less well recognized $\mathrm{Mg}^{2+}$-trapped-hole pairs are responsible for yellow to

TABLE 1. Comparison of ppma and ppmw for selected elements. ${ }^{a}$

\begin{tabular}{|c|c|c|}
\hline Element & ppma & ppmw \\
\hline Beryllium & 1.000 & 0.442 \\
\hline Sodium & 1.000 & 1.128 \\
\hline Magnesium & 1.000 & 1.192 \\
\hline Silicon & 1.000 & 1.378 \\
\hline Potassium & 1.000 & 1.919 \\
\hline Calcium & 1.000 & 1.996 \\
\hline Titanium & 1.000 & 2.349 \\
\hline Chromium & 1.000 & 2.550 \\
\hline Iron & 1.000 & 2.739 \\
\hline Gallium & 1.000 & 3.420 \\
\hline \multicolumn{3}{|c|}{ ppma $=\frac{\left(\text { molecular weight of } A l_{2} \mathrm{O}_{3}\right) / 5}{\text { (atomic weight of the element) }} \cdot$ ppmw } \\
\hline
\end{tabular}




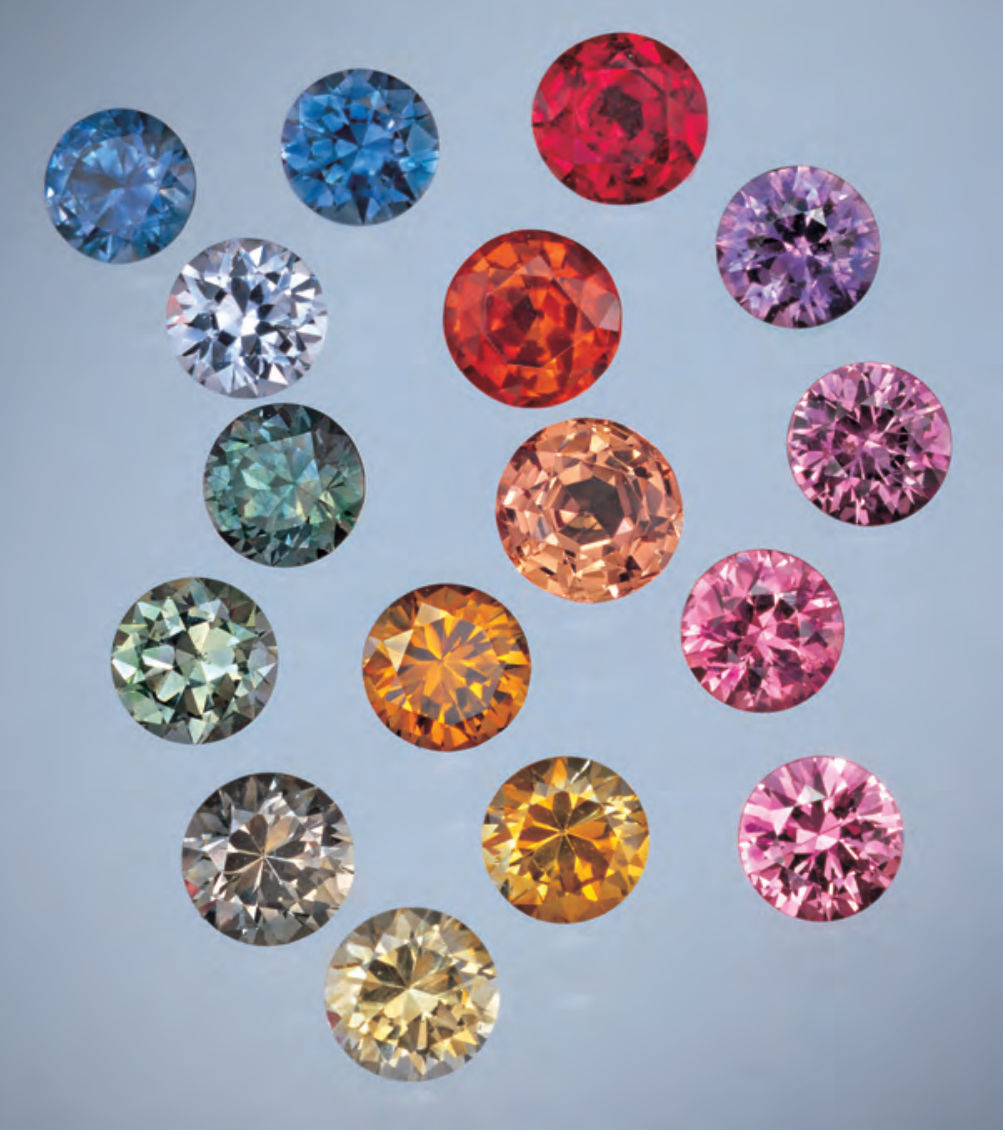

Figure 4. Non-diffused corundum (here, approximately 0.40 ct each), whether natural or heat treated, comes in a wide variety of colors. Courtesy of Fine Gems International; photo by Harold and Erica Van Pelt.

orangy yellow (Kvapil et al., 1973; Schmetzer, 1981; Schmetzer et al., 1983; Boiko et al., 1987; Emmett and Douthit, 1993; Häger, 1993). A much wider range of colors is produced by combinations of these primary chromophores. For example, green is caused by $\mathrm{Fe}^{3+}$ yellow plus $\mathrm{Fe}^{2+}-\mathrm{Ti}^{4+}$ blue. Purple or violet is a combination of $\mathrm{Cr}^{3+}$ red with $\mathrm{Fe}^{2+}-\mathrm{Ti}^{4+}$ blue, and orange can be a combination of the $\mathrm{Mg}^{2+}$ trapped-hole yellow plus the $\mathrm{Cr}^{3+}$ pink.

While these causes of color are understood in very general terms, a more detailed understanding is required to determine the impact of adding beryllium to the already complex set of natural trace elements in corundum. In addition, we must understand the chemical interactions that occur among the various trace elements within the corundum crystal lattice. Although most of us are more familiar with chemical interactions in liquids than in solids, the latter nonetheless occur during the growth of the corundum crystal in nature and during its heat treatment at high temperatures.

First, we must note that there are two general classes of impurities in the corundum lattice: (1) those such as $\mathrm{Cr}^{3+}$ that have the same chemical valence (i.e., a positive charge of three) as $\mathrm{Al}^{3+}$ and are termed isovalent; and (2) those such as $\mathrm{Mg}^{2+}$ or $\mathrm{Ti}^{4+}$ with a valence different from that of the $\mathrm{Al}^{3+}$ they replace-termed aliovalent. The most common impurities in corundum are (by valence):

$$
\begin{aligned}
& \text { +1-Hydrogen }(\mathrm{H}) \\
& \text { +2-Magnesium }(\mathrm{Mg}) \\
& \text { +2-Iron (Fe) } \\
& \text { +3-Iron }(\mathrm{Fe}) \\
& \text { +3-Chromium }(\mathrm{Cr}) \\
& \text { +4-Titanium }(\mathrm{Ti}) \\
& \text { +4-Silicon }(\mathrm{Si})
\end{aligned}
$$

Unfortunately, we know of no complete traceelement analyses (that is, down to the parts per million atomic-ppma-levell in the literature for any natural corundum sample. Yet, as we shall see, as little as 5 to 10 ppma of an impurity can have a substantial impact on the color of corundum.

Isovalent Ions. $\mathrm{Cr}^{3+}$ by itself in corundum produces a red coloration-from pale pink through deep red, depending on its concentration (McClure, 1962; figure 5). The quantitative relationship between the strength of the optical absorption and the concentration of chromium is well known, primarily because it has been carefully studied for ruby laser design (Dodd et al., 1964; Nelson and Sturge, 1965).

$\mathrm{Fe}^{3+}$ in corundum at high concentration $1 \geq 2,500$ ppma) produces a weak yellow coloration (McClure, 1962; Eigenmann et al., 1972; figure 6). The relationship between the strength of the absorption and the $\mathrm{Fe}^{3+}$ concentration is not nearly as well understood as that of $\mathrm{Cr}^{3+}$. The weak broad bands at 540, 700, and $1050 \mathrm{~nm}$, and the narrow peak at $388 \mathrm{~nm}$, have been assigned to single $\mathrm{Fe}^{3+}$ ions, while the narrow peaks at 377 and $450 \mathrm{~nm}$ have been tentatively assigned to $\mathrm{Fe}^{3+}-\mathrm{Fe}^{3+}$ pairs on the nearest-neighbor lattice sites (Ferguson and Fielding, 1971, 1972; Krebs and Maisch, 1971). However, this does not preclude the existence of a higher-order cluster with additional ions or other point defects. A quantitative relationship between the strength of each of these iron-absorption features and iron concentration has not been completely established. 
Charge Compensation. The field known as defect chemistry provides a very useful framework for studying charge-compensation mechanisms at trace-element concentrations and the chemical interactions among trace elements (Kröger, 1974; Kingery et al., 1976; Chiang et al., 1997; Smyth, 2000). In this context a "defect" refers to any deviation from a perfect lattice. Thus impurities, ion vacancies, interstitial ions, and free electrons or (electron) holes are defects. To help explain the impact of diffusion treatment, we will review here a few principles of defect chemistry as it relates to corundum.

In discussing corundum coloration, it simplifies matters somewhat if we think about the charge of an ion relative to the charge of a perfect lattice. In defect chemistry, ions with excess positive charge (e.g., $\mathrm{Ti}^{4+}$ in $\mathrm{Al}_{2} \mathrm{O}_{3}$ ) are termed donors, because they must "give up" an extra electron to enter the corundum lattice. Similarly, ions with a relative charge of -1 are termed acceptors, because they must "accept" an electron from some other ion in the lattice. $\mathrm{Ti}^{4+}$ (for example) has one extra positive charge than the $\mathrm{Al}^{3+}$ ion it can replace in corundum, so we say that its relative charge is $+1 . \mathrm{Mg}^{2+}$ has one less positive charge than the $\mathrm{Al}^{3+}$ it can replace, so we say that its relative charge is -1 . If both magnesium (relative charge -1 ) and titanium $(+1)$ are incorporated together, they will tend to attract each other and co-locate at adjacent or nearby sites in the atomic lattice, thereby balancing their charges. Acceptor or donor properties can also be ascribed to other point defects in the corundum lattice. Thus, oxygen vacancies (relative charge +2 ) and aluminum interstitials $(+3)$ are donors, while oxygen interstitials $(-2)$ and aluminum vacancies $(-3)$ are acceptors.

A crystal must be electrically neutral, which means that the sum of all the relative positive charges and electron holes equals the sum of the relative negative charges and free electrons. Consequently, when an ion with a valence of more or less than +3 replaces $\mathrm{Al}$, the excess or deficiency of electrical charge must be compensated in some way so that the average positive charge still is +3 . There are several ways charge compensation can occur. During growth of corundum at low temperature, pairs of ions, one with a valence of +4 and one with a valence of +2 , could be incorporated near each other in a crystal. The total charge of the pair, +6 , is the same as the two $\mathrm{Al}$ ions they would replace. Thus the crystal remains electrically neu-

\section{UV-VIS-NIR ABSORPTION SPECTRUM}

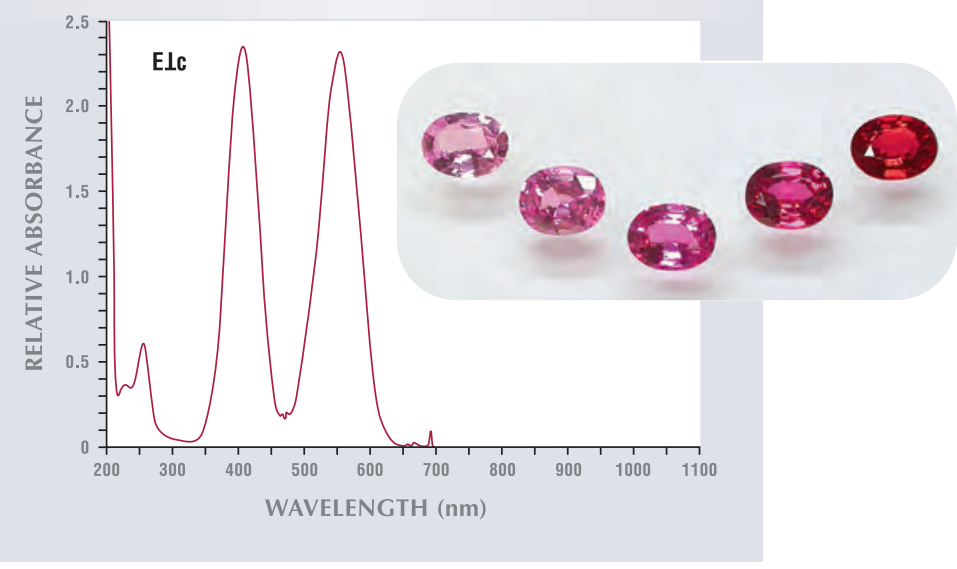

Figure 5. These synthetic rubies and sapphires are colored only by chromium. As the concentration of chromium increases (left to right), so does the saturation of the red. The spectrum shows chromium absorption in corundum. The samples weigh approximately 2.5 ct each; photo by Sriurai Scarratt.

tral. Vacancies (atoms missing from lattice sites) and interstitial ions (atoms located between lattice sites) can also charge compensate trace elements.

Figure 6. The $1.10 \mathrm{ct}$ Australian sapphire on the left is unusual in that its color results only from a high concentration of iron. The $1.40 \mathrm{ct}$ heat-treated Sri Lankan sapphire on the right is colored by $\mathrm{Mg}^{2+}$-trapped-hole centers. Iron causes pale yellow in sapphire primarily by absorption of $\mathrm{Fe}^{3+}-\mathrm{Fe}^{3+}$ pairs as shown in this spectrum. The narrow peak at $388 \mathrm{~nm}$ and the broad bands at 540,700, and $1050 \mathrm{~nm}$ are attributed to $\mathrm{Fe}^{3+}$, while the narrow peaks at 377 and $450 \mathrm{~nm}$ are attributed to $\mathrm{Fe}^{3+}-\mathrm{Fe}^{3+}$ pairs. Photo by Maha Tannous.

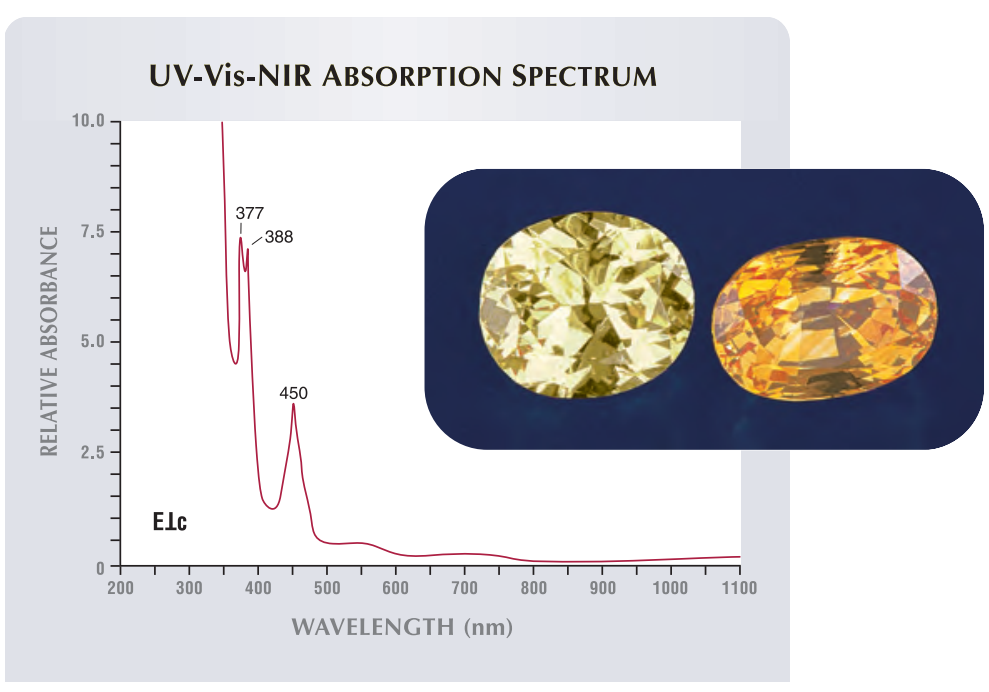


For example, an oxygen vacancy can charge compensate two divalent $(+2)$ ions, and an oxygen interstitial can charge compensate two tetravalent $(+4)$ ions. Likewise, an aluminum $\left(\mathrm{Al}^{3+}\right)$ vacancy can charge compensate three tetravalent ions, and an aluminum interstitial ion can charge compensate three divalent ions. In special cases, a free electron (relative charge -1) can charge compensate a tetravalent ion; or an electron hole (relative charge +1 , hereafter simply called a hole) can compensate a divalent ion. (A hole in corundum can be viewed as an oxygen ion carrying a charge of -1 rather than -2 .)

The way aliovalent ions are charge compensated can be a large factor in determining the color of corundum. As noted above, when an aliovalent ion such as $\mathrm{Ti}^{4+}$ is incorporated into a corundum crystal during growth, it can (in principle) be charge compensated by a divalent ion such as $\mathrm{Mg}^{2+}$, or by an aluminum vacancy, or by an oxygen interstitial ion. However, it takes far less thermal energy to incorporate a divalent ion than to produce an aluminum vacancy or an oxygen interstitial ion. Corundum growth in nature takes place at temperatures from $250^{\circ} \mathrm{C}$ to $1400^{\circ} \mathrm{C}$, depending on the growth environment (G. Rossman, pers. comm., 2003). At these temperatures, it is far more likely that $\mathrm{Ti}$ will be charge compensated by a divalent ion (e.g., $\mathrm{Mg}^{2+}$ or $\left.\mathrm{Fe}^{2+}\right)$, assuming one is available in the growth medium, than by a vacancy or an interstitial ion. However, when corundum is grown in the laboratory at temperatures near its melting point $\left(2045^{\circ} \mathrm{C}\right)$, or is heat treated at high temperatures, charge compensation by vacancies, interstitial ions, holes, or electrons becomes more probable.

Aliovalent Ions. $\mathrm{Fe}^{2+}$ in corundum is an acceptor (Dutt and Kröger, 1975; Koripella and Kröger, 1986). When not associated with other impurity ions, it produces little or no coloration. Its major absorption bands are expected to be located in the near-infrared portion of the spectrum but have not been observed. In corundum with a relatively high iron concentration, $\mathrm{Fe}^{2+}$ often is found paired with $\mathrm{Fe}^{3+}$, leading to the creation of an intervalence charge-transfer (IVCT) absorption (Burns, 1981; Nassau, 1983; Fritsch and Rossman, 1987) centered at $875 \mathrm{~nm}$ (Krebs and Maisch, 1971; Smith and Strens, 1976). This band is very broad, with the short-wavelength edge extending into the red region of the spectrum, thereby producing a weak gray-blue coloration. Because this absorption fea- ture is rarely seen in crystals that do not contain titanium, it is sometimes difficult to evaluate how much of the blue coloration is contributed by this band (as opposed to that contributed by the $\mathrm{Fe}^{2+}-\mathrm{Ti}^{4+}$ pairs). $\mathrm{Fe}^{2+}$ also can be charge compensated by tetravalent donor ions (e.g., $\mathrm{Si}^{4+}$ or $\mathrm{Ti}^{4+}$ ) forming donor-acceptor pairs; by hydrogen, which is also a donor; or, in the absence of either of these options, by an oxygen vacancy or an aluminum interstitial ion.

$\mathrm{Mg}^{2+}$ in corundum is also an acceptor (Mohapatra and Kröger, 1977; Wang et al., 1983). It can be charge compensated by tetravalent donor impurities (e.g., $\mathrm{Si}^{4+}$ or $\mathrm{Ti}^{4+}$ or, in their absence, by an oxygen vacancy or a hole. Charge compensation by an oxygen vacancy can occur when the crystal grows in reducing conditions, or is heat treated in a reducing atmosphere (Emmett and Douthit, 1993). When corundum is grown or heat treated in oxidizing conditions, charge compensation of $\mathrm{Mg}^{2+}$ appears to be by holes. The $\mathrm{Mg}^{2+}$-induced trapped hole (an $\mathrm{O}^{1-}$ ion in the lattice) absorbs light very strongly in the blue region of the spectrum (figure 7), which leads to a yellow to orangy yellow color in natural sapphire. In high-purity synthetic sapphire containing only $\mathrm{Mg}^{2+}$, the color is a violet-brown. The difference between these two colors is caused by the location of the trapped hole in the lattice. In the latter case, the hole is trapped close to the $\mathrm{Mg}^{2+}$ ion. However, in natural sapphires, which contain

Figure 7. The absorption spectrum of the $\mathrm{Mg}^{2+}$ trapped hole, as seen here in synthetic corundum, produces the strong yellow to orangy yellow color in some natural sapphires that are heat treated without beryllium.

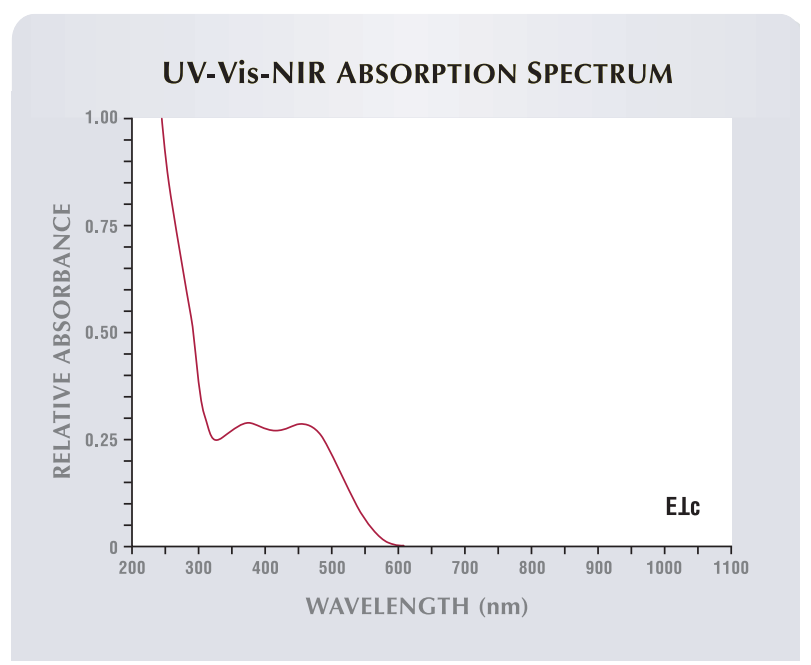


a variety of other impurities, the hole would preferentially associate with $\mathrm{Cr}^{3+}$ if available, or with $\mathrm{Fe}^{3+}$ in the absence of $\mathrm{Cr}^{3+}$, leading to an altered absorption spectrum. As we shall see, in corundum $\mathrm{Be}^{2+}$ behaves much like $\mathrm{Mg}^{2+}$. The heat-treated yellow sapphires of Sri Lanka and the natural-color or heattreated yellow portions of the sapphires from Rock Creek, Montana, are both colored by the $\mathrm{Mg}^{2+}$ trapped-hole mechanism. As shown in figure 6, the weak yellow produced by $\mathrm{Fe}^{3+}$ and the orangy yellow of the $\mathrm{Mg}^{2+}$-induced trapped hole differ greatly in appearance. At this point we should note that the $\mathrm{Mg}^{2+}$-related absorption center may be more complex than a simple $\mathrm{Mg}^{2+}$-induced trapped hole. Häger (1996) has shown that the addition of iron increases the absorption strength of the trapped hole in synthetic sapphire. The details of this interaction remain to be elucidated.

One of the unusual properties of the $\mathrm{Mg}^{2+}$ trapped-hole coloration in corundum is its sensitivity to oxygen partial pressure (oxygen concentration in the furnace atmosphere; Mohapatra and Kröger, 1977; Wang et al., 1983; Emmett and Douthit, 1993). If corundum containing $\mathrm{Mg}^{2+}$ is heat treated in pure oxygen, the color saturation is maximized. If that stone is then re-heated at an oxygen partial pressure of $10^{-3}$ atmospheres (atm), the color saturation is greatly reduced. This very strong relationship between color saturation and oxygen partial pressure is not observed with other chromophores in corundum, such as $\mathrm{Cr}^{3+}, \mathrm{Fe}^{3+}$, and $\mathrm{Fe}^{2+}-\mathrm{Ti}^{4+}$.

Silicon, a common trace element and $\left(\mathrm{as} \mathrm{Si}^{4+}\right)$ a donor in corundum (Lee and Kröger, 1985), produces no coloration but poses some unique issues. All of the other impurities discussed so far normally occupy octahedral sites (i.e., a site surrounded by six oxygen atoms) in corundum and in many other minerals. Si almost always occurs in a tetrahedral site (surrounded by four oxygen atoms) in minerals, although there are no tetrahedral cation sites in the corundum lattice. So far, we do not know whether Si occupies an octahedral site in natural corundum, or forms as micro- or nanosized crystals of some simple aluminosilicate mineral embedded in the corundum crystal. We do know, however, that in Si-containing synthetic corundum that has been heated to high temperature and cooled rapidly (that is, compared to geologic cool-down times), at least a portion of the silicon is located on octahedral aluminum sites (Lee and Kröger, 1985). If Si actually occupies an aluminum site, it will be "active"; that is, it will take

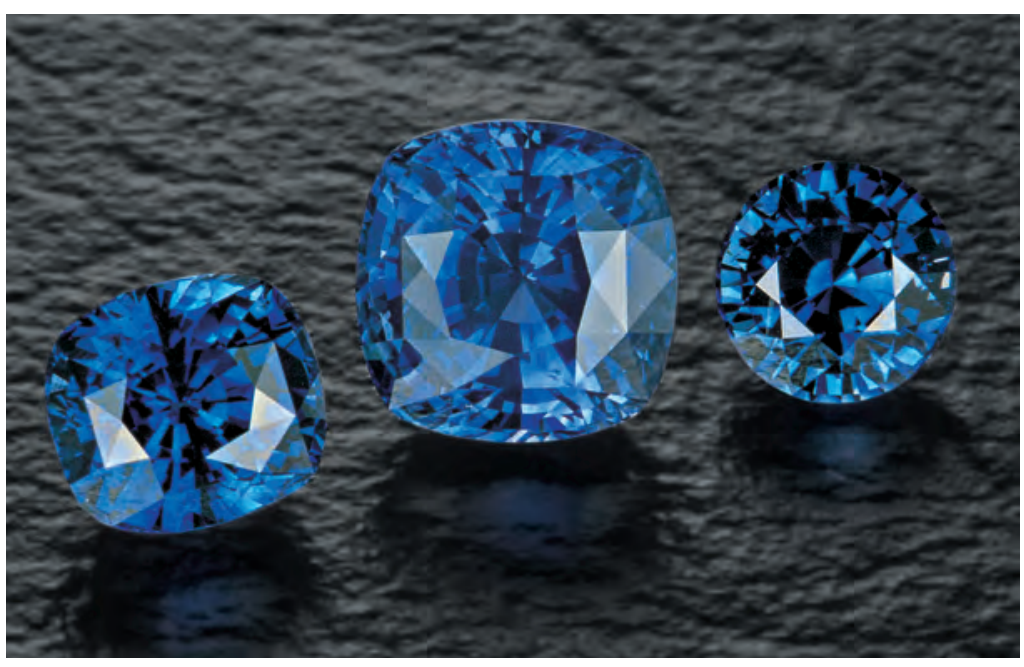

Figure 8. These magnificent blue sapphires (weighing approximately 2-4 ct) owe their color primarily to $\mathrm{Fe}^{2+}-\mathrm{Ti}^{4+}$ pairs. Courtesy of Gordon Bleck; photo by Maha Tannous.

part in the charge-compensation process as a donor. If it is part of a nano-crystal of another mineral phase, it will not. Since we are primarily concerned here with corundum that has been heat treated for tens to hundreds of hours at a very high temperature during the Be-diffusion process, we will make the assumption that low concentrations of naturally occurring silicon (i.e., $\leq 100 \mathrm{ppma}$ ) are in solution on $\mathrm{Al}^{3+}$ sites. Proving this conjecture will require additional studies. We may eventually find that only a portion of the silicon is active.

$\mathrm{Fe}^{2+}-\mathrm{Ti}^{4+}$ acceptor-donor pairs, located on nearest-neighbor Al sites in corundum, produce the strong blue color that we normally associate with sapphire (figure 8), resulting from strong absorptions at 580 and $700 \mathrm{~nm}$. Figure 9 shows the $\mathrm{Fe}^{2+}$ $\mathrm{Ti}^{4+}$ absorption spectrum of a synthetic sapphire sample containing only $\mathrm{Fe}$ and $\mathrm{Ti}$ impurities at color-significant concentrations. This IVCT absorption feature in corundum was first explained by Townsend (1968). More recent studies indicate that the actual defect cluster may contain other ions and point defects in addition to single iron and titanium ions (Moon and Phillips, 1994).

The relative effectiveness of each of these trace elements, or trace-element pairs, in coloring corundum varies widely. Considering the color saturation in a 2 ct stone, in the course of earlier research we observed the following: 2,500 ppma $\mathrm{Fe}^{3+}$ will produce a weak yellow color; 1,000 ppma $\mathrm{Cr}^{3+}$ will produce a strong pink-red; 50 ppma of $\mathrm{Fe}^{2+}-\mathrm{Ti}^{4+}$ pairs will produce a very deep blue; and, finally, 15 ppma of $\mathrm{Mg}^{2+}$-hole pairs will produce a strong 
- When Fe, Ti, and Mg are present, Ti will charge compensate $\mathrm{Mg}$ before Fe.

- When $\mathrm{Fe}, \mathrm{Si}$, and $\mathrm{Mg}$ are present, Si will charge compensate $\mathrm{Mg}$ before Fe.

- When both Ti and Si are present with Fe and $\mathrm{Mg}$, Ti will charge compensate both $\mathrm{Mg}$ and Fe before $\mathrm{Si}$ will charge compensate $\mathrm{Mg}$ and Fe.

- When the concentration of Mg exceeds the sum of the concentrations of $\mathrm{Si}$ and $\mathrm{Ti}, \mathrm{Mg}$ will be charge compensated by oxygen vacancies if the corundum formed or later was heat treated at low oxygen partial pressures. If it was formed or heat treated at high oxygen partial pressures, the Mg will be charge compensated by a trapped hole.

A simple example excluding silicon (Häger, 2001) will illustrate how these rules can be applied. In all of the examples given here, we assume an $\mathrm{Fe}$ concentration substantially greater than the concentration of $\mathrm{Ti}, \mathrm{Si}, \mathrm{Mg}$, and $\mathrm{Be}$, as this is typical of natural sapphire. Suppose we have an iron-containing sapphire with $60 \mathrm{ppma} \mathrm{Ti}^{4+}$. If this stone grew or was heat treated in a reducing environment, all 60 ppma $\mathrm{Ti}^{4+}$ would form $\mathrm{Fe}^{2+}-\mathrm{Ti}^{4+}$ pairs, so the stone would be deep blue. Another stone with exactly the same iron and titanium content but also with 40 ppma $\mathrm{Mg}^{2+}$ would be a lighter blue, since 40 ppma of the $\mathrm{Ti}^{4+}$ charge compensates the $\mathrm{Mg}^{2+}$ leaving only 20 ppma of $\mathrm{Ti}^{4+}$ to form $\mathrm{Fe}^{2+}-\mathrm{Ti}^{4+}$ pairs.

Now consider that the magnesium concentration of our stone is 60 ppma. All 60 ppma of the $\mathrm{Ti}^{4+}$ must charge compensate the 60 ppma $\mathrm{Mg}^{2+}$, leaving none to form $\mathrm{Fe}^{2+}-\mathrm{Ti}^{4+}$ pairs. Thus, if the stone has only a few hundred ppma of iron, it is nearly colorless; with more iron, it would be pale yellow or greenish yellow.

To push our example one step further, suppose that the magnesium content is even higher, at 75 ppma. Now there is 15 ppma excess $\mathrm{Mg}^{2+}$ that is not charge compensated by $\mathrm{Ti}^{4+}$. If this stone formed or was treated at low oxygen partial pressures, it will be nearly colorless or pale yellow, depending on its iron concentration (as for the 60 ppma $\mathrm{Mg}^{2+}$ case). This is because at low oxygen partial pressures, the charge compensation is by oxygen vacancies. However, high oxygen partial pressure would result in a strong orangy yellow color (figure 11), due to charge compensation of the 15 ppma excess $\mathrm{Mg}^{2+}$ by holes forming the trapped-hole color center.

Using square brackets (such as $[\mathrm{Mg}]$ ) to denote concentrations, we have summarized these interactions for iron-containing sapphire in table 2.

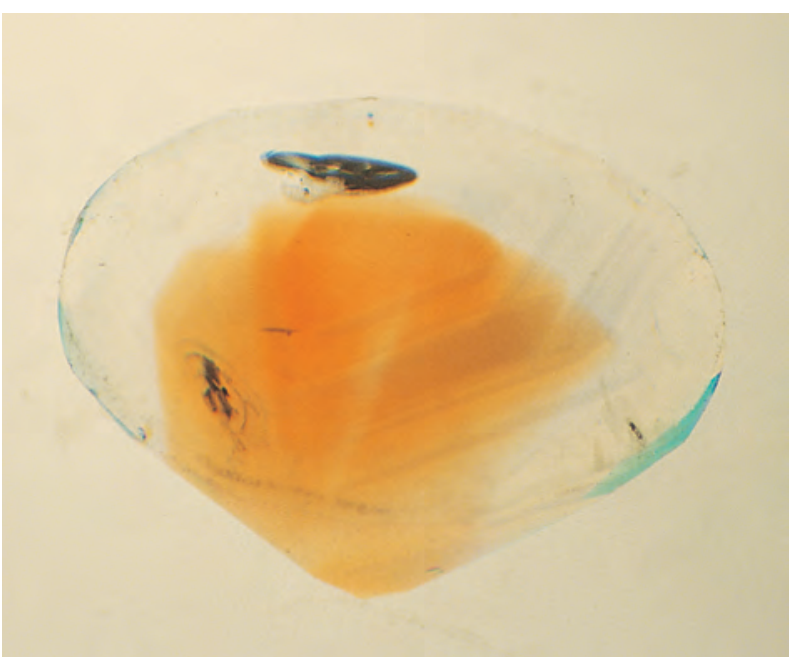

Figure 11. This strong orangy yellow color zone in a heat-treated Montana sapphire is caused by the presence of $\mathrm{Mg}^{2+}$ trapped-hole centers. Photomicrograph by Shane F. McClure; immersion, magnified 10x.

Aspects of this relationship between $\mathrm{Fe}, \mathrm{Ti}$, and Mg have been discussed previously (Häger, 1992, 2001; Emmett and Douthit, 1993). Häger (1993, 2001) represented the charge compensation of titanium by magnesium as $\mathrm{MgTiO}_{3}$ (that is, Ti and $\mathrm{Mg}$ form a cluster occupying two nearest neighbor $\mathrm{Al}$ sites). While this is certainly possible, it is not at all necessary. The charge compensation of these two ions only requires that they be in the same general region of the lattice.

The $\mathrm{Mg}$, Fe, Ti relationship described (Häger, 1992, 1993, 2001; Emmett and Douthit, 1993) is unfortunately an oversimplified model for natural corundum. The actual trace-element chemistry of natural corundum is often far more complex. For

TABLE 2. Relative trace-element concentrations and color in iron-bearing corundum.

\begin{tabular}{ll}
\hline Composition & \multicolumn{1}{c}{ Color } \\
\hline$\left[\mathrm{Ti}^{4+}\right]>>\left[\mathrm{Mg}^{2+}\right]$ & Very dark blue under reducing conditions \\
{$\left[\mathrm{Ti}^{4+}\right]>\left[\mathrm{Mg}^{2+}\right]$} & Blue under reducing conditions \\
{$\left[\mathrm{Ti}^{4+}\right] \approx\left[\mathrm{Mg}^{2+}\right]$} & $\begin{array}{l}\text { Nearly colorless or iron colored (pale yellow } \\
\text { to greenish yellow) under oxidizing or } \\
\text { reducing conditions }\end{array}$ \\
& $\begin{array}{l}\text { Nearly colorless or iron colored (pale yellow } \\
\text { to greenish yellow) under reducing condi- } \\
\text { tions; strong yellow to orangy yellow under } \\
\end{array}$ \\
& oxidizing conditions \\
\hline
\end{tabular}

a Key to symbols:

> "greater than" (approximately 5-25 ppma excess)

>> "much greater than" (approximately 25-100 ppma excess)

$\approx$ nearly equal to 


\section{BOX B: UNDERSTANDING TRACE-ELEMENT INTERACTIONS IN CORUNDUM}

There are several different ways to picture interactions (chemical reactions) among ions in solids. One of these, known as the band model (Bube, 1992; Smyth, 2000), has been exceedingly effective in describing semiconductors. Surprisingly, it has also proved very effective in describing materials like corundum, where all constituents other than aluminum and oxygen are at a concentration of $1 \%$ or far less. Figure B-1 shows a band-model energy-level diagram of corundum and some of its trace elements. In this model, the energy of an electron (in electron volts) is plotted on the vertical axis. The extent of the horizontal axis is meant to imply only that the corundum energy levels are the same everywhere in the crystal. The lowest energy level on this plot is known as the valence band, because it contains all the valence electrons of corundum. The uppermost energy level is called the conduction band, because if it contained a lot of electrons, the solid would conduct electricity. In corundum, the conduction band is empty at room temperature, which is why pure corundum is an excellent electrical insulator. The region between the valence band and the conduction band is called the band gap or forbidden band, which has a width of approximately 9 electron volts in corundum. In pure corundum, the energy-level diagram consists of only the valence band and the conduction band.

When trace elements (impurities) are added to corundum, they can form discrete energy levels that are often in the band gap. These energy levels are shown here as short lines to indicate they are localized around the impurity ion. To understand how these ions interact with one another, we need to know their positions relative to each other; their absolute positions in the band gap are of somewhat lesser importance. There is an agreed-upon convention by which the ions are labeled: Donor ions, such as titanium (see "Color in Corundum" section), are labeled with their charge before donating their electron, while acceptors are labeled with their charge after accepting the electron.

If we place magnesium into the corundum lattice on an aluminum site replacing an aluminum ion, it must have an overall charge of $+3\left(\right.$ like $\left.\mathrm{Al}^{3+}\right)$ for the crystal to remain electrically neutral. But we know that the charge on $\mathrm{Mg}$ is +2 . One method to accommodate this discrepancy is to create a hole (a missing electron) in the valence band near the $\mathrm{Mg}^{2+}$ ion. This type of charge compensation only occurs in highly oxidizing environments. Since the relative charge of a hole is +1 , the hole plus the $\mathrm{Mg}^{2+}$ ion makes a total charge of +3 to satisfy the $\mathrm{Al}^{3+}$ site requirement. It is this $\mathrm{Mg}^{2+}$-hole pair that absorbs light, giving rise to the yellow and brown hues in Mg-containing corundum. Physically, the hole corresponds to one of the oxygen ions near the magnesium having a charge of -1 rather than the normal charge -2 . A more structural way of looking at this situation is to observe that an $\mathrm{Al}^{3+}-\mathrm{O}^{2-}$ group has been replaced by an $\mathrm{Mg}^{2+}$ $\mathrm{O}^{1-}$ group having the same total charge of +1 .

If titanium, a donor, were introduced into otherwise high-purity corundum, its preferred valence would be +3 , and thus it would meet the charge requirements of the $\mathrm{Al}^{3+}$ site. What happens if both Ti and $\mathrm{Mg}$ are in a corundum crystal in the same amounts? The $\mathrm{Ti}^{3+}$ electron donor level is far above the $\mathrm{Mg}$ acceptor level, so an electron is transferred from $\mathrm{Ti}^{3+}$ (which becomes $\mathrm{Ti}^{4+}$ ) to the $\mathrm{Mg}^{2+}$-hole pair (which becomes just $\mathrm{Mg}^{2+}$ ). The electron and the hole combine, or annihilate each other, to refill the valence band or, physically, the $\mathrm{O}^{1-}$ near the $\mathrm{Mg}^{2+}$ becomes $\mathrm{O}^{2-}$ as is normal. In this energy-level diagram, electrons move (fall) down to positions of lower energy. This interaction can also be pictured from the point of view of the hole rather than the electron. In that perspective, the hole is transferred from the $\mathrm{Mg}^{2+}$-hole pair to the $\mathrm{Ti}^{3+}$, resulting in $\mathrm{Mg}^{2+}$ and $\mathrm{Ti}^{4+}$ exactly as before. Also in this energy-level diagram, holes fall up. It doesn't matter which view is used since they are both the same, but usually we use the electron point of view if there are excess donors and the hole point of view if there are excess acceptors.

We now see a little more clearly what charge compensation is, and how it takes place. By this mechanism of donor-acceptor electron (or hole) transfer, the two ions charge compensate each other as +2 and +4 , adding to +6 , which is the charge of the two $\mathrm{Al}^{3+}$ ions they replace. This electron transfer only occurs because the Ti donor level is far above the $\mathrm{Mg}$ acceptor level and electrons always move down to the lowest available energy level. If the acceptor level was above the donor level, it would not occur. The $\mathrm{Mg}^{2+}$ $\mathrm{Ti}^{4+}$ pair does not absorb light in the visible region of the spectrum, so its formation does not produce color in corundum. However, other pairs absorb light strongly and lead to strong coloration. Figure B-2A shows the formation of a pair between the $\mathrm{Ti}^{3+}$ donor and the $\mathrm{Fe}^{2+}$-hole acceptor, where the $\mathrm{Ti}^{3+}$ becomes $\mathrm{Ti}^{4+}$ and the $\mathrm{Fe}^{2+}$-hole pair becomes just $\mathrm{Fe}^{2+}$. This donor-acceptor transfer creates the $\mathrm{Fe}^{2+}-\mathrm{Ti}^{4+}$ pair responsible for the blue coloration in sapphire.

$\mathrm{The}^{\mathrm{Ti}} \mathrm{i}^{3+}$ donor level lies far above all acceptor levels in corundum, and thus will always transfer its electron (becoming $\mathrm{Ti}^{4+}$ ) to some acceptor impurity if one is available. This is one of the reasons why the $\mathrm{Ti}^{3+}$ absorption spectrum is never 


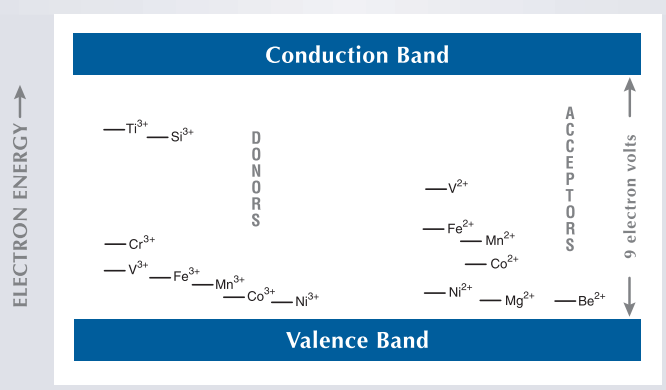

Figure B-1. In this energy-level diagram of impurities in corundum, trivalent donor ions are shown on the left, with divalent acceptor ions on the right. A charge-compensating donor-acceptor pair can form when the donor level is above the acceptor level. There is no significance to the lateral positions of the energy levels; the vertical positions are absolute, measured from the top of the valence band. Data from Kröger (1984) and references therein.

observed in natural corundum.

Now if there are two donors at different levels and a single acceptor, the highest donor will preferentially charge compensate the acceptor. If the two donor energy levels are close together, they will both take part in charge compensation of the acceptor. The same situation occurs in reverse if there are two acceptors and a single donor. That is, the lowest acceptor preferentially charge compensates the donor unless they are both close together (see figure B-2).

Silicon in corundum is a little more complex (see discussion in "Color in Corundum" section). In natural unheated corundum, silicon probably exists as broadly distributed nano- or micro-crystals of a silicate mineral. However, when the host corundum crystal is heat treated at a high temperature for a long time, all or part of the silicon will enter the corundum lattice in solution, replacing aluminum and producing the donor states shown in figure B-1 (Lee and Kröger, 1985). $\mathrm{Si}^{4+}-\mathrm{Mg}^{2+}$ pairs do not add color. $\mathrm{Si}^{4+}$-transition metal pairs in corundum have not been studied.

There are no published data on the position of the Be acceptor level. However, because the oxygen partial pressure dependence on the strength of the $\mathrm{Be}^{2+}$. hole pair absorption is very similar to that of the $\mathrm{Mg}^{2+}$-hole pair, as is the absorption spectrum itself, the energy levels must be fairly close to each other. For the examples in this article, we have assumed they are at the same level.

Now we can see the origin of the rules we have stated in the "Color in Corundum" section. If $\left[\mathrm{Ti}^{4+}+\right.$ $\left.\mathrm{Si}^{4+}\right]>\left[\mathrm{Mg}^{2+}+\mathrm{Be}^{2+}\right]$, there are more than enough

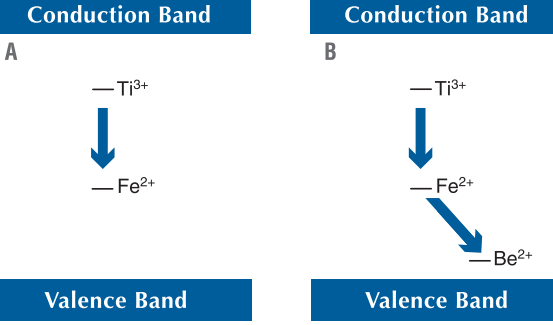

Figure B-2. In $\mathrm{A}$, the $\mathrm{Ti}^{3+}$ donor exchanges an electron with the $\mathrm{Fe}^{2+}$-hole acceptor, thus producing the $\mathrm{Fe}^{2+}$ $\mathrm{Ti}^{4+}$ pair responsible for blue in sapphire. In $\mathrm{B}$, when beryllium is diffused into $\mathrm{A}$, the Be $e^{2+}$-hole acceptor presents a more attractive site (lower energy) for the $\mathrm{Ti}^{3+}$ donor electron than $\mathrm{Fe}^{2+}$, causing the electron to be transferred to the Be $e^{2+}$-hole acceptor (or the Beinduced hole is transferred to the $\mathrm{Fe}^{2+}$ ). The transfer results in $\mathrm{Fe}^{2+}$ becoming $\mathrm{Fe}^{3+}$, eliminating the $\mathrm{Fe}^{2+}-\mathrm{Ti}^{4+}$ pair and the blue color. The $\mathrm{Be}^{2+}-\mathrm{Ti}^{4+}$ pair formed does not absorb light in the visible region of the spectrum and thus does not contribute color to the sapphire.

donor electrons to annihilate all trapped holes associated with $\mathrm{Be}^{2+}$ and $\mathrm{Mg}^{2+}$, and thus the yellow coloration cannot form. Likewise, if $\left[\mathrm{Mg}^{2+}+\mathrm{Be}^{2+}\right]>$ $\left[\mathrm{Ti}^{4+}+\mathrm{Si}^{4+}\right]$ there are excess $\mathrm{Mg}^{2+}$ or $\mathrm{Be}^{2+}$ trapped-hole pairs to cause the yellow coloration.

We can also see why the absorption spectrum of Be in high-purity corundum is different from that in Cr-containing corundum. In pure synthetic corundum, the Be-induced trapped hole is near the $\mathrm{Be}^{2+}$ ion, producing an orangy brown. However, if $\mathrm{Cr}^{3+}$ (a donor) is also present, the Be-induced hole is transferred to the $\mathrm{Cr}^{3+}$ (holes fall up), producing a $\mathrm{Cr}^{3+}$ trapped-hole pair and, thus, the characteristic orangy yellow coloration. (The $\mathrm{Cr}^{3+}$ trapped-hole pair could combine to form $\mathrm{Cr}^{4+}$, but much more work is needed to determine if it does.) The $\mathrm{Fe}^{3+}$ donor state is below that of the $\mathrm{Cr}^{3+}$ donor state, so if both ions are present the Beinduced hole again pairs with $\mathrm{Cr}^{3+}$, producing orangy yellow. In corundum without $\mathrm{Cr}^{3+}$ (or where $\mathrm{Cr}^{3+}$ is less than the excess holes available), holes would pair with the $\mathrm{Fe}^{3+}$ to produce an $\mathrm{Fe}^{3+}$ trapped-hole pair (or perhaps $\mathrm{Fe}^{4+}$. . The $\mathrm{Fe}^{3+}$ trapped-hole pair may be responsible for the unusual "Post-it" yellow color observed in some Be-diffused sapphire. Additional research involving Be diffusion into sapphire with only iron as an impurity will be required to elucidate this matter. By examining the relative energy-level positions of other donor and acceptor ions, however, we can deduce how they will interact. 
example, adding silicon, a common trace element in corundum assuming that it is fully active, the condition for the formation of the trapped-hole color center changes from $\left[\mathrm{Mg}^{2+}\right]>\left[\mathrm{Ti}^{4+}\right]$ to $\left[\mathrm{Mg}^{2+}\right]>$ $\left[\mathrm{Ti}^{4+}+\mathrm{Si}^{4+}\right]$, so more magnesium is needed to observe the yellow trapped-hole color. $\mathrm{Zr}^{4+}$ (zirconium) can be expected to react chemically in ways similar to $\mathrm{Ti}^{4+}$ and $\mathrm{Si}^{4+}$. Likewise, $\mathrm{Ca}^{2+}$ (calcium) and $\mathrm{Ba}^{2+}$ (barium) will react similarly to $\mathrm{Mg}^{2+}$. The problem becomes substantially more complex when we consider the possible roles of other transition metal impurities such as vanadium (V), manganese $(\mathrm{Mn})$, cobalt $(\mathrm{Co})$, and nickel (Ni), each of which can potentially exist in multiple valence states. V and Mn could exist in corundum in 2+, $3+$, or 4+ valence states; thus, they could be either donors or acceptors, or both. As donors, they could suppress the formation of trapped-hole color centers by forming donor-acceptor pairs with excess divalent ions. As acceptors, they would enhance the formation of trapped-hole color centers by forming donor-acceptor pairs with excess tetravalent ions. $\mathrm{Ni}$ and Co could act as acceptors, enhancing the probability of trapped-hole color center formation. Enhancing trapped-hole formation increases the yellow color component, while reducing trapped hole formation reduces the yellow component.

Vanadium is commonly observed in Cr-containing corundum (Hänni and Pettke, 2002; Peretti and Günther, 2002), and Mn is often seen in traceelement analyses of corundum. There appears to be no information in the literature on $\mathrm{Ni}$ and $\mathrm{Co}$

TABLE 3. Trace elements other than $\mathrm{Fe}, \mathrm{Mg}$, Ti, and $\mathrm{Cr}$ that could impact the color of corundum.

\begin{tabular}{llll}
\hline \multicolumn{3}{c}{ Valence } \\
\hline+1 & \multicolumn{1}{c}{+2} & \multicolumn{1}{c}{+3} & \multicolumn{1}{c}{+4} \\
\hline Hydrogen & Beryllium & Vanadium & Carbon \\
Lithium & Calcium & Manganese & Silicon \\
Sodium & Vanadium & Cobalt & Manganese \\
Copper & Manganese & Nickel & Germanium \\
Silver & Cobalt & & Zirconium \\
& Nickel & & Tin \\
& Copper & & Lead \\
& Zinc & & Vanadium \\
& Cadmium & & \\
& Tin & & \\
& Barium & & \\
& Lead & & \\
\hline
\end{tabular}

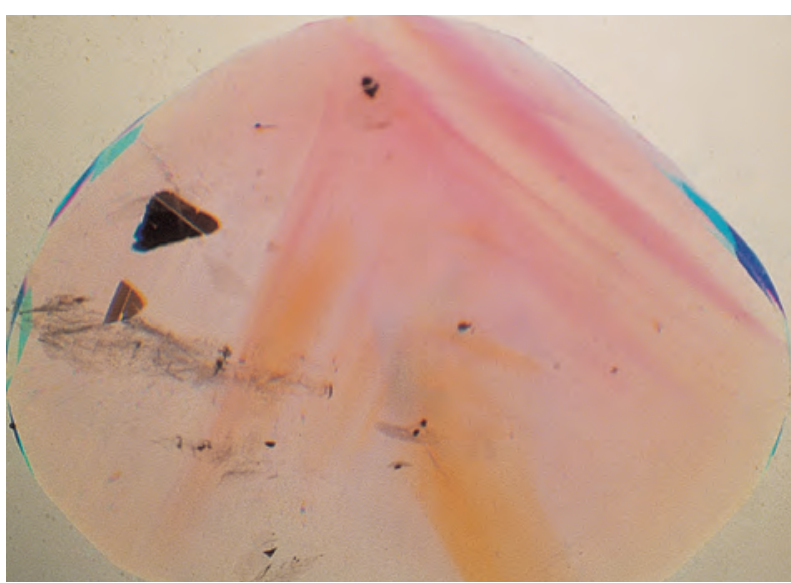

Figure 12. Variations in trace-element concentrations create the color zoning typically seen in many natural sapphires, such as the orange and pink zones shown here, which makes accurate chemical analysis very laborious. Photomicrograph by Shane F. McClure; immersion, magnified 10x.

concentrations in natural corundum. It is important to note that, in discussing these additional trace elements, we are not referring to concentrations high enough to contribute color on their own part. We are referring to concentrations in the range of 1 to $30 \mathrm{ppma}$, where they might play a significant role in the charge-compensation relationships among ions. Table 3 lists additional trace elements that could potentially impact the color of corundum if they were in solid solution, whether naturally occurring or from a diffusion process. Several appear in two or three columns, because they can potentially assume two or three valences. Thus, a quantitatively accurate analysis of the color of a ruby or sapphire would, in principle, require a complete trace-element analysis down to a level of a few ppma. Much additional trace-element data on a wide variety of natural corundum, as well as additional diffusion experiments, will be needed before we fully understand which of these ions may be important. Inasmuch as most natural corundum exhibits color zoning (figure 12), and thus zoning of trace-element concentrations, such an analysis would indeed be time consuming. Fortunately, we can understand the main features of how the addition of beryllium alters the color of most types of corundum by considering only the short list of trace elements presented earlier: $\mathrm{Fe}$, $\mathrm{Cr}, \mathrm{Ti}, \mathrm{Si}, \mathrm{Mg}$, and perhaps $\mathrm{V}$.

Color Modifications Associated with Beryllium Diffusion. Now that we have an idea of how different elements interact in corundum, we can turn to 
Figure 13. Many of the off-color sapphires from Songea that do not improve with standard heat treatment (left) will turn a strong orangy yellow after Be diffusion (right). This stone weighs $0.50 \mathrm{ct}$; photos by Elizabeth Schrader.
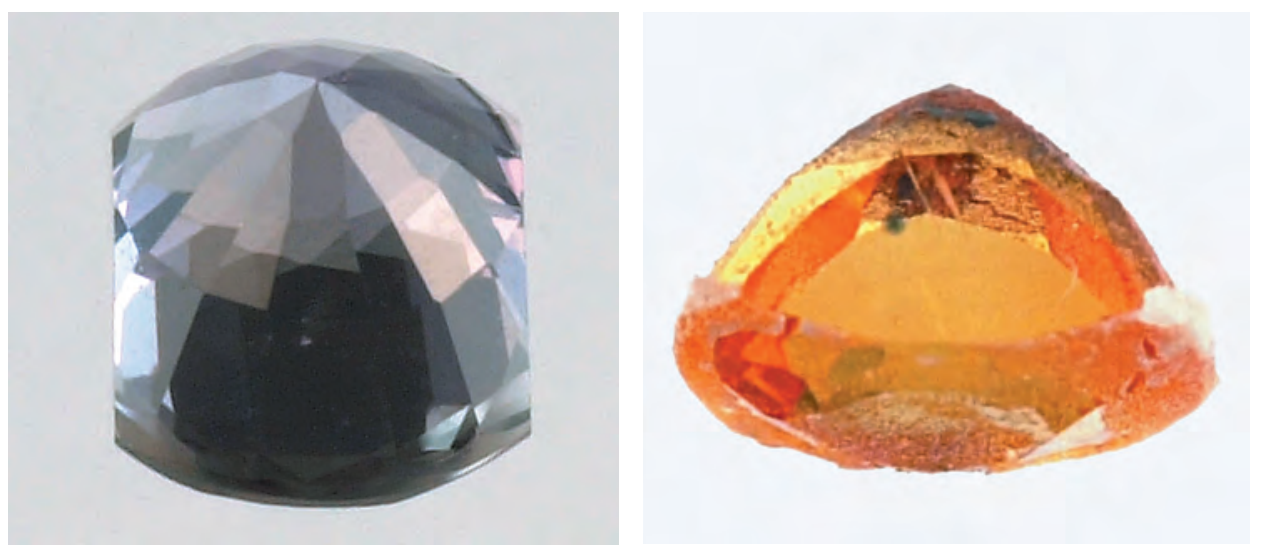

the specific case of beryllium and the color modifications caused by the diffusion of beryllium into natural corundum. As noted earlier, the presence of Be has been established in the color-altered layer of sapphires heat treated in Thailand by the "new" method (McClure et al., 2002; Wang and Green, 2002a,b), at concentrations well above those measured in unaltered regions. When beryllium is added to corundum by diffusion, there is another layer of complexity in color determination, because the beryllium concentration is not always spatially uniform throughout the stone (see Appendix). The final color may be some combination of the remaining core of original color plus the Be-altered outer color. We will return to this point later, and for the present consider only Be-induced color modifications resulting from a uniform beryllium concentration.

Drawing on our earlier studies (Emmett and Douthit, 1993) of Mg-induced trapped holes in corundum and subsequent research, our working hypothesis was that $\mathrm{Be}^{2+}$ would position itself in the corundum lattice by replacing an aluminum ion, thus becoming an acceptor (again, see Box B). As such, it would act much like $\mathrm{Mg}^{2+}$, trapping holes and producing a strong yellow coloration under exactly the same conditions. However, given the very small size of $\mathrm{Be}^{2+}$, we thought that its solubility in corundum would be lower than that of Mg. From experimental measurements on Be-diffused corundum (Hänni and Pettke, 2002; McClure et al., 2002; Peretti and Günther, 2002; Wang and Green, 2002a,b; see also the "Beryllium Diffusion into Corundum: Process and Results" section below), it appears that concentrations of diffused beryllium range from about 10 to $30 \mathrm{ppma}$, and that 10 to 15 ppma can produce a strong yellow coloration. In many ways, then, the effect of diffusing beryllium into corundum is similar to that of increasing the magnesium concentration. Thus, we can add the following to our list of rules:
- $\mathrm{Ti}^{4+}$ will preferentially charge compensate $\mathrm{Be}^{2+}$ before $\mathrm{Fe}^{2+}$.

- The condition for the formation of a yellow trappedhole color center in an oxidizing atmosphere becomes $\left[\mathrm{Mg}^{2+}+\mathrm{Be}^{2+}\right]>\left[\mathrm{Ti}^{4+}+\mathrm{Si}^{4+}\right]$.

With these simplified rules, we can predict most of the color modifications that will result from beryllium diffusion. First, let us examine the light green and light blue sapphires typical of Songea (Tanzania), the Montana alluvial deposits, and the pale-colored or colorless sapphire that results from heat treating some Sri Lankan geuda. In such stones, we have the condition that $\left[\mathrm{Ti}^{4+}+\mathrm{Si}^{4+}\right] \geq$ $\left[\mathrm{Mg}^{2+}\right]$ (that is, donor impurities are slightly greater than or about equal to acceptor impurities). The addition of beryllium as an acceptor changes the concentration relationship to $\left[\mathrm{Mg}^{2+}+\mathrm{Be}^{2+}\right]>\left[\mathrm{Ti}^{4+}+\right.$ $\mathrm{Si}^{4+}$ — so there is an excess of acceptor impurities. In a reducing atmosphere, the excess acceptor impurities $\left(\mathrm{Mg}^{2+}, \mathrm{Be}^{2+}\right)$ will be charge compensated by oxygen vacancies and thus produce no color. However, in an oxygen atmosphere, excess $\mathrm{Mg}^{2+}$ and $\mathrm{Be}^{2+}$ will trap holes, producing a strong yellow to orangy yellow coloration (figure 13). This is the reason that beryllium diffusion of corundum must always be carried out in a highly oxidizing atmosphere. In the cases of Montana alluvial sapphire, Sri Lankan sapphire, and Sri Lankan geuda, there are many stones with $\left[\mathrm{Mg}^{2+}\right]>\left[\mathrm{Ti}^{4+}+\mathrm{Si}^{4+}\right]$ that are nearly colorless or pale yellow as a result of slightly reducing conditions during formation. When these stones are heat treated in an oxidizing atmosphere, strong yellow colors will be produced. When beryllium is diffused into these stones so that $\left[\mathrm{Mg}^{2+}+\mathrm{Be}^{2+}\right]>>\left[\mathrm{Ti}^{4+}+\right.$ $\left.\mathrm{Si}^{4+}\right]$, a very saturated orange will result.

Some of the first Be-diffused stones studied in the U.S. were pink/orange combinations, the result of processing pink sapphires from Madagascar. Pink Madagascar sapphire contains $\mathrm{Cr}^{3+}$ far in excess of 


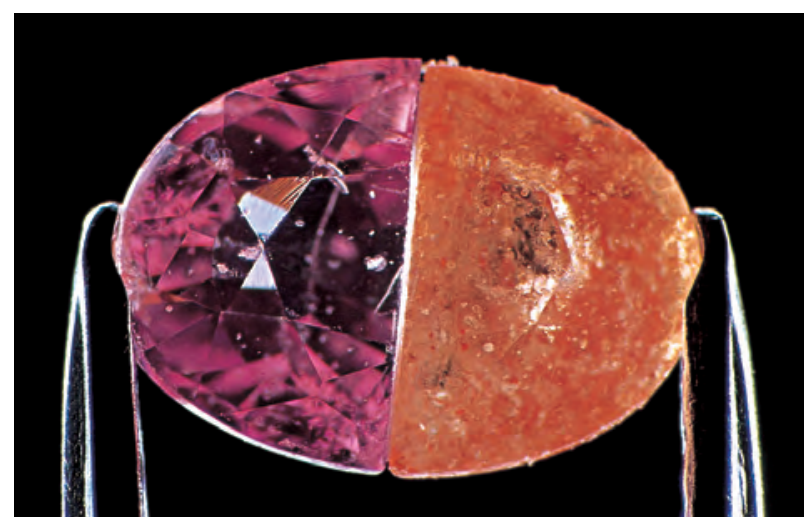

Figure 14. When Be-induced yellow color is added to the natural pink color of some Madagascar sapphires, a bright orange is produced, as can be seen in this 0.51 ct pink sapphire that was cut in half with one half then being Be diffused. Photomicrograph by Shane F. McClure; magnified 10×.

the added beryllium concentrations, so the $\mathrm{Cr}^{3+}$ concentration is largely unaffected by heat treatment. Thus, we can apply our previous rules for Fe-containing corundum to corundum that also contains $\mathrm{Cr}$, taking into consideration the original Cr-pink body color. For example, when Be is diffused in an oxidizing atmosphere into a pink Madagascar sapphire where $\left[\mathrm{Ti}^{4+}+\mathrm{Si}^{4+}\right] \geq\left[\mathrm{Mg}^{2+}\right]$, the chemistry changes to $\left[\mathrm{Mg}^{2+}+\mathrm{Be}^{2+}\right]>\left[\mathrm{Ti}^{4+}+\mathrm{Si}^{4+}\right]$, which shifts the stone from donor- to acceptor-dominated; the resulting trapped holes produce a yellow coloration. When this yellow coloration permeates most or all of the original pink sapphire, an orange stone results (figure 14).

Some of the pink stones do not change color with Be diffusion. In that case, we have $\left[\mathrm{Ti}^{4+}+\mathrm{Si}^{4+}\right]$ $>>\left[\mathrm{Mg}^{2+}\right]$, which becomes $\left[\mathrm{Ti}^{4+}+\mathrm{Si}^{4+}\right]>\left[\mathrm{Mg}^{2+}+\mathrm{Be}^{2+}\right]$ from the Be diffusion; the material remains donordominated, does not trap holes, and does not become orange (figure 15). Earlier it was discussed that other transition elements may also play a role as donors or acceptors. As previously noted, the pink Madagascar sapphires contain 5 to 20 ppma of vanadium. If $\mathrm{V}$ acts as a donor in these stones, which we would expect, it could also play a role in suppressing the formation of trapped-hole color centers. Substantial additional analytical work and careful optical spectroscopy will be required to resolve these issues.

We also need to understand the impact of Be diffusion into blue sapphire. As noted previously, dark blue natural sapphire results from the condition $\left[\mathrm{Ti}^{4+}\right]>>\left[\mathrm{Mg}^{2+}\right]$. (Note again that we are assuming an iron concentration far in excess of the $\mathrm{Ti}^{4+}$ con-

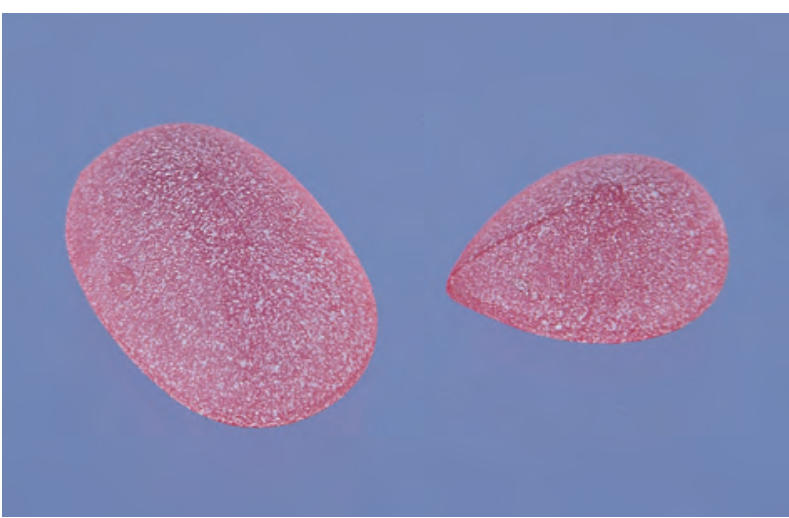

Figure 15. These two pink preforms (the larger weighs $0.77 \mathrm{ct}$ ) were reportedly subjected to the Be-diffusion process 10 times in Thailand, yet they did not change color. Photo by Maha Tannous.

centration.) If $\mathrm{Be}$ is diffused into such stones, the condition becomes $\left[\mathrm{Ti}^{4+}\right]>\left[\mathrm{Mg}^{2+}+\mathrm{Be}^{2+}\right]$, and the stone is still blue but much reduced in color saturation. Thus, it is possible to render unacceptably dark blue sapphire into marketable blue colors.

It is interesting to note that the earlier diffusion process - of titanium into otherwise colorless or pale-colored sapphire (see, e.g., Kane et al., 1990) - is just the reverse of the process previously described. The sapphire typically used in the blue diffusion process is the very pale yellow, pale blue, pale pink, or completely colorless material that results from the unsuccessful heat treatment of some Sri Lankan geuda. For this material, we can presume the condition $\left[\mathrm{Mg}^{2+}\right] \approx\left[\mathrm{Ti}^{4+}+\mathrm{Si}^{4+}\right]$, since it did not turn blue or yellow from the initial heat-treatment process. Note that it also contains iron. When titanium is diffused into the stone, the condition in the diffusion layer shifts to

Figure 16. A dark blue color layer is formed near the surface when Ti is diffused into sapphire. This 1.3-mmthick section was sawn from a $1.45 \mathrm{ct}$ stone, and shows a Ti diffusion-induced layer of blue color that is $0.4 \mathrm{~mm}$ deep. Photo by Shane F. McClure; immersion.

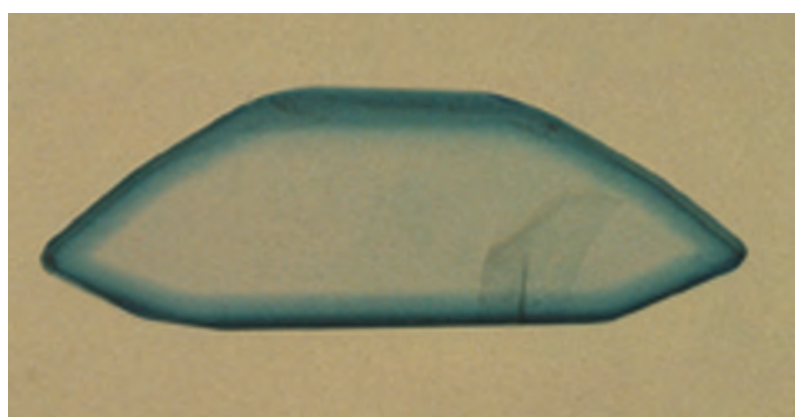



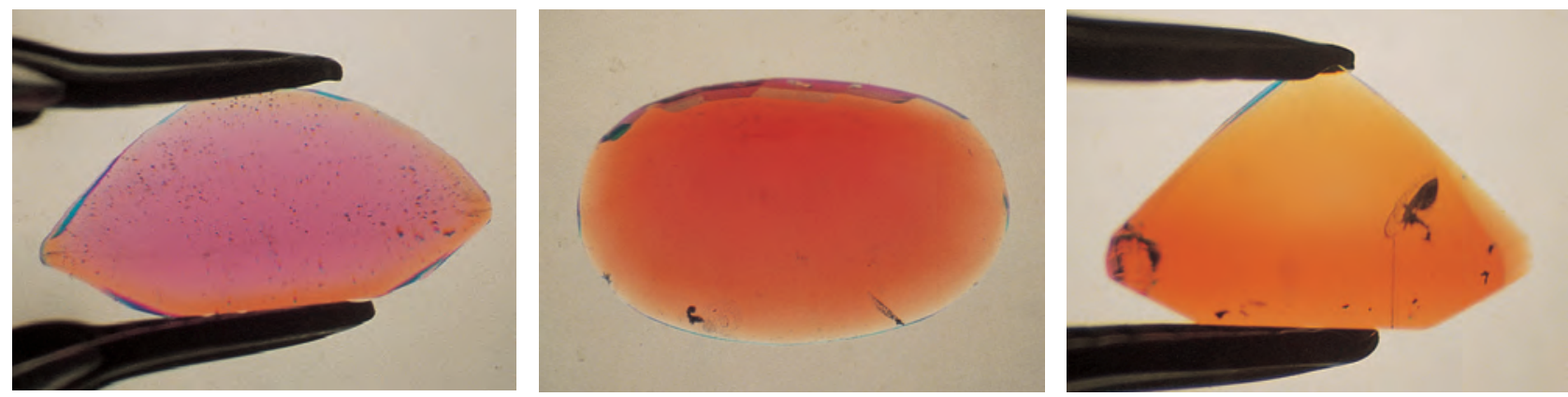

Figure 17. Depending on the duration of the Be-diffusion process, the induced color layer can penetrate to any depth, including throughout the stone. This figure shows examples of shallow (left), moderate (center), and deep (right) penetration. Photomicrographs by Shane F. McClure; immersion, magnified 10x.

$\left[\mathrm{Ti}^{4+}+\mathrm{Si}^{4+}\right]>>>\left[\mathrm{Mg}^{2+}\right]$; that is, it becomes donor dominated, and a very dark blue layer is formed (figure 16). Since titanium has a much greater solubility in corundum than does beryllium, the final condition is $\left[\mathrm{Ti}^{4+}+\mathrm{Si}^{4+}\right]>>>\left[\mathrm{Mg}^{2+}\right]$, rather than $\left[\mathrm{Ti}^{4+}+\mathrm{Si}^{4+}\right]>\left[\mathrm{Mg}^{2+}\right]$. Nevertheless, it becomes clear that the mechanisms behind the Ti blue-diffusion process and the Be-diffusion process are essentially the same.

The foregoing discussion addressed the color modifications in various types of corundum assuming that the added Be is essentially uniformly diffused throughout the stone. We now need to consider the effect of non-uniform diffusion of beryllium into a natural-color stone that has essentially uniform natural coloration, such as the orangy pink (padparadscha-like) sapphires in which the final color appearance is produced by diffusing a layer of yellow into an originally pink stone. Depending on the duration of the diffusion process, the depth of penetration can vary from a few tenths of a millimeter to the full thickness of the stone (see the Appendix and figure 17).

As a hypothetical example, suppose we start with a 2 ct pink Madagascar sapphire, and examine how the color could alter with diffusion time. It can be assumed that we are dealing with a stone where $\left[\mathrm{Be}^{2+}+\mathrm{Mg}^{2+}\right]>\left[\mathrm{Ti}^{4+}+\mathrm{Si}^{4+}\right]$, and thus the Bediffused areas will exhibit added yellow coloration from the trapped-hole color centers that form during the diffusion process. From our experiments (see the Appendix), we know that the diffusion depth for this type of material is about $2 \mathrm{~mm}$ in 40 hours at $1800^{\circ} \mathrm{C}$. If the diffusion is conducted for one hour, the penetration depth will be roughly $0.35 \mathrm{~mm}$; the pink overall color of the stone will be slightly modified in the direction of a padparadscha color. In 10 hours, the penetration will be about $1 \mathrm{~mm}$ and the stone will be the orangy pink of a good padparadscha. Further increasing the diffusion time, and thus the depth to which the Be penetrates, will successively yield pinkish orange, orange, and finally a very saturated deep orange coloration as the beryllium penetrates the entire stone (figure 18).

Ruby is another important example of color modification with diffusion depth. Many of the rubies from Songea and Madagascar contain substantial iron and titanium, and thus have a strong blue hue component as a result of $\mathrm{Fe}^{2+}-\mathrm{Ti}^{4+}$ pairs. As discussed previously, Be diffusion in an oxidizing atmosphere shifts the equilibrium from $\left[\mathrm{Ti}^{4+}+\right.$ $\left.\mathrm{Si}^{4+}\right]>\left[\mathrm{Mg}^{2+}\right]$ to $\left[\mathrm{Mg}^{2+}+\mathrm{Be}^{2+}\right]>\left[\mathrm{Ti}^{4+}+\mathrm{Si}^{4+}\right]$, so the blue component becomes yellow. If these stones are Be diffused all the way through, the entire blue component is replaced with yellow, and the stone becomes a very strong orange. However, if the Be diffusion only penetrates into the stone a relatively short distance, the yellow surface layer will visually cancel out or offset the bluish core. Thus, the

Figure 18. The depth of the Be-diffusion layer directly affects face-up color. The stone on the far left has a very shallow diffusion layer. Moving right, each stone has a progressively deeper layer, making each more orange than the last. These stones weigh 0.80-1.89 ct; photo by Maha Tannous.

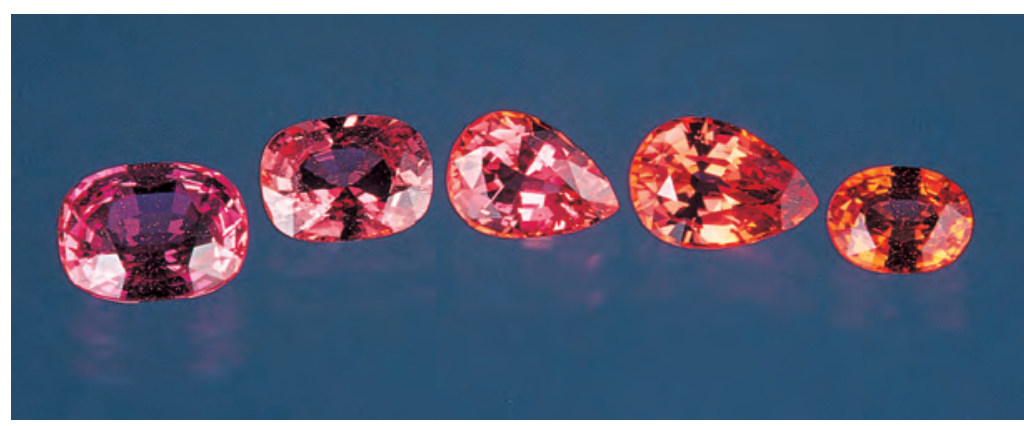




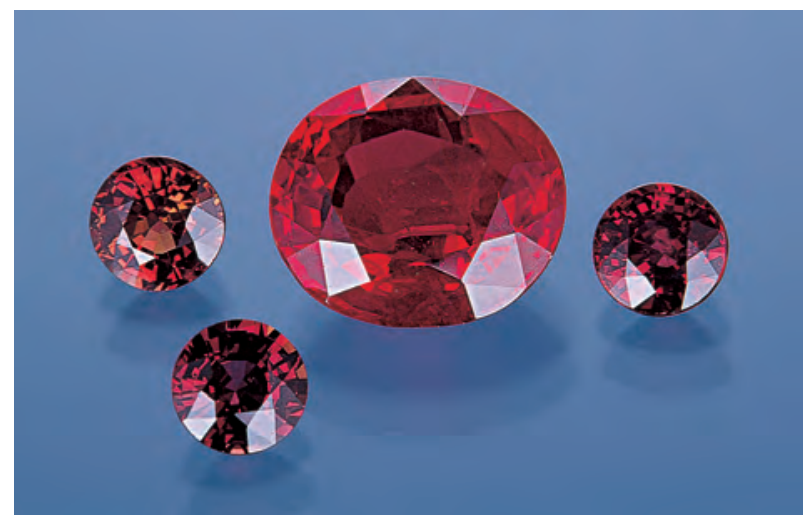

Figure 19. Be diffusion can produce good ruby colors (center, $5.05 \mathrm{ct}$ ) from strongly purplish or brownish red stones from some localities that typically do not respond to standard heat treatment, such as the small stones from Songea in this image. Photo by Maha Tannous.

appearance will be a good ruby red. In this way, many attractive red rubies can be produced from stones with a strong purple component (figure 19).

In principle, these stones can be detected easily by observing the yellow rim in immersion. However, it is conceptually possible to create the same visual effect without producing a yellow surface-conformal layer. After processing such rubies with full Be penetration, so they turn orange, we can reduce saturation of the yellow trapped-hole color component by heating the stones at a lower oxygen partial pressure. Reducing the oxygen partial pressure will reduce the yellow coloration. Thus, by "tuning" the oxygen partial pressure in a heat-treatment process that takes place after the Bediffusion process, an optimal ruby color may be achieved. This full-depth diffusion followed by an oxygen partial pressure post-process could also be used with our pink sapphire above to achieve padparadscha coloration without a visible diffusion layer. Unfortunately, rubies and padparadscha-colored sapphires produced by this two-step method will be more difficult to detect.

It is also useful to consider the color modifications resulting from partial Be diffusion into a blue sapphire where $\left[\mathrm{Ti}^{4+}\right]>\left[\mathrm{Mg}^{2+}\right]$. As we have already discussed, uniform Be diffusion into such stones converts them from blue to yellow. However, a green overall color appearance results when the inward diffusion of beryllium converts only the outermost layer from blue to yellow. If this green stone were to be heat treated subsequently in a reducing atmosphere, it would be blue with a colorless outer layer (figure 20).

\section{BERYLLIUM DIFFUSION INTO CORUNDUM: PROCESS AND RESULTS}

Over the course of the last year and a half, the authors have conducted numerous experiments into both the Be-diffusion treatment of corundum and the characteristics of rubies and sapphires that have been treated by this method. This first section describes those experiments conducted primarily to explain the nature of beryllium diffusion and how it affects corundum. The following section reports on the examination of known Be-diffused corundum samples, as well as natural-color and heat-treated stones, to establish criteria by which rubies and sapphires treated by this new diffusion process can be identified.

The extensive set of experiments in this first section were initiated to understand and then replicate Thai results, to study the diffusion rates, and to determine just how broadly applicable this new process was to a wide variety of different types of corundum. By conducting these experiments in the laboratory, we could fully control all aspects of the process and not have to guess the treatment conditions (which has been the case with stones processed in Thailand).

\section{Materials and Methods}

Corundum Samples. For the Be-diffusion experiments, we selected samples from large lots of

Figure 20. Partial Be diffusion of a blue sapphire followed by heating in a reducing atmosphere can create a colorless layer around the outside of an otherwise blue stone, in effect lightening the overall color. Photomicrograph by Shane F. McClure; immersion, magnified 27x. 
rough sapphire that were mined from several different localities, including Australia, Madagascar, Tanzania, and Montana, as detailed in table 4. In general, we preferred to use small pieces $(\leq 0.5 \mathrm{ct})$ to assure that we could diffuse beryllium completely through the samples in 50 hours or less; however, we also conducted experiments on larger individual pieces to measure diffusion depths. Many of the samples listed in table 4 are from large, carefully collected mine-run parcels from the deposits indicated, and thus they contain a wide range of stone sizes. From these lots we selected samples primarily on the basis of size, while endeavoring to maintain representative color and clarity.

For spectroscopic experiments on Be-diffused Thai-processed sapphire, we obtained a variety of samples (15 pieces) in Bangkok that ranged from $0.25 \mathrm{ct}$ to $2.1 \mathrm{ct}$. According to the treaters, they were comprised of both Songea pale green and blue sapphire that had been processed to a vivid yellow, and Madagascar pink sapphire processed to padparadscha and saturated orange colors. As much as possible, samples were chosen with the c-axis perpendicular to the table facet to facilitate obtaining absorption spectra that included the ordinary ray (o-ray) optical direction. On these 15 samples, the culet was ground off parallel to the table and polished to produce wafers from 0.5 to $1.8 \mathrm{~mm}$ thick. Samples with similar geometry were also prepared from rough material produced in our diffusion experiments, or from rough pieces prior to diffusion treatment. Samples polished before diffusion treatment required repolishing after diffusion treatment. In total, about 30 samples were prepared and studied.

In addition to the natural sapphire samples described in table 4, four types of high-purity synthetic corundum were also used for the Be-diffusion experiments and spectroscopic testing (see table 5). These samples were prepared as polished wafers prior to Be diffusion, and repolished afterward. In all cases the c-axis was perpendicular to the polished face. We have not tested low-purity gem-grade Verneuil-grown sapphire.

Applying Beryllium Compounds. To apply beryllium to the surfaces of the corundum samples for diffusion, we used both molten fluxes (Emmett, 1999) and dry powders as carriers for Be-containing compounds. (A flux in this context is a high-temperature solvent for inorganic compounds.) While it is common knowledge that Thai heat treaters employ fluxes in many processes, the actual formu-

TABLE 4. Rough corundum samples used for Be-diffusion treatment experiments.

\begin{tabular}{|c|c|c|c|c|}
\hline Origin & Color & Lot size & Avg. stone size & Source \\
\hline $\begin{array}{l}\text { King's Plain, New South } \\
\text { Wales, Australia }\end{array}$ & $\begin{array}{l}\text { Basaltic dark blue, transparent } \\
\text { to opaque }\end{array}$ & $10 \mathrm{~kg}$ & $0.3-0.5 \mathrm{ct}$ & Great Northern Mining \\
\hline $\begin{array}{l}\text { Subera Area C, Queensland, } \\
\text { Australia }\end{array}$ & $\begin{array}{l}\text { Basaltic dark blue, transparent } \\
\text { to opaque } \\
\text { Yellowish green }\end{array}$ & $10 \mathrm{~kg}$ & $\begin{array}{l}0.3-0.5 \mathrm{ct} \\
0.3-0.8 \mathrm{ct}\end{array}$ & Great Northern Mining \\
\hline $\begin{array}{l}\text { Wutu Township, Shandong } \\
\text { Province, China }\end{array}$ & Basaltic dark blue & $1 \mathrm{~kg}$ & $\begin{array}{l}\sim 0.3 \text { ct (large crystals } \\
\text { sliced for wafers) }\end{array}$ & Diversified Mineral Resources \\
\hline Antsiranana, Madagascar & Basaltic dark blue, dark green & $250 \mathrm{~g}$ & $0.3-0.6 \mathrm{ct}$ & Budsol Co., Hargem Ltd. \\
\hline llakaka, Madagascar & "Pink" sapphire ${ }^{a}$ & $350 \mathrm{~g}$ & \multicolumn{2}{|c|}{$\begin{array}{l}\text { 0.4-1.0 ct } \\
\text { Cushman \& Co., Paul Wild }\end{array}$} \\
\hline $\begin{array}{l}\text { Dana Bar, Missouri River, } \\
\text { Montana }\end{array}$ & Pale green, pale blue & $1 \mathrm{~kg}$ & $1.5 \mathrm{ct}$ & American Gem Corp. \\
\hline $\begin{array}{l}\text { Dry Cottonwood Creek, } \\
\text { Montana }\end{array}$ & $\begin{array}{l}\text { Very pale green, very pale } \\
\text { yellowish green }\end{array}$ & $10 \mathrm{~kg}$ & $0.7 \mathrm{ct}$ & American Gem Corp. \\
\hline Rock Creek, Montana & Pale blue, pale yellowish green & $10 \mathrm{~kg}$ & $0.7 \mathrm{ct}$ & American Gem Corp. \\
\hline Yogo Gulch, Montana & Medium blue, violet & $200 \mathrm{~g}$ & $0.2 \mathrm{ct}$ & American Gem Corp. \\
\hline Sri Lanka & "Colorless" heat-treated geudab & $100 \mathrm{~g}$ & $0.3-1.0 \mathrm{ct}$ & Paul Wild \\
\hline Songea, Tanzania & $\begin{array}{l}\text { Pale blue, pale yellowish green } \\
\text { Ruby, ranging from bluish red } \\
\text { to brownish red }\end{array}$ & $600 \mathrm{~g}$ & $0.3-1.2 \mathrm{ct}$ & American Gem Corp. \\
\hline Umba, Tanzania & A wide variety & $600 \mathrm{~g}$ & $3 \mathrm{ct}$ & Nafco Gems, Paul Wild \\
\hline
\end{tabular}

aThis parcel of "pink" sapphires showed a range of pink color saturation, and also included some violetish pink, pale yellow, pale blue, and colorless pieces.

${ }^{b}$ The sapphires in this parcel ranged from colorless to very pale blue, pink, or yellow, after heat treatment in an oxidizing or reducing atmosphere. 
lations are closely guarded trade secrets. Rather than attempt to find out actual Thai formulas, we chose to formulate our own from calcium borate, calcium phosphate, sodium phosphate, or a sodium feldspar (a silicate mineral). To each main flux component we added small amounts of $\mathrm{Al}_{2} \mathrm{O}_{3}$ and $\mathrm{ZrO}_{2}$ to raise the flux viscosity at high temperatures. To these fluxes we then added $\sim 4 \%$ natural chrysoberyl that had been finely powdered. Chrysoberyl, $\mathrm{BeAl}_{2} \mathrm{O}_{4}$, is $7.1 \%$ Be or $19.7 \%$ by weight $\mathrm{BeO}$.

These flux mixtures were blended with water or alcohol containing a binder until they reached the consistency of a heavy paint. For water mixtures, Varethane $\mathrm{T}^{\mathrm{TM}}$ or methocel was used as a binder. (Methocel is a modified cellulose ether used as a binder in many industrial applications.) For alcohol mixtures, orange shellac was used as a binder. Little consistent difference was noted among the binders. The rough stones were dipped into the flux paint mixture and then allowed to dry. Polished corundum wafers were hand painted on both sides with the mixtures.

Dry powders, that is, mixtures of a carrier and a beryllium compound, do not melt and flow like a flux. The dry powders used were very high purity $\mathrm{Al}_{2} \mathrm{O}_{3}$ containing either $4 \%$ powdered chrysoberyl or $0.8 \%$ very high purity $\mathrm{BeO}$. We also used a mixture containing $2.65 \% \mathrm{BeO}$. Two application methods were employed. First, we completely buried the corundum samples in the powder mixture, in an alumina crucible. This is the original technique developed by Union Carbide Corp. (Carr and Nisevich, 1975, 1976, 1977). It works very well from the point of view of diffusion uniformity, but sintering of the powder to a fairly solid mass made sample recovery laborious. In the second method, the powder was mixed to the consistency of a paint, just as was done for the fluxes, and applied to rough stones and polished wafers as previously described. This latter process makes sample recovery very easy but does not always result in completely uniform diffusion.

Heat Treatment. Heat-treatment experiments were conducted with an electrically heated furnace manufactured by Thermal Technology of Santa Rosa, California (figure 21). The modified type1000A furnace uses a graphite heating element and graphite insulation, and is capable of operation at $2500^{\circ} \mathrm{C}$ (which far exceeds the $2045^{\circ} \mathrm{C}$ melting point of corundum). For controlled atmosphere operation, the furnace separates the heating element from the sapphires with a muffle tube made from Coors $99.8 \% \mathrm{Al}_{2} \mathrm{O}_{3}$ ceramic. This ceramic muffle tube becomes very soft at temperatures over $1800^{\circ} \mathrm{C}$, and it can collapse if it becomes too hot. This limits the temperature for the long runs typical of beryllium diffusion to 1800 to $1850^{\circ} \mathrm{C}$. The sapphires are placed inside the muffle tube where any type of process gas can flow over them. A more detailed description of this equipment and how it is used can be found in Emmett and Douthit (1993).

For the heat-treatment experiments described below, the process gas used was pure oxygen. This choice was made because, as discussed earlier, the trapped-hole coloration is sensitive to oxygen partial pressure, and is maximized in 100\% oxygen.

\begin{tabular}{|c|c|c|c|c|c|c|c|c|c|}
\hline Samples ${ }^{b}$ & $\mathrm{Na}$ & $\mathrm{K}$ & $\mathrm{Be}$ & $\mathrm{Mg}$ & $\mathrm{Ca}$ & $\mathrm{Cr}$ & $\mathrm{Fe}$ & $\mathrm{Ga}$ & $\mathrm{Ti}$ \\
\hline $\begin{array}{l}\text { SS1, SG Czochralski-grown } \\
\text { synthetic sapphire }\end{array}$ & 0.48 & 0.07 & 1.46 & 0.16 & 0.02 & 0.8 & 0.04 & 3.1 & 1.27 \\
\hline $\begin{array}{l}\text { SS8, CSI Hemlite grade heat } \\
\text { exchanger method-grown } \\
\text { synthetic sapphire }\end{array}$ & 0.39 & 0.14 & 13.4 & 0.83 & 0.04 & 0.25 & 0.03 & 0.94 & 1.98 \\
\hline $\begin{array}{l}\text { SS3, SG Czochralski-grown } \\
\text { light red synthetic ruby }\end{array}$ & 0.18 & 0.02 & 1.57 & 0.05 & 0.02 & 316 & 0.04 & 1.8 & 2.14 \\
\hline $\begin{array}{l}\text { SS18, SG Czochralski-grown } \\
\text { dark red synthetic ruby }\end{array}$ & 0.23 & 0.04 & 1.57 & 1.27 & 0.04 & 2580 & 0.13 & 7.5 & 2.00 \\
\hline
\end{tabular}


The coated sapphires were placed in shallow alumina crucibles made from Coors $99.8 \% \mathrm{Al}_{2} \mathrm{O}_{3}$ ceramic. When the stones were embedded in a dry powder, deeper Coors crucibles were used. Depending on the number of stones in a sample lot, up to 12 separate experiments could be run in the furnace at the same time. For these experiments, temperatures of $1780^{\circ} \mathrm{C}$ or $1800^{\circ} \mathrm{C}$ were chosen. Run times from 25 to 100 hours at temperature were chosen, with 33 hours being typical.

Spectroscopy. The ultraviolet-visible and nearinfrared (UV-Vis-NIR) spectra were recorded for the range $200-1100 \mathrm{~nm}$ at room temperature using a Hitachi U-2000 spectrophotometer. More than 60 spectra were collected on natural and synthetic Be-diffused sapphire wafers. For those natural sapphire samples where the color was not spatially uniform, reproducible spectra were assured by the method described by Emmett and Douthit (1993). Spectra were recorded only for the o-ray $(\mathrm{E} \perp \mathrm{c})$.

There are three feasible methods for determining trapped-hole spectra. In all cases we refer to these methods as producing differential spectra. First, the spectra can be taken in the Be-diffused layer and in the center of the stone where beryllium has not penetrated. If the spectrum from the unaltered portion of the sample is subtracted from that from the Be-diffused region, the trapped-hole spectrum will result. This method works well with synthetic sapphire and ruby, where dopant concentrations are spatially uniform, but it leads to inaccurate results on natural corundum samples, which are rarely uniform in chemistry.

The second method is to take one spectrum before Be diffusion and another after. If the before spectrum is subtracted from the after spectrum, an accurate trapped-hole spectrum results. This technique works very well on uniform synthetic corundum samples, and on natural samples if great care is taken to assure both measurements are taken through exactly the same place in the sample (Emmett and Douthit, 1993).

The third method, for use on a sample already diffused, is to take two spectra on the sample equilibrated at two different oxygen partial pressures. As noted previously, the strength of the trappedhole absorption spectrum is very sensitive to oxygen partial pressure. From a practical point of view, the spectrum is taken on the Be-diffused sample as received. Then the sample is heated to

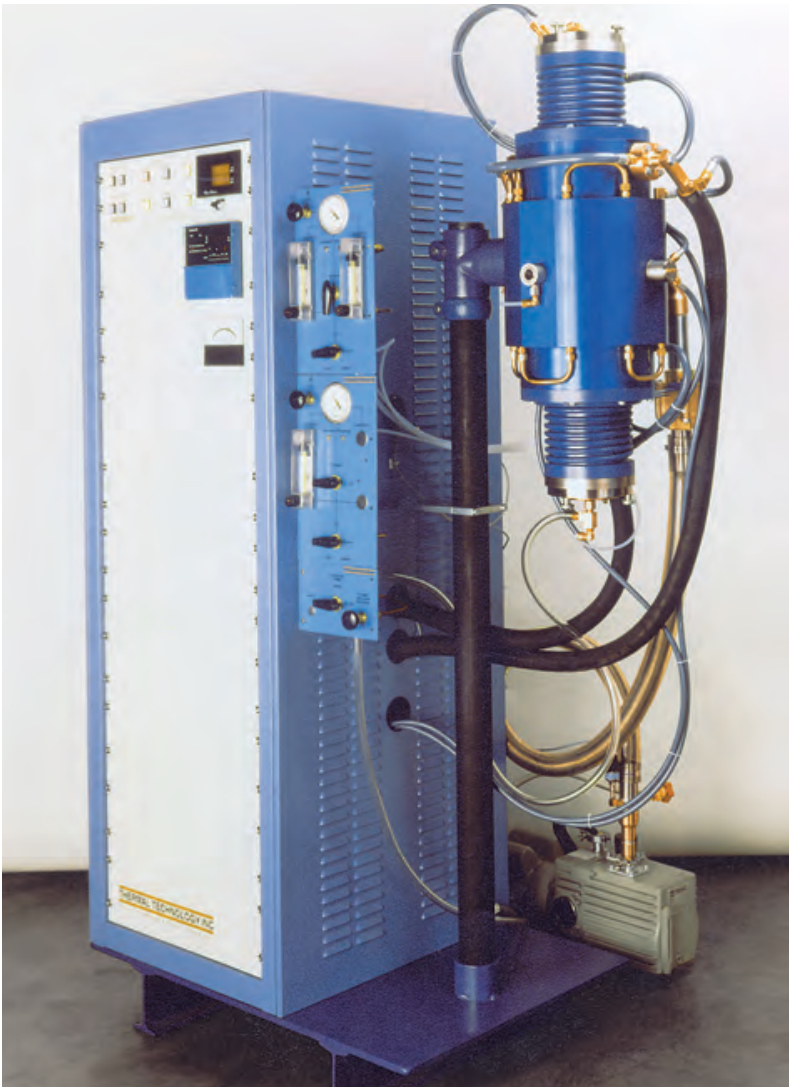

Figure 21. Most of the Be-diffusion experiments described in this article were conducted using an electrically heated furnace. Photo courtesy of Thermal Technology Inc.

$1650^{\circ} \mathrm{C}$ for a few hours in an oxygen partial pressure of $10^{-3} \mathrm{~atm}$, cooled, and the spectrum is taken again. If the after spectrum is subtracted from the as-received spectrum, the spectrum of the trappedhole center results. This works well on synthetic corundum samples, and on natural corundum samples if great care is taken to position the sample as described above. Heating for a few hours at $1650^{\circ} \mathrm{C}$ has little impact on a sample that has been heated for a few tens to hundreds of hours at temperatures of $1800^{\circ} \mathrm{C}$ or above. For the work described here, the second or third method was used on all samples, as the first method proved to be too inaccurate.

Chemistry. Secondary ion mass spectrometry with element-in-sapphire standards (again, see SIMS Box A) was used at Evans East to determine Be and other trace-element concentrations in some of the natural Be-diffused wafer samples used for absorption spectroscopy, and in some of the synthetic samples before and/or after Be-diffusion treatment. 


\section{Results and Discussion}

Identification of the Be-Induced Trapped Hole. In April 2002, we initiated a set of experiments to determine the origin of the color induced by Be diffusion. We believed that we were observing trapped-hole-center absorption, similar to that observed much earlier in both natural and synthetic corundum (Mohapatra and Kröger, 1977; Wang et al., 1983; Emmett and Douthit, 1993; Häger, 1993). Because holes only form in corundum under highly oxidizing conditions, the concentrations of $\mathrm{Mg}$ - or Be-hole pairs are very sensitive to the oxygen partial pressure at which they are equilibrated in the furnace. An orange sapphire Be-diffused in Thailand from pink Madagascar starting material was chosen for the first experiment. Figure 22 shows the results. At an oxygen partial pressure of $10^{-2} \mathrm{~atm}(1 \%$ oxygen, $1 \mathrm{~atm}$ total pressure), the Beinduced coloration has been reduced by about one half. This extreme sensitivity is not typical of the spectra of single ions in corundum.

From this experiment, we can also determine the absorption spectrum of this Be-induced coloration. By taking the differential spectrum of the figure 22 spectra, we obtain the result in figure 23 , which is the absorption spectrum of the Be-induced coloration in this sapphire. Note that it is quite similar to the $\mathrm{Mg}^{2+}$ - trapped hole pair spectrum pre-

Figure 22. These absorption spectra were taken of a pink sapphire that was Be diffused, both as received and after a portion of the Be-induced coloration was removed by equilibrating the stone at a lower $\left(10^{-2}\right.$ atm) oxygen partial pressure.

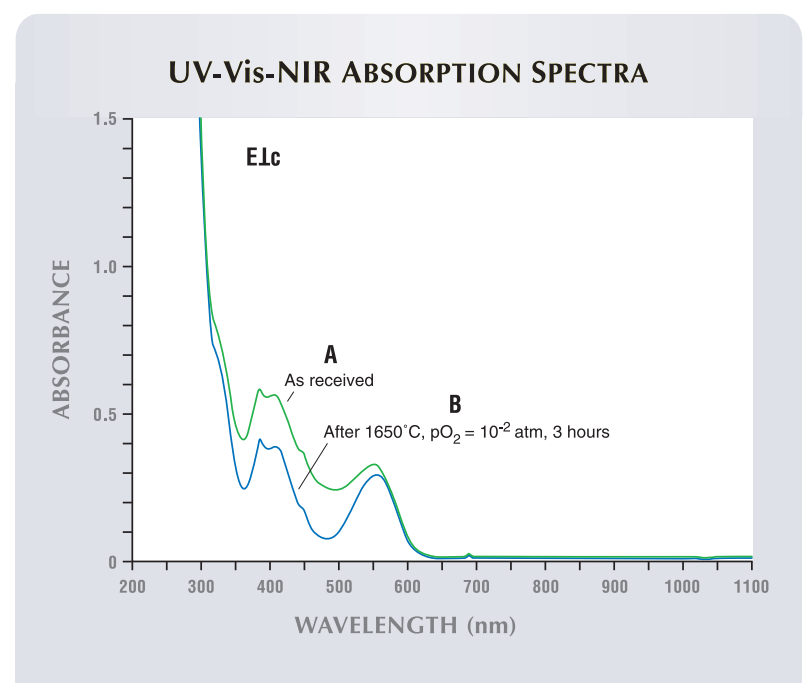

sented in figure 7 . These two pieces of data, taken together and compared with the well-studied example of the $\mathrm{Mg}^{2+}$-trapped hole pair, form the basis of our identification of the Be-induced coloration as arising from Be-induced trapped-hole formation. These spectral changes are reversible. When the sample was then equilibrated at an oxygen partial pressure of $1 \mathrm{~atm}$, the original absorption spectrum was restored. Subsequently, we tested a wide variety of sapphire samples from different locations over a wider range of oxygen partial pressures and temperatures with very similar results. In each case, the predominant $460 \mathrm{~nm}$ absorption band appeared and showed the same oxygen partial pressure dependence (see "Absorption Spectra" section below). Additional confirmatory evidence of the induced trapped hole nature of these spectra would be the change of the spectra with temperature. It is known that such spectra broaden to the low-energy side when the stones are heated several hundred degrees above room temperature. Data that tend to confirm this are shown in the "Gemological Testing and Identification" section, but additional studies would be useful.

Be-Diffusion Experiments. The next task was to diffuse beryllium into sapphire under controlled conditions to study the effects. Since the inception of this project, we have conducted 17 furnace runs devoted to beryllium-diffusion experiments, using different samples, carriers, and application methods, at tem-

Figure 23. The absorption shown here represents the difference $(B-A)$ of the two spectra shown in figure 22. Because the chromium spectrum is unchanged by reequilibration of the stone at a lower oxygen partial pressure, this differential spectrum shows the absorption associated with the beryllium-induced coloration.

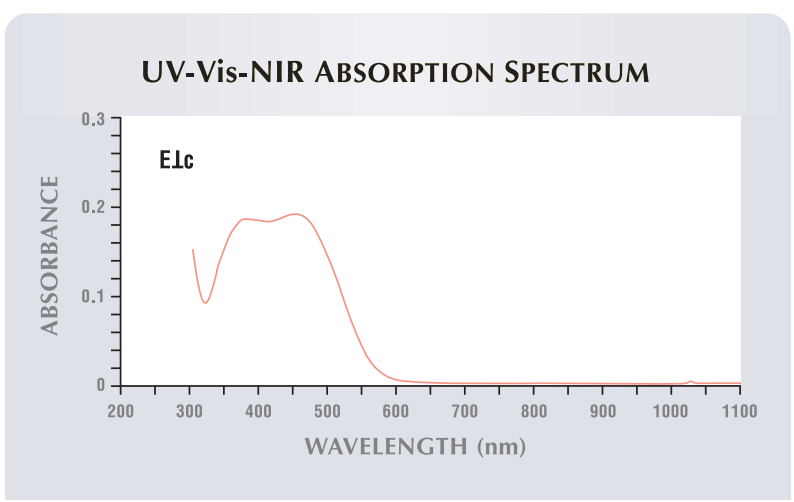


TABLE 6. Selected beryllium-diffused corundum experiments.

\begin{tabular}{|c|c|c|c|c|c|c|}
\hline Experiment & Samples & No. of pieces & Carrier & Application method & $\underset{\left({ }^{\circ} \mathrm{C}\right)}{\text { Temp. }}$ & $\begin{array}{c}\text { Time } \\
(\mathrm{hrs})\end{array}$ \\
\hline 1 & $\begin{array}{l}\text { Madagascar pink } \\
\text { Sri Lanka near colorless } \\
\text { heat-treated geuda }\end{array}$ & $\begin{array}{l}7 \\
8\end{array}$ & $\begin{array}{l}\text { Calcium phosphate } \\
\text { flux }+4 \% \text { chrysoberyl }\end{array}$ & Paint & 1800 & 25 \\
\hline 2 & $\begin{array}{l}\text { Madagascar pink } \\
\text { Sri Lanka colorless } \\
\text { heat-treated geuda }\end{array}$ & $\begin{array}{l}6 \\
9\end{array}$ & $\begin{array}{l}\text { Calcium borate flux } \\
+4 \% \text { chrysoberyl }\end{array}$ & Paint & 1800 & 25 \\
\hline 3 & $\begin{array}{l}\text { Madagascar pink } \\
\text { Sri Lanka colorless } \\
\text { heat-treated geuda }\end{array}$ & $\begin{array}{l}8 \\
7\end{array}$ & $\begin{array}{l}\text { Sodium phosphate flux } \\
+4 \% \text { chrysoberyl }\end{array}$ & Paint & 1800 & 25 \\
\hline 4 & $\begin{array}{l}\text { Madagascar pink } \\
\text { Sri Lanka colorless } \\
\text { heat-treated geuda }\end{array}$ & $\begin{array}{l}6 \\
4\end{array}$ & $\begin{array}{l}\text { Na-feldspar flux + } \\
4 \% \text { chrysoberyl }\end{array}$ & Paint & 1800 & 25 \\
\hline 5 & $\begin{array}{l}\text { Madagascar pink } \\
\text { Sri Lanka colorless } \\
\text { heat-treated geuda }\end{array}$ & $\begin{array}{l}10 \\
10\end{array}$ & $\begin{array}{l}\mathrm{Al}_{2} \mathrm{O}_{3}+4 \% \text { chrysoberyl } \\
\text { powder }\end{array}$ & Embedded in powder & 1780 & 100 \\
\hline 6 & $\begin{array}{l}\text { Madagascar pink } \\
\text { King's Plain blue } \\
\text { Dry Cottonwood Creek } \\
\text { Subera } \\
\text { Rock Creek } \\
\text { Songea ruby } \\
\text { Songea blue-green } \\
\text { Sri Lanka colorless } \\
\text { heat-treated geuda } \\
\text { SS8 synthetic sapphire }\end{array}$ & $\begin{array}{l}3 \\
3 \\
3 \\
3 \\
3 \\
3 \\
3 \\
3 \\
3\end{array}$ & $\begin{array}{l}\mathrm{Al}_{2} \mathrm{O}_{3}+0.8 \% \mathrm{BeO} \\
\text { powder }\end{array}$ & Embedded in powder & 1780 & 33 \\
\hline 7 & $\begin{array}{l}\text { SS1 synthetic sapphire } \\
\text { Madagascar pink } \\
\text { Sri Lanka colorless } \\
\text { heat-treated geuda } \\
\text { Rock Creek }\end{array}$ & $\begin{array}{l}1 \\
5 \\
6 \\
5\end{array}$ & $\begin{array}{l}\mathrm{Al}_{2} \mathrm{O}_{3}+2 \% \mathrm{MgO} \\
\text { powder }\end{array}$ & Embedded in powder & 1780 & 100 \\
\hline 8 & $\begin{array}{l}\text { Madagascar pink } \\
\text { King's Plain blue } \\
\text { Dry Cottonwood Creek } \\
\text { Subera } \\
\text { Rock Creek } \\
\text { Songea ruby } \\
\text { Songea blue-green } \\
\text { Sri Lanka colorless } \\
\text { heat-treated geuda } \\
\text { SS8 synthetic sapphire }\end{array}$ & $\begin{array}{l}3 \\
3 \\
3 \\
3 \\
3 \\
3 \\
3 \\
3 \\
1\end{array}$ & $\mathrm{Al}_{2} \mathrm{O}_{3}$ powder & Embedded in powder & 1780 & 33 \\
\hline 9 & $\begin{array}{l}\text { Songea blues, greens, } \\
\text { and ruby }\end{array}$ & 311 & $\begin{array}{l}\mathrm{Al}_{2} \mathrm{O}_{3}+2.65 \% \mathrm{BeO} \\
\text { powder }\end{array}$ & Paint & 1800 & 33 \\
\hline 10 & King's Plain & 363 & $\begin{array}{l}\mathrm{Al}_{2} \mathrm{O}_{3}+2.65 \% \mathrm{BeO} \\
\text { powder }\end{array}$ & Paint & 1800 & 33 \\
\hline 11 & Rock Creek & 146 & $\mathrm{Al}_{2} \mathrm{O}_{3}+2.65 \% \mathrm{BeO}$ & Paint & 1800 & 33 \\
\hline 12 & Ilakaka, Madagascar & 150 & $\begin{array}{l}\mathrm{Al}_{2} \mathrm{O}_{3}+2.65 \% \mathrm{BeO} \\
\text { powder }\end{array}$ & Paint & 1800 & 33 \\
\hline 13 & $\begin{array}{l}\text { Shandong, China- } \\
\text { very dark blue wafer }\end{array}$ & 1 & $\begin{array}{l}\mathrm{Al}_{2} \mathrm{O}_{3}+2.65 \% \mathrm{BeO} \\
\text { powder }\end{array}$ & Paint & 1800 & 33 \\
\hline 14 & Synthetic ruby wafer & 2 & $\begin{array}{l}\mathrm{Al}_{2} \mathrm{O}_{3}+2.65 \% \mathrm{BeO} \\
\text { powder }\end{array}$ & Paint & 1800 & 33 \\
\hline
\end{tabular}

peratures from $1780^{\circ} \mathrm{C}$ to $1800^{\circ} \mathrm{C}$ and treatment times of 25, 33, and (in two cases where the samples were embedded in powder) 100 hours. In each of the 17 runs, from 1 to 14 separate experiments were conducted for a total of 105 individual experiments. A subset of the 105 experiments is presented in table 6 . In addition, another 21 furnace runs, for a total of 53 individual experiments, were conducted 


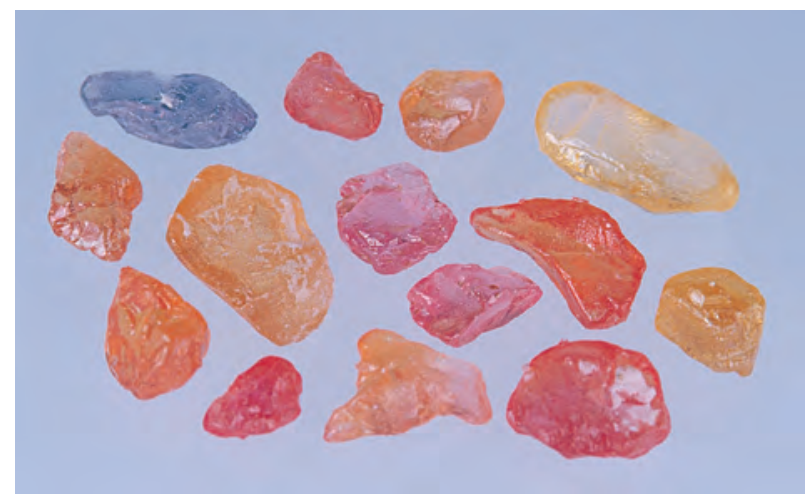

Figure 24. Experiments 1-4 in this study were able to reproduce every color and color layer that we had observed in the Be-diffused samples processed in Thailand. Some of those colors are shown by these corundum samples $(0.4-2.1 \mathrm{ct})$. Photo by Maha Tannous.

to produce differential spectra, and to study oxygen partial pressure dependence of the trapped-hole absorption spectra. As first reported in Emmett and Douthit (2002a), experiments 1 through 4 reproduced the full range of colors and diffusion-layer phenomenology that we had observed in the Thaiprocessed stones (see, e.g., figure 24). The stones showing color modification exhibited the typical surface-conformal color layer with a thickness of roughly $1.4 \mathrm{~mm}$. A few of the pink Madagascar stones did not change color. As discussed previously, this lack of color modification can be attributed to the chemistry of the specific sapphire, where $\left[\mathrm{Ti}^{4+}+\mathrm{Si}^{4+}\right]>\left[\mathrm{Mg}^{2+}+\mathrm{Be}^{2+}\right]$ or, more completely, [the total of all donors $]>\left[\mathrm{Mg}^{2+}+\mathrm{Be}^{2+}\right]$. With the exception of the silicate (sodium-feldspar) flux, there were few or no discernable differences in the apparent effectiveness of the fluxes. The corundum samples in the silicate flux showed little or no color modification, and thus silicate fluxes were not pursued further.

During this same time period, there was a large amount of disinformation coming from Thailand to the effect that neither beryllium nor chrysoberyl was involved in the new treatment process, and that these dramatic color modifications were the result of naturally occurring impurities. As a direct consequence, a more extensive set of experiments was undertaken to significantly narrow the possibilities (Emmett and Douthit, 2002b).

The next experiment (No. 5) was designed to eliminate any possible effect from the flux itself.
To accomplish this, ground natural chrysoberyl was mixed with high-purity reagent-grade $\mathrm{Al}_{2} \mathrm{O}_{3}$ powder. Another set of stones was packed in this powder mixture in high-purity alumina crucibles and heat-treated. The longer time for this experiment (100 hours vs. 25 hours for experiments 1-4) was chosen to assure that we could diffuse completely through some of the smaller stones. The results of this experiment, in terms of induced coloration, were just like the flux diffusion experiments, with the additional fact that the smaller stones were diffused, and thus colored, completely through. Again, a few of the pink Madagascar sapphires did not show any color alteration.

Natural chrysoberyl is not a high-purity material containing just $\mathrm{BeO}$ and $\mathrm{Al}_{2} \mathrm{O}_{3}$. It can contain significant quantities of iron, chromium, and/or a variety of other elements. Since we had no lowlevel trace-element analyses on natural chrysoberyl, it was at least conceptually feasible that trace-element impurities in the chrysoberyl could be responsible for the induced coloration in corundum. To address that possibility, high-purity reagent-grade $\mathrm{BeO}$ powder was procured, and mixtures were made with the high-purity $\mathrm{Al}_{2} \mathrm{O}_{3}$ powder and used in experiment 6 . A wide variety of representative sapphires were then heated for 33 hours at $1780^{\circ} \mathrm{C}$. The results of these experiments were the same as the earlier experiments using chrysoberyl (that is, all the orangy pink, orange, orangy yellow, and yellow colors were produced). Again, some of the pink Madagascar sapphires remained unchanged in color.

We also wished to evaluate the possible role of magnesium. As discussed earlier, if $\left[\mathrm{Mg}^{2+}\right]>\left[\mathrm{Ti}^{4+}+\right.$ $\left.\mathrm{Si}^{4+}\right]$, the trapped-hole yellow coloration will form when corundum is heat treated in an oxygen atmosphere. It is at least possible that Thai fluxes could contain some $\mathrm{Mg}$ compounds, which might diffuse into the corundum causing the yellow trapped-hole coloration. To determine if magnesium diffusion could be a factor in the Thai process, we added $2 \%$ $\mathrm{MgO}$ into the high-purity $\mathrm{Al}_{2} \mathrm{O}_{3}$ powder in experiment 7 . Even after heating for 100 hours, there was no induced coloration in the stones. This result was consistent with what we would expect, since the diffusion rate of magnesium into sapphire is very low, and an $\mathrm{MgAl}_{2} \mathrm{O}_{4}$ (spinel) layer forms rapidly at the interface between the sapphire and the powder.

As a final check, we conducted a "null" experiment (No. 8). We embedded a group of test sam- 
ples from several different localities in high-purity $\mathrm{Al}_{2} \mathrm{O}_{3}$ powder with no other additives, and replaced the entire inside ceramic surface of the furnace to assure no beryllium contamination from previous experiments. These samples were again heat treated for 33 hours at $1780^{\circ} \mathrm{C}$. In this case, there were no substantive color modifications at all.

To determine the diffusion rate of beryllium, we sectioned several of the larger stones from the various experiments described above, so we could measure the thickness of the diffusion layer. From these measurements, the chemical diffusion coefficient was determined to be roughly $10^{-7} \mathrm{~cm}^{2} / \mathrm{sec}$ (see Appendix). While this is a rather crude measurement, we note that this diffusion coefficient is about 1/100 that of hydrogen in corundum (El-Aiat and Kröger, 1982), and about 100 times that of titanium (our measurements) in corundum, at the same temperature. Also noted were minor variations in diffusion depth for different stones processed for the same duration at the same temperature. The variation of diffusion rate with impurity concentration is well known for diffusion measurements in solids.

To further understand the role of $\mathrm{Be}^{2+}$ in corundum, we diffused Be into colorless, very high-purity synthetic sapphire and high-purity synthetic ruby, with Fe contents on the order of 0.1 ppma or

Figure 25. These two high-purity synthetic sapphire samples were Be diffused in the experiments described in the text. The cube was Czochralski grown by Union Carbide Corp., while the cylinder (14 $\mathrm{mm}$ in diameter) was grown by Crystal Systems Inc. using the heat exchanger method. The concentration of beryllium in these samples is approximately 14 ppma, which illustrates that beryllium is a very strong colorant in sapphire. Photo by Maha Tannous.

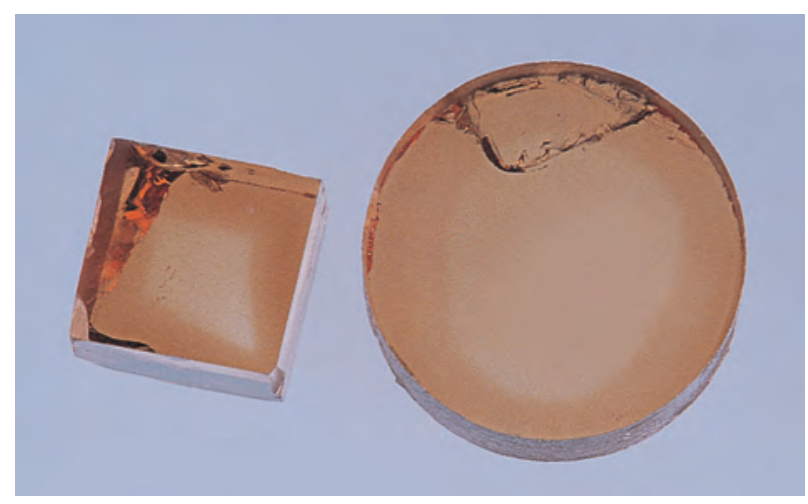

less and titanium contents of only about 2 ppma. Table 5 shows the low concentrations of $\mathrm{Fe}, \mathrm{Ti}$, and for the sapphire samples, Cr. These high-purity materials were chosen in an attempt to ensure that existing impurities in these materials could not cause any significant coloration. Beryllium diffusion into these types of materials resulted in concentrations ranging from 13 to 35 ppma. Figure 25 shows samples of both the Czochralski-grown and heat exchanger method (HEM)-grown synthetic sapphire after beryllium diffusion (for information on HEM, see Khattak and Schmid, 1984; Khattak et al., 1986). Both samples exhibit a strong orangy brown diffusion layer. Clearly, 10 to 30 ppma beryllium is a very strong chromophore in both natural and synthetic corundum, and there is no question that beryllium diffused into corundum in an oxygen atmosphere is the single causative agent of these color modifications.

After completing the experiments above, we were curious as to just how universal this Beinduced color modification might be. Using a combination of aluminum oxide and $2.65 \% \mathrm{BeO}$ powder mixed as a paint, we performed Be-diffusion experiments on a wide variety of natural corundum samples (again, see table 4). All of these experiments were run at $1800^{\circ} \mathrm{C}$ for 33 hours. The color alteration produced is evident in these before-andafter pictures of mine-run sapphire and ruby from Songea, Tanzania (experiment 9, figure 26); Rock Creek, Montana (experiment 11, figure 27); King's Plain, Australia (experiment 10, figure 28); and Ilakaka, Madagascar (experiment 12, figure 29). Using the same procedure as for experiments 9 through 12, we obtained similar results with sapphire from Dry Cottonwood Creek and Eldorado Bar, Montana; Subera, Australia; Shandong, China; and Umba, Tanzania. While this list is not exhaustive of sapphire deposits by any means, it does imply broad applicability of the Be-diffusion process. Many additional photographs of the colors produced by Be diffusion into corundum are shown in Themelis (2003).

The reason that beryllium diffusion modifies the color of most corundum can be easily understood. Gem corundum usually is not strongly colored, which means that the net concentration of either $\mathrm{Fe}^{2+}-\mathrm{Ti}^{4+}$ pairs or $\mathrm{Mg}^{2+}$-hole pairs is not large. Consequently, reducing the effective concentration of $\mathrm{Fe}^{2+}-\mathrm{Ti}^{4+}$ pairs or increasing the effective concentration of $\mathrm{Mg}^{2+}$ by diffusing in 10 to 30 ppma beryllium, has a strong impact on color. 

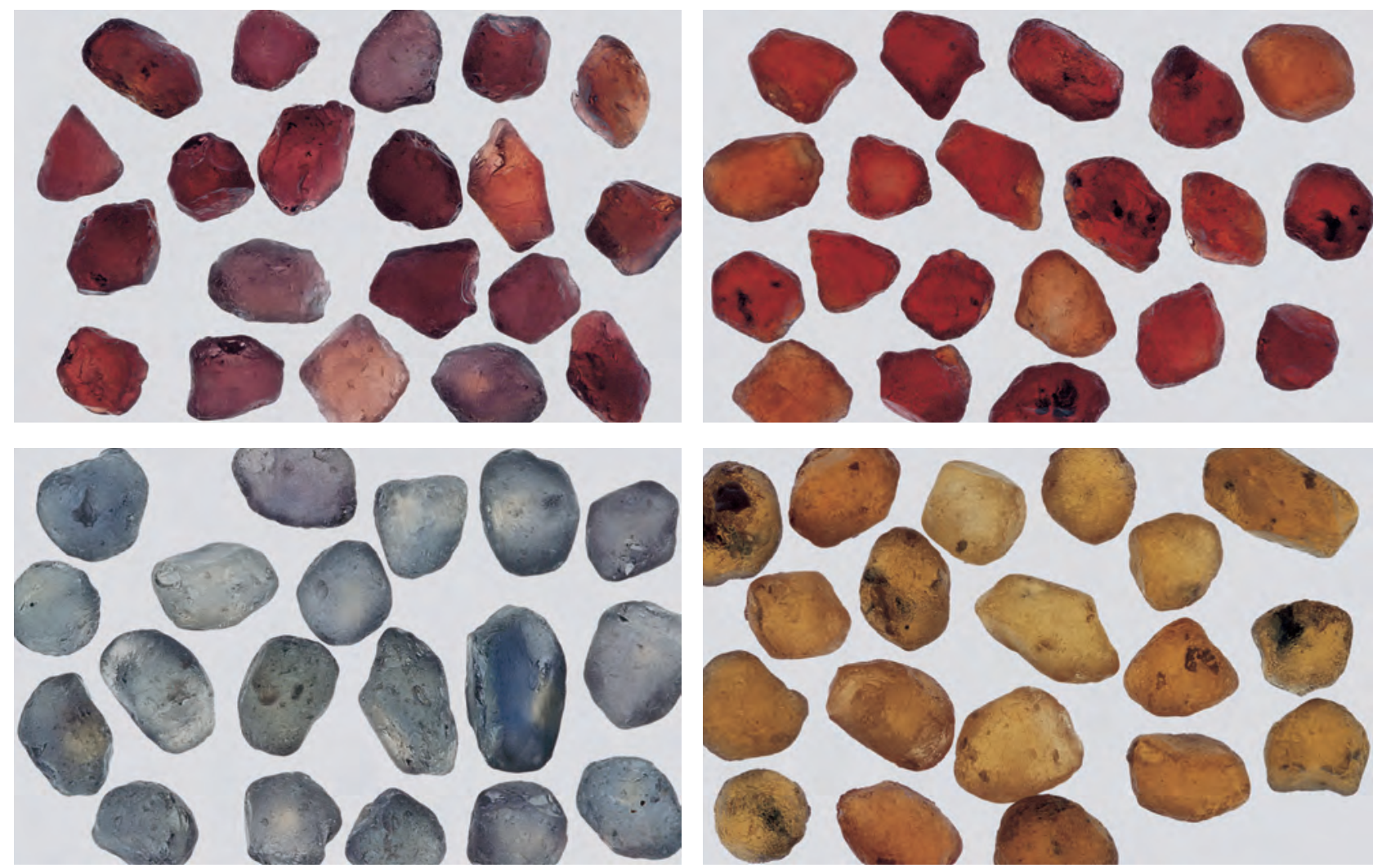

Figure 26. These two groups of different colors of sapphire rough (top, 0.5-1.2 ct; and bottom, 0.8-2.5 ct), from Songea, Tanzania, are shown before (left) and after (right) Be diffusion by the authors. Photos by J. Emmett.

Experiments on Blue Sapphire. From our analysis of the impact of beryllium diffusion on very dark blue sapphires where $\left[\mathrm{Ti}^{4+}\right]>>\left[\mathrm{Mg}^{2+}\right]$, we find that beryllium diffusion should produce the condition $\left[\mathrm{Ti}^{4+}\right]>\left[\mathrm{Mg}^{2+}+\mathrm{Be}^{2+}\right]$, substantially reducing the blue color saturation. To test this point (experiment 13$)$, we cut a very thin $(0.9 \mathrm{~mm})$ wafer of extremely dark blue sapphire from a Shandong crystal (figure 30A). Figure 30B shows the same wafer after Be diffusion in an oxygen atmosphere. The lighter blue areas have been rendered either colorless or pale yellow by the mechanisms previously discussed, and the remaining blue areas are much less saturated. After subsequent normal heat treatment in a reducing atmosphere (figure 30C), the yellow areas have been rendered essentially colorless, while the previously colorless or pale blue areas in figure 30B are a more saturated blue.

Figure 27. Rough sapphire from Rock Creek, Montana, also responded well to Be diffusion, as seen in these images before (left) and after (right) Be-diffusion treatment. These samples weigh 0.4-1.4 ct. Photos by J. Emmett.
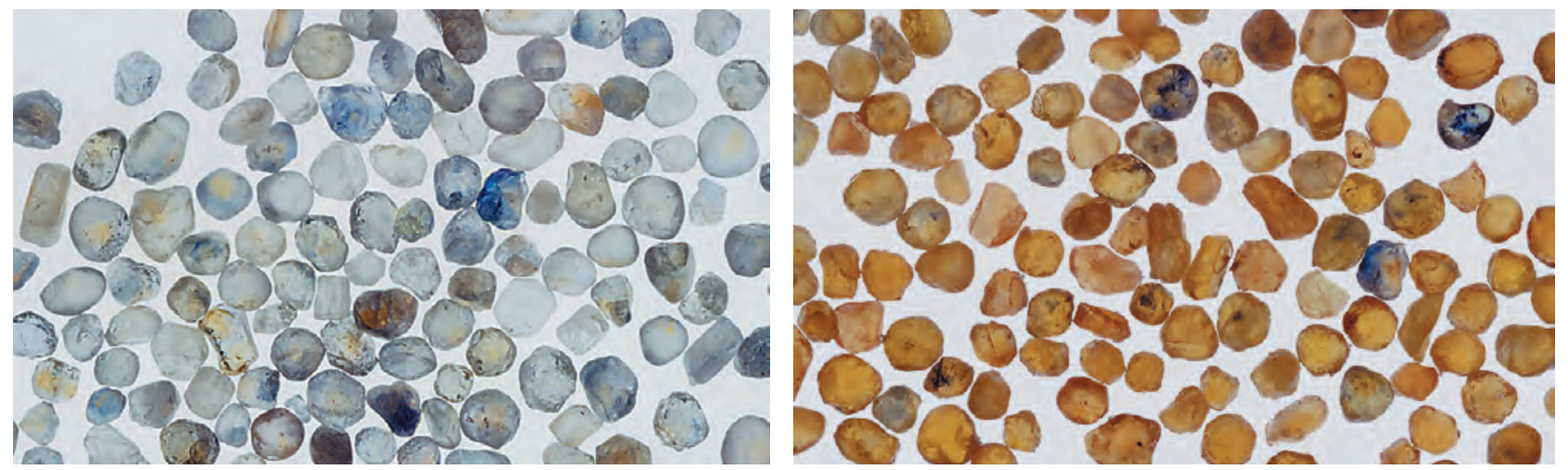

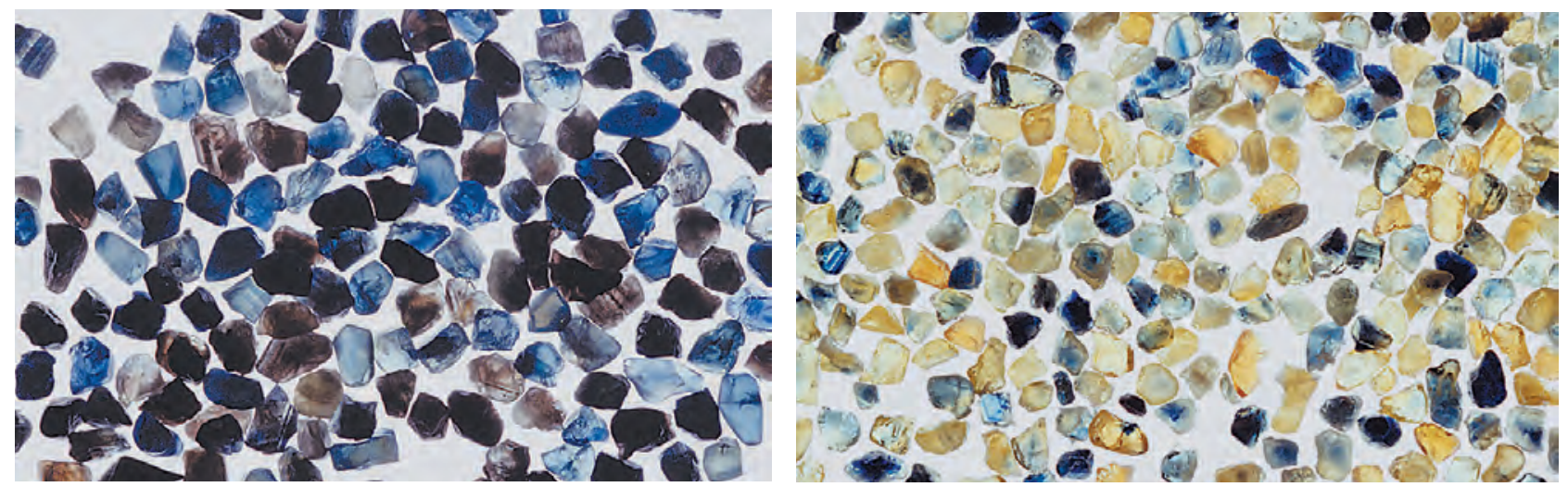

Figure 28. Significant color alteration was also seen in this parcel of rough sapphire from King's Plain, NSW,

Australia (average 0.3-0.5 ct), shown here before (left) and after (right) Be-diffusion treatment. Photos by J. Emmett.

Overall the blue areas are now far less saturated than in the wafer before treatment. Thus, a simple process for turning some types of very dark-blue sapphire into a much lighter blue is to diffuse beryllium into the crystal, followed by a standard reduction heat-treatment process. This process can be conducted in 30 to 60 hours on pieces of rough sapphire sufficient to cut 2 ct faceted stones. Given the efficacy of this two-step processing, it is recommended that high-value blue sapphires also be tested for Be-diffusion treatment.

Absorption Spectra. Figure 31 shows the differential absorption spectrum of a Be-diffused high-purity synthetic sapphire (sample SS8 in table 5) and a similar spectrum of an orange Madagascar sapphire that was Be diffused in Thailand from originally pink material (sample TD-1). While these two spectra both show strong absorption in the blue region, there are significant differences. The absorption peak of the SS8 synthetic sapphire is centered at $420 \mathrm{~nm}$, while that of the natural sapphire is at
$460 \mathrm{~nm}$. In addition, the SS8 material exhibits a weak broad band centered at about $700 \mathrm{~nm}$. To gain some insight into these differences, we diffused beryllium into two synthetic rubies (SS3 and SS18) that contained different levels of chromium but otherwise were of very high purity. The differential absorption spectra of both were essentially the same (see, e.g., figure 31).

Comparing the Be-diffused SS3 differential spectrum with that of the Be-diffused natural sapphire (TD-1), we note that both show peaks at 380 $\mathrm{nm}$ and $460 \mathrm{~nm}$, and neither shows the $700 \mathrm{~nm}$ peak. The $460 \mathrm{~nm}$ peaks are essentially identical, while the 380 peaks exhibit different amplitudes. It thus appears that the spectral differences between the SS8 synthetic sapphire and the sample TD-1 natural sapphire are associated with the presence of chromium. In high-purity Be-containing synthetic sapphire, the trapped hole is associated with the beryllium ion. However, in sapphire containing chromium in addition to beryllium, the Be-induced trapped hole will preferentially

Figure 29. Rough sapphire from Ilakaka, Madagascar (average 0.4-1.0 ct), also showed dramatic color differences, as evident in this material before (left) and after (right) Be-diffusion treatment. Photos by J. Emmett.

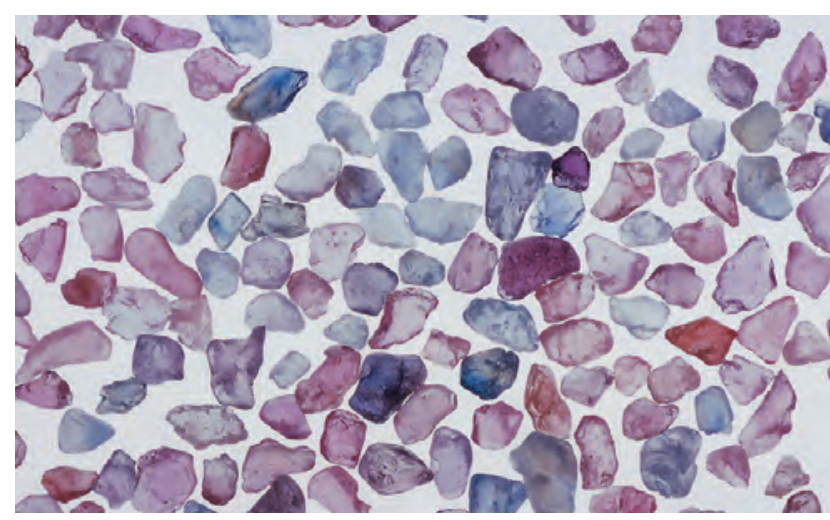

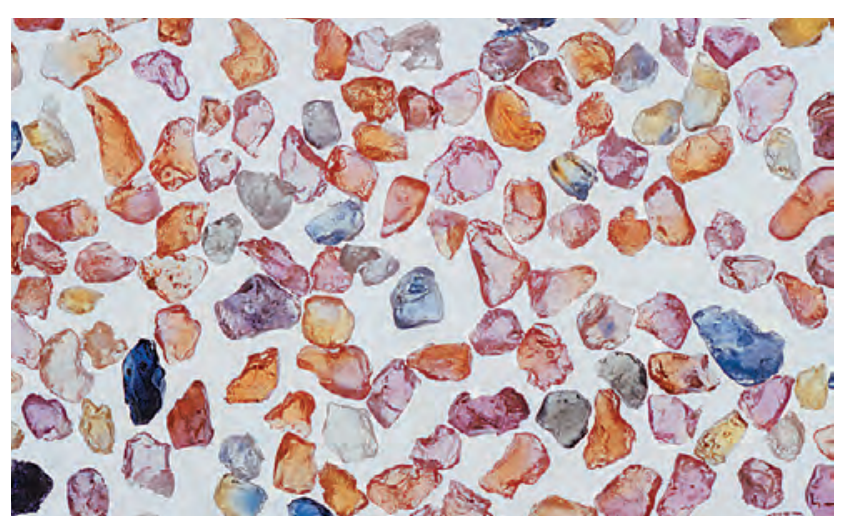



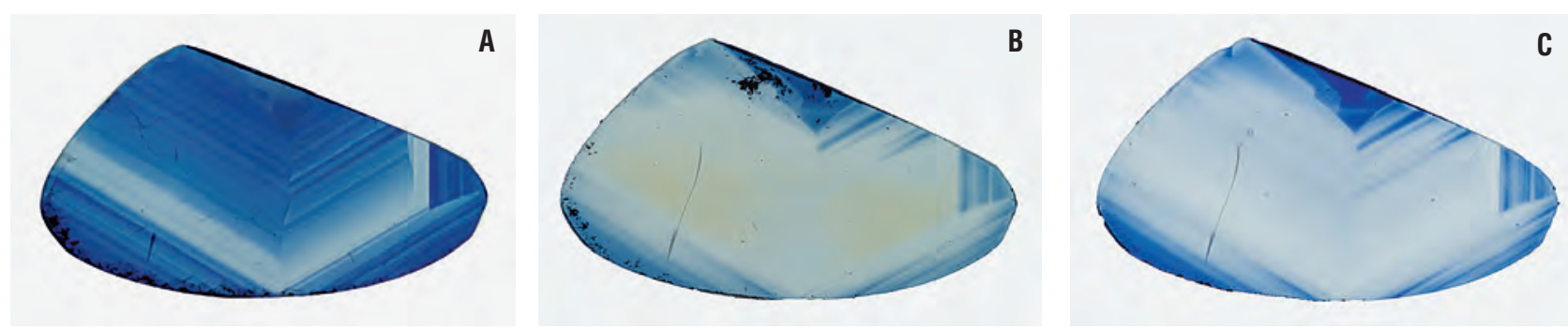

Figure 30. This thin wafer $(0.9 \times 16 \mathrm{~mm})$ was cut from an extremely dark blue sapphire crystal from Shandong, China. It is illuminated from below so that the color is apparent. The wafer in its untreated state is on the far left (A). After Be diffusion in an oxygen atmosphere (B), most of the blue color has been removed or greatly lightened and a small amount of yellow color has appeared. Subsequent standard reduction heat treatment removed the yellow color and slightly increased the saturation of the blue (C). The blue color has now effectively been lightened by this process. Photos by J. Emmett.

associate with the $\mathrm{Cr}^{3+}$ ion (again, see Box B). Thus, the differential absorption spectrum in this case is that of a trapped hole near a $\mathrm{Cr}^{3+}$ ion, not that of a trapped hole near an $\mathrm{Mg}^{2+}$ ion, a result we anticipated in the "Color in Corundum" section. There are two possibilities for the origin of this spectrum. First, we could be observing the spectrum of a $\mathrm{Cr}^{3+}$-trapped hole pair. Second, we could be observing the spectrum of $\mathrm{Cr}^{4+}$ resulting from combining the hole and the $\mathrm{Cr}^{3+}$ ion. Determining which of these possibilities is correct will require significant additional research.

In sapphire that does not contain chromium, but does contain $\mathrm{Fe}^{3+}$, beryllium-induced trapped holes will preferentially associate with $\mathrm{Fe}^{3+}$ rather than

Figure 31. This figure shows the berylliuminduced absorption from sample TD-1 (a Thai Be-diffused pink Madagascar sapphire), sample SS3 (a Be-diffused synthetic ruby), and sample SS8 (a high-purity synthetic sapphire grown by the heat-exchanger method). The absorption spectrum of the Cr-containing samples differs significantly from that of SS8, because the beryllium-induced trapped hole interacts with the chromium.

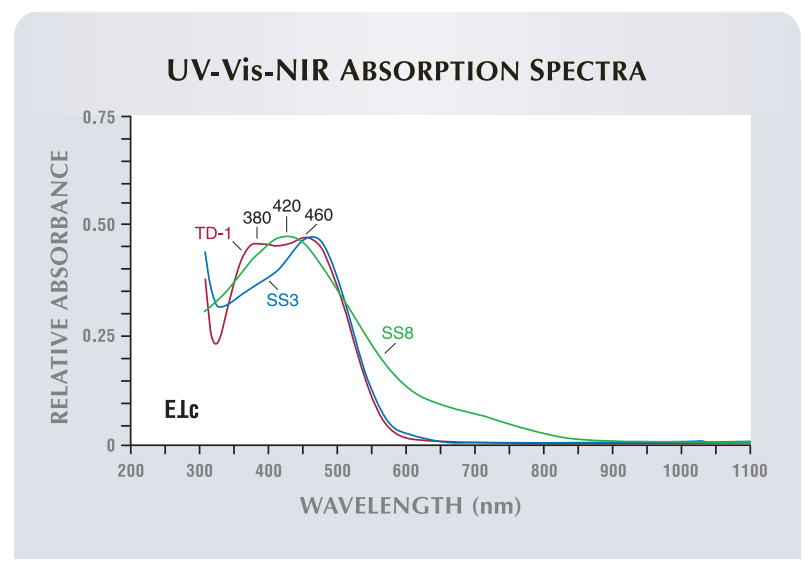

$\mathrm{Be}^{2+}$. The resulting absorption spectrum again can be a $\mathrm{Fe}^{3+}$-trapped hole pair, or the spectrum of $\mathrm{Fe}^{4+}$. We would expect the absorption spectrum from the hole association with $\mathrm{Cr}^{3+}$ to differ somewhat from the spectrum of the association with $\mathrm{Fe}^{3+}$. However, all the natural sapphires for which we have both SIMS data and careful differential spectroscopy contain chromium at $\geq 10$ ppma. Thus it is understandable why all exhibit the $460 \mathrm{~nm}$ absorption if it is indeed associated with a $\mathrm{Cr}^{3+}$-hole pair. To test this hypothesis, we need to diffuse Be into sapphire containing iron, but not containing chromium at more than a few ppma. There are two possibilities for obtaining such material. First, it may be possible to find such stones among the "colorless" heat-treated Sri Lanka geuda. Second, a high-purity iron-doped synthetic sapphire could be grown. We are working with a number of colleagues to pursue both approaches. Be diffusing such material should allow us to unambiguously observe the $\mathrm{Fe}^{3+}$-hole pair spectrum, and thus resolve remaining color issues.

\section{GEMOLOGICAL TESTING AND IDENTIFICATION}

It is essential that the role of the diffused $\mathrm{Be}$ in corundum be understood before any identification techniques, whether simple or complex, are proposed. The foregoing provides that foundation. The experiments described below were conducted to characterize Be diffusion-treated ruby and sapphire, and to provide possible identification criteria.

\section{Materials and Methods}

Samples. The number of samples (898) examined for the gemological identification portion of this study is necessarily quite large, to examine as many of the effects of the Be-diffusion process as 
possible, and yet there are stones from some geographic areas, and in some color combinations, that remain to be studied.

From the 898 samples, 285 were known to be beryllium diffused, 178 were used for before-andafter experiments, and 435 were not diffused. Approximately half were faceted. The known-diffused samples were either acquired as such directly from treaters or dealers in Thailand, were proved to be Be diffused through chemical analysis or characteristic color zoning, or were treated by us. These samples were yellow, pink to orange to red, blue, purple, green, and colorless; they came from Madagascar (Ilakaka and unspecified deposits), Montana, Tanzania (Songea and Umba), and unknown localities.

The samples that were obtained for the beforeand-after experiments were either colorless or showed the following colors before treatment: light yellow, yellowish orange, pink, brownish red, blue, purple, green, brown, and gray, with some multicolored. These samples were sourced from Australia (Lava Plains), Laos, Montana, Madagascar (Ilakaka, northern, and unspecified deposits), Sri Lanka, Tanzania (Songea and Umba), Thailand (Kanchanaburi and unspecified deposits), Vietnam (Lam Dong, Quy Chau, and unspecified deposits), and unknown localities.

The samples that were not Be diffused were colorless to yellow to orange, pink to purple to red, blue to green, brown, gray, and mixed pale colors; both natural-color and standard heat-treated stones were represented. Specific information on the sample population and the tests to which they were subjected can be found in the Be-diffusion samples table in the $G \oplus G$ Data Depository (http://www.gia.edu/gemsandgemology, click on "GeG Data Depository").

Standard Gemological Testing. Routine gem testing was performed on a portion of the samples examined for this study, although not all samples were studied by all methods (again, see the Be-diffusion samples table in the $G \uplus G$ Data Depository). The tests included determination of refractive index, specific gravity by the hydrostatic method, and pleochroism, as well as observing absorption spectra from desk-model spectroscopes and the reaction to ultraviolet radiation.

Since color distribution was anticipated to be the most important identification criterion, we examined virtually all samples with a gemological

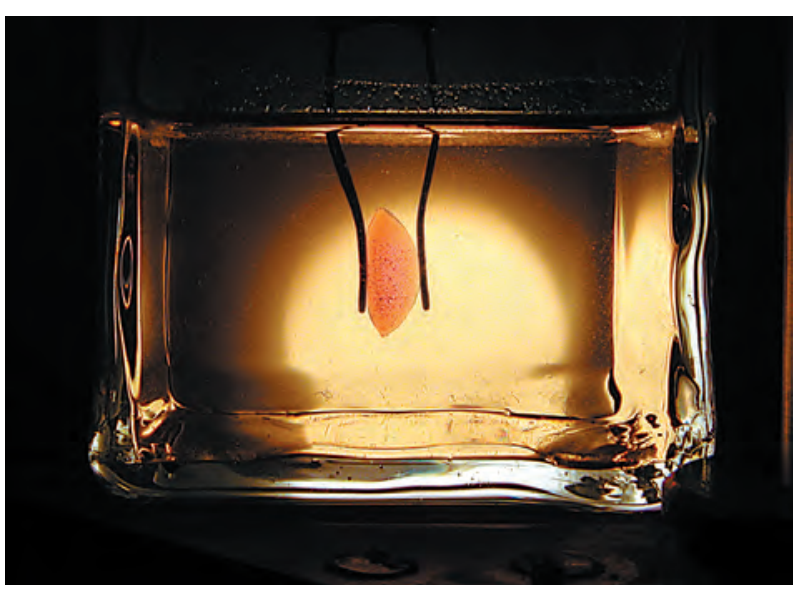

Figure 32. This Be-diffused sapphire is shown in an immersion cell filled with methylene iodide; a diffuser plate was placed between the light source and the cell. In conjunction with a horizontal microscope, this was one of the methods used to examine the stones in this study. Photo by Ken Scarratt.

microscope, using various types of lighting and immersion techniques.

Our equipment included a horizontal binocular microscope configured with an immersion cell (figure 32), and upright microscopes with both a standard immersion cell and specially prepared, grooved, translucent white plastic trays. In all cases, the samples were immersed in methylene iodide (di-iodomethane, R.I.=1.74). (Other immersion fluids, such as water or baby oil, may be used, but their lower refractive indices render them less effective.) Illumination of the sample with diffused white light greatly facilitated the observation of color gradients. Low magnification $(10 \times)$ was used to search for surface-conformal color zoning, whereas higher magnification (up to 63x) was used to examine internal and surface features.

UV-Vis-NIR Spectroscopy. The UV-Vis-NIR spectra at room and liquid-nitrogen temperatures were recorded for the range 190-900 $\mathrm{nm}$ using Unicam UV500 and Hitachi U-2000 instruments. Spectra for natural, heated, and Be diffusion-treated stonesboth faceted and in the form of polished waferswere recorded in the direction of the o-ray $(\mathrm{E} \perp \mathrm{c})$.

Infrared Spectroscopy. The infrared spectra of selected samples (including natural, heated, and Be-diffusion treated of various colors) were recorded in the range of $6000-400 \mathrm{~cm}^{-1}$ using Fouriertransform infrared (FTIR) spectrometers (Nicolet 560 and 760, Nexus 670, and Avitar) and various accessories (beam condenser, diffuse reflectance 


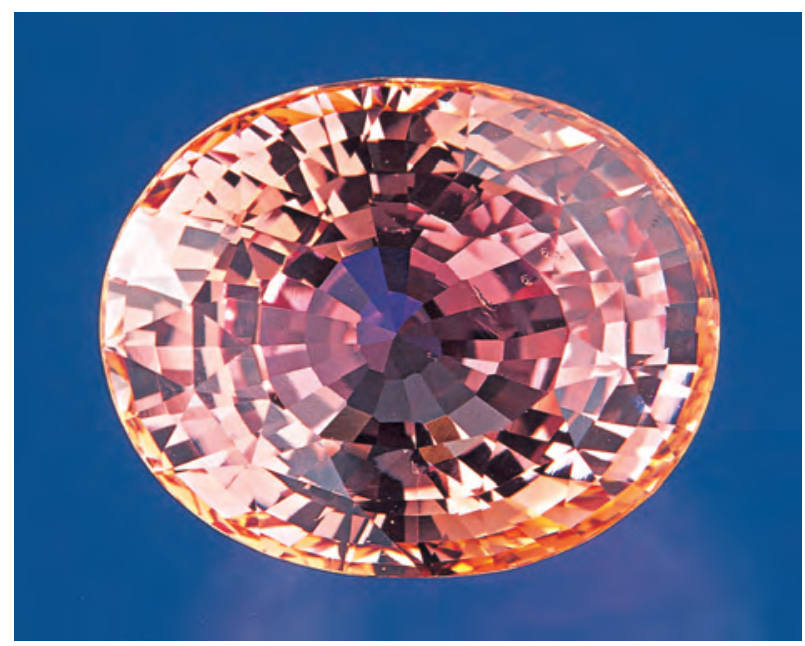

Figure 33. Not all sapphires treated with beryllium have an intense color, as this $14.38 \mathrm{ct}$ Be-diffused sapphire illustrates. It has a medium tone very similar to that of some natural-color sapphires. It is interesting to note that the thin orange layer present in this stone is visible even without immersion, which is not usually the case. Photo by Maha Tannous.

[DRIFTS], and attenuated total reflectance [ATR]). We employed an MCT-B detector and a KBr beam splitter, using various resolutions (from 0.5 to 4.0 $\mathrm{cm}^{-1}$ ), to observe the $\mathrm{O}-\mathrm{H}$ region and other spectral areas of interest.

Raman Spectroscopy. Raman spectra were gathered using a laser Raman microspectrometer (Renishaw 1000 system) at both room and liquid nitrogen temperatures, with an argon-ion laser providing excitation at $514.5 \mathrm{~nm}$. We used this technique to determine whether any Raman peaks were induced or changed as a result of Be diffusion, as well as to identify surface-reaching fluxes, synthetic overgrowths, and crystal inclusions.

Chemistry. Chemical analysis by energy-dispersive $\mathrm{X}$-ray fluorescence (EDXRF) was performed on an
EDAX DX 95 and a Spectrace QuanX. The full range of elements within the detection limits of these instruments was surveyed (from sodium through the heavier elements). This technique was primarily used early in the study of these new diffused materials to see if there were any elements peculiar to this treatment that were detectable by these instruments (see, e.g., McClure et al., 2002). This did not prove to be the case, showing that this testing technique is not useful for this purpose.

To search for light elements in the diffused layer, we also used SIMS analysis at Evans East (again, see Box A). Since February 2002, we have submitted 62 rubies and sapphires to SIMS analysis with 153 separate analyses. Samples were selected from stones known to have been treated in Thailand by beryllium diffusion; stones treated to specific parameters by two of the authors; stones that were known to be untreated; and stones that were submitted by clients for examination and laboratory reports.

\section{Results and Discussion}

Visual Appearance. We observed that many of the colors produced by Be-diffusion treatment are very saturated, particularly those in the pinkorange, yellow, and orange ranges (again, see figure 1). These colors have never been common in natural corundum, even among typical heat-treated sapphires. The availability of large quantities of such colors in one place, as several of the authors have seen in Thailand, would immediately suggest that they have been treated by this new technique. When a single stone is examined, however, color alone is not diagnostic, as natural and heattreated sapphires and rubies exist in all the colors seen in Be-diffused corundum (see Box C and chart figure C-31). Note, too, that not all sapphires treated with Be diffusion produce such

Figure 34. A wafer cut from this $0.83 \mathrm{ct}$ Vietnamese pink sapphire (before treatment, left) was Be diffused for this study (right). There was no observable change in color (the white material is residual flux). Photos by Elizabeth Schrader.
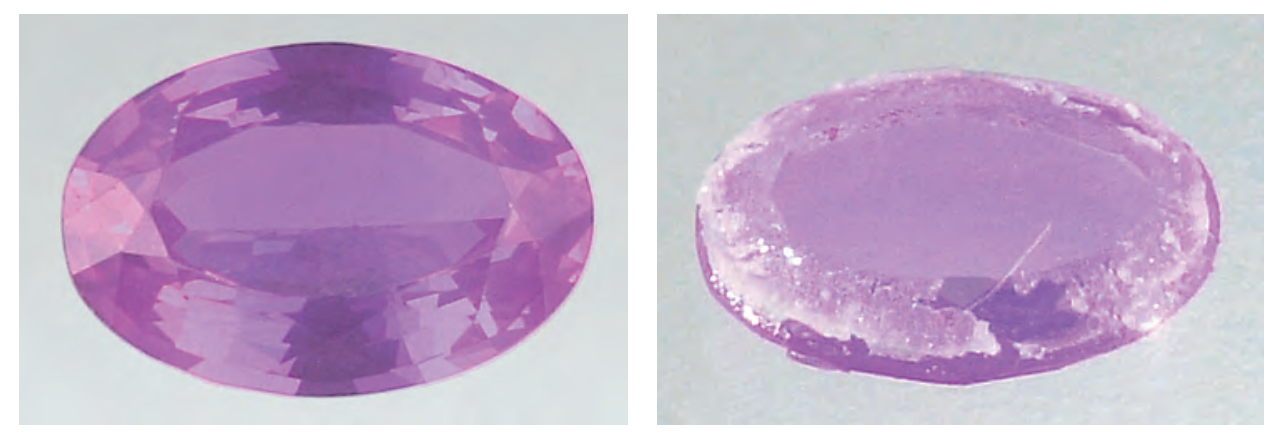
vibrant, saturated colors (figure 33). In fact, as discussed in the "Color in Corundum" section, some stones do not change color at all, even though SIMS analysis shows that beryllium has penetrated them (figure 34). In addition, as described earlier, this new treatment can lessen the intensity of color in some dark blue sapphires.

Optical and Physical Properties. The refractive index, birefringence, pleochroism, and specific gravity of our samples did not vary significantly from those properties recorded for other types of natural or treated corundum. This is consistent with the very low concentration of beryllium that has been detected in the diffused stones (see table 7). The Be diffusion-treated stones had a broad range of reactions to UV radiation, from inert to strong, and the fluorescence colors varied from orange to reddish orange. This probably is due to the wide variety of corundum being subjected to this treatment. However, we did notice a somewhat higher-than-expected occurrence of moderate-to-strong orange fluorescence to long-wave UV in the pink-orange stones. This reaction was by no means consistent, and in our experience it is not uncommon in non-diffused stones of the same color. Consequently, it cannot be considered a useful identification clue.

Most of the diffused stones we tested, particularly those in the yellow-to-orange range, showed weak-to-strong $450 \mathrm{~nm}$ iron-related absorption in the desk-model spectroscope. All the samples with a pink or red component, as well as some orange stones, also showed $\mathrm{Cr}$ absorption in the red region of the spectrum (692 and $694 \mathrm{~nm}$ ). The Fe-related absorption was stronger than expected for some of

TABLE 7. Representative trace-element compositions of corundum by SIMS (ppma). ${ }^{\text {a }}$

\begin{tabular}{|c|c|c|c|c|c|c|c|c|c|c|c|c|}
\hline Sample no. & Color & Notes & $\mathrm{Be}$ & $\mathrm{Na}^{\mathrm{b}}$ & $\mathrm{Mg}$ & $\mathrm{Si}$ & $K^{b}$ & $\mathrm{Ti}$ & $\mathrm{Cr}$ & $\mathrm{Fe}$ & $\mathrm{Ga}$ & Geographic source \\
\hline \multicolumn{13}{|l|}{ Untreated } \\
\hline 48718 & Red & & 1.15 & 2.04 & 45.2 & 38.4 & 0.63 & 334 & 4300 & 6.55 & 62.9 & Mong Hsu, Myanmar \\
\hline 49081 & Green & & 1.46 & 0.12 & 80.3 & 17.8 & 0.03 & 63.2 & 90.1 & 1461 & 16.1 & Montana, U.S. \\
\hline 49081 & Orange & & 1.46 & 0.20 & 76.1 & 16.1 & 0.04 & 63.0 & 80.7 & 1358 & 13.0 & Montana, U.S. \\
\hline 49089 & Yellow & & 1.48 & 3.96 & 35.8 & 17.7 & 0.17 & 29.1 & 4.61 & 2646 & 39.7 & Unknown \\
\hline 49089 & Blue & & 1.52 & 0.16 & 9.20 & 18.2 & 0.03 & 120 & 2.57 & 1998 & 29.6 & Unknown \\
\hline 49102 & Pink & & 1.42 & 0.10 & 28.5 & 40.3 & 0.07 & 742 & 1061 & 8.91 & 18.4 & Vietnam \\
\hline \multicolumn{13}{|c|}{ Before / after Be-diffusion treatment } \\
\hline 49106 & $\begin{array}{l}\text { Yellowish } \\
\text { brown }\end{array}$ & Before & 1.24 & 0.07 & 56.8 & 22.1 & 0.04 & 40.1 & 237 & 2496 & 20.7 & Songea, Tanzania \\
\hline $49106 \mathrm{~T}$ & Orange & After & 17.4 & 0.54 & 43.9 & 15.4 & 0.41 & 28.6 & 222 & 1610 & 28.8 & Songea, Tanzania \\
\hline 45031 & Pink & Before & 1.20 & 0.04 & 105 & na & 0.02 & na & 292 & 153 & 22.7 & Unknown \\
\hline 45002 & $\begin{array}{l}\text { Pinkish } \\
\text { orange }\end{array}$ & After & 13.2 & 0.13 & 109 & na & 0.09 & na & 322 & 145 & 25.4 & Unknown \\
\hline 45494 & Pink & Before & 1.44 & 0.62 & 167 & na & 0.12 & 121 & 928 & 158 & 51.1 & Unknown \\
\hline 45493 & $\begin{array}{l}\text { Pinkish } \\
\text { orange }\end{array}$ & After & 18.0 & 2.20 & 134 & na & 0.67 & 89.9 & 781 & 115 & 33.6 & Unknown \\
\hline \multicolumn{13}{|c|}{ Be diffusion-treated samples } \\
\hline 45033 & $\begin{array}{l}\text { Orangy } \\
\text { red }\end{array}$ & Center & 16.4 & 0.28 & 76.5 & na & 0.18 & na & 712 & 1056 & 19.0 & Unknown \\
\hline 45033 & $\begin{array}{l}\text { Orangy } \\
\text { red }\end{array}$ & Edge & 19.2 & 0.21 & 78.5 & na & 0.14 & na & 707 & 1083 & 19.5 & Unknown \\
\hline 45490 & Yellow & Center & 3.14 & 0.03 & 11.8 & na & 0.01 & 15.8 & 3.93 & 1509 & 46.9 & Unknown \\
\hline 45490 & Yellow & Edge & 24.5 & 0.04 & 5.20 & na & 0.01 & 20.0 & 3.91 & 1490 & 33.8 & Unknown \\
\hline 48415 & Red & & 25.1 & 0.43 & 64.0 & na & 0.24 & 47.4 & 4118 & 2441 & 53.8 & Unknown \\
\hline
\end{tabular}

ana $=$ not analyzed. Accuracy of $\mathrm{Be}$ and $\mathrm{Fe}$ is $\pm 10-20 \% ; \mathrm{Ga}, \mathrm{Mg}, \mathrm{Si}, \mathrm{Ti}, \mathrm{Cr}, \mathrm{Na}$, and $\mathrm{K}$ is about $\pm 30 \%$. A complete listing of the analyses performed for this study can be found in the G\&G Data Depository (www. gia.edu/GemsandGemology, click on "G\&G Data Depository").

${ }^{b}$ High concentrations of $\mathrm{Na}$ and $\mathrm{K}$ in some analyses could be due to surface contamination. 


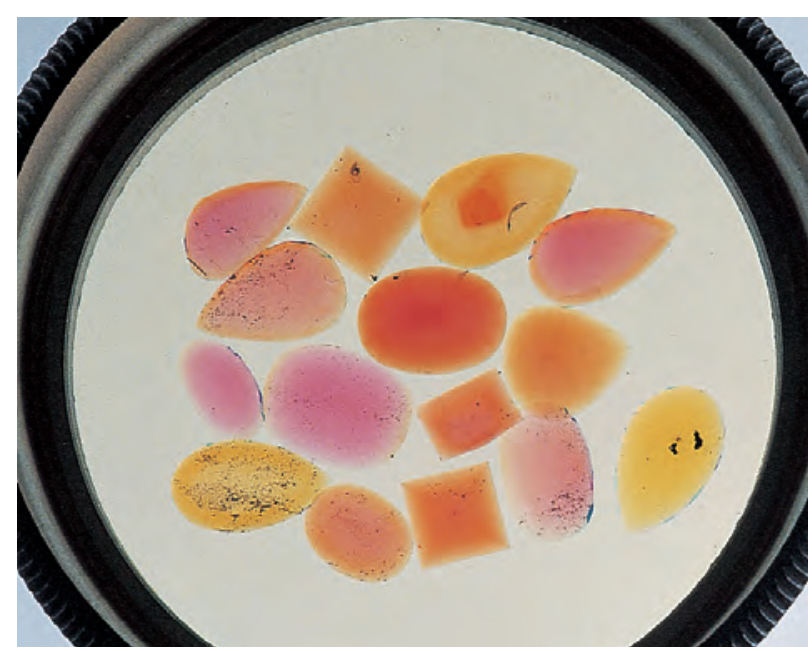

Figure 35. A wide variation in the penetration depths of surface-conformal color layers can be seen in this group of faceted Be-diffused sapphires (0.51-1.92 ct), immersed in methylene iodide. Photo by Maha Tannous.

the colors tested. We believe this absorption is related to the starting material used for Be diffusion, rather than to the treatment itself. It must be emphasized, however, that this observation is in no way diagnostic of Be diffusion, as many natural yellow or orange sapphires show similar absorption.

Color Distribution. Beryllium diffusion came to the attention of gemologists and the trade after yellowto-orange three-dimensional surface-conformal layers were seen on faceted orangy pink padparadschalike sapphires (McClure et al., 2002; Scarratt $2002 a, b)$. We have never observed-either in the

Figure 37. Many different combinations of Be-diffused colors are possible. Some, as in this $1.51 \mathrm{ct}$ purple and orange briolette with an orange surface-conformal layer, are very unusual. Photomicrograph by Shane F. McClure; immersion, magnified 10x.

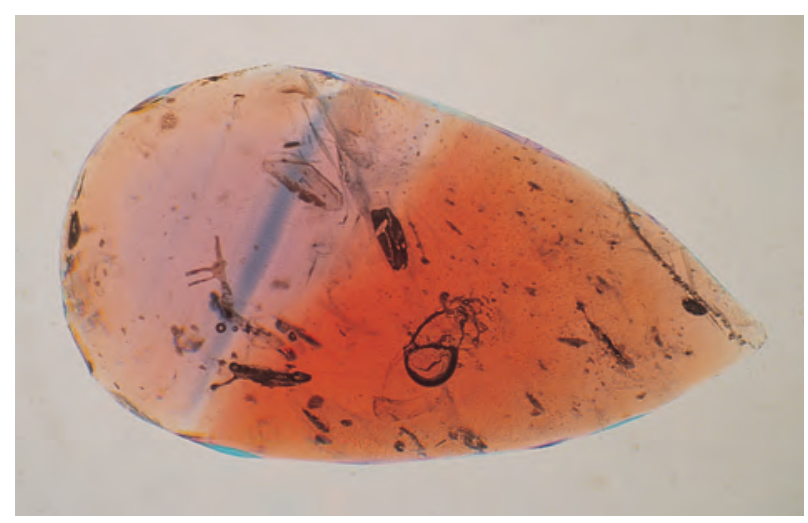

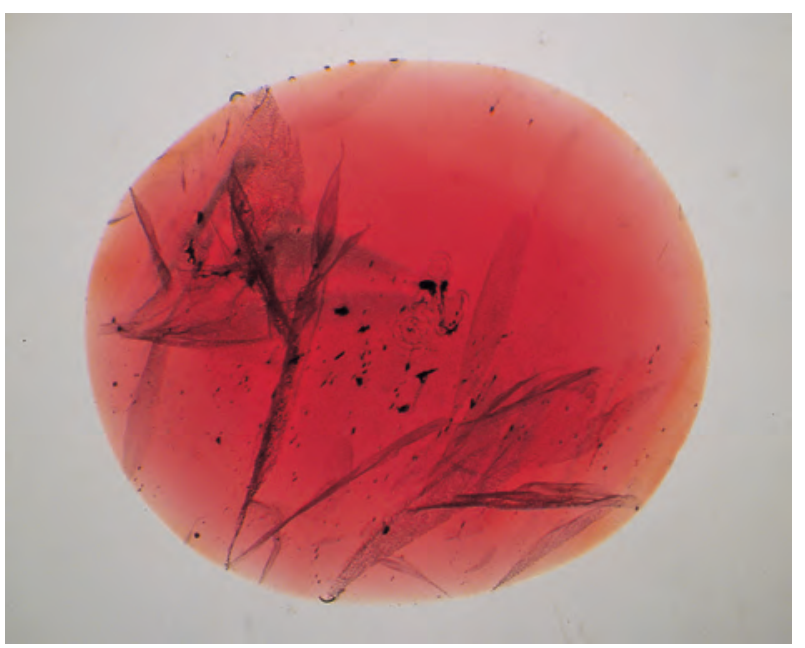

Figure 36. The vast majority of predominantly red Bediffused samples we examined showed a relatively thin, surface-conformal layer of orange color. The layer in this $5.05 \mathrm{ct}$ stone is somewhat uneven, which suggests that it was recut after treatment. Photomicrograph by Shane F. McClure; immersion, magnified 10x.

course of this study or in our many years of experience-such a three-dimensional layer of color paralleling the surface of a natural-color polished gemstone. To the best of our knowledge, it can only be caused by a diffusion treatment.

Therefore, careful observation of color distribution became critical to this investigation. Exami-

Figure 38. Natural color zoning in corundum does not conform to the faceted shape of the stone. Instead, it follows the structure of the corundum crystal, creating angular zones and parallel bands, as can be seen in this group of non-diffused rubies and sapphires (0.14-1.29 ct). Photo by Maha Tannous; in immersion.

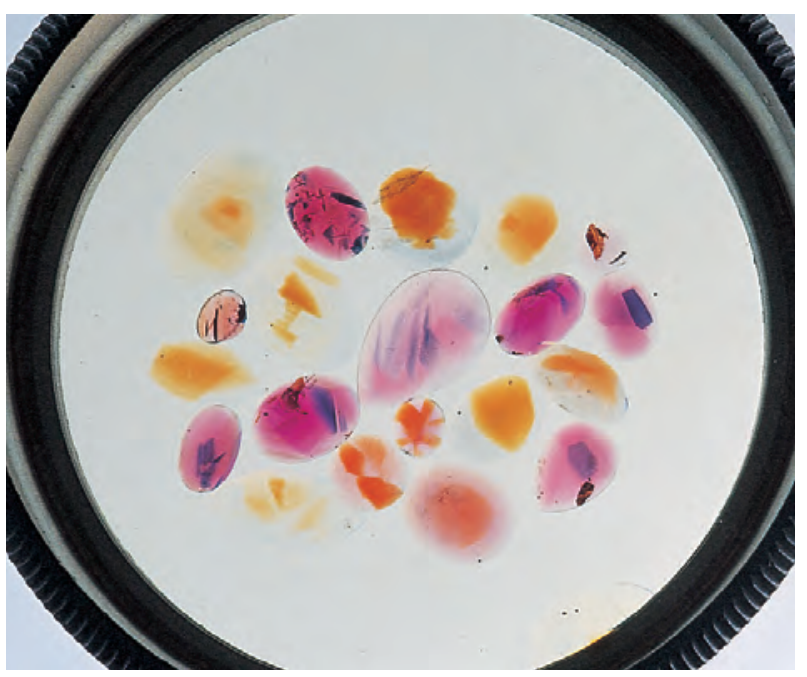



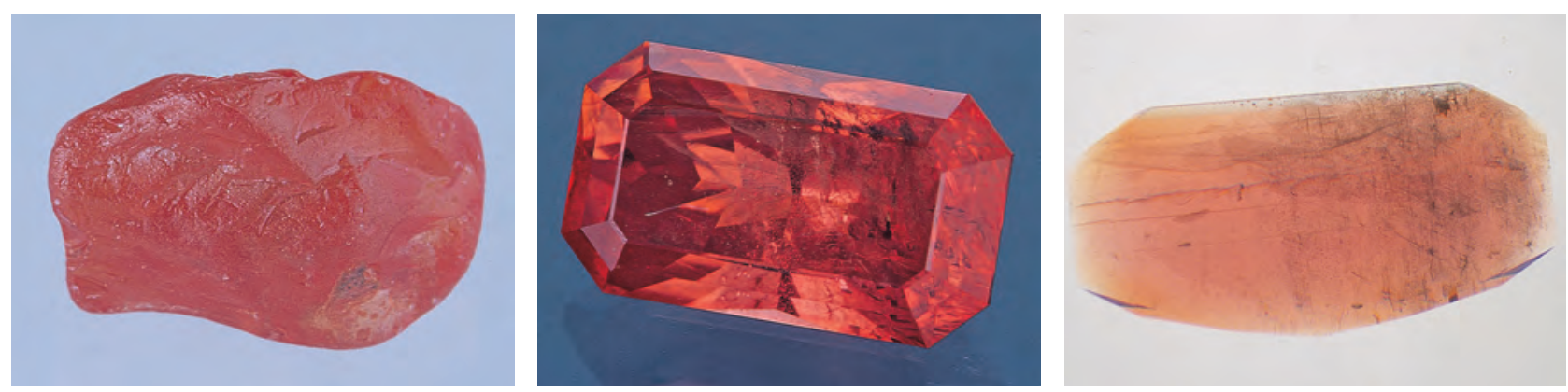

Figure 39. A Be-diffused stone will not always have a complete surface-conformal layer of color, which could cause confusion with natural color zoning. We had the diffused piece of rough on the left cut into the $1.74 \mathrm{ct}$ stone in the center. As can be seen with immersion on the right, the orange diffusion layer was evident only as concentrations just under the surface along the edges of the table and one side of the pavilion, and not all the way around the stone. Left and center photos by Maha Tannous; photomicrograph on the right by Shane F. McClure, magnified 10×.

nation of the Be-diffused samples in our study with magnification and immersion revealed that all of the fashioned orangy pink and pinkish orange samples showed color zones that related directly to the faceted shape of the stone (see, e.g., figure 35). In some, this zone penetrated as much as $80 \%$ of the stone (again, see figure 17 right and chart figure C1); those stones with the deepest penetration appeared most orange. The vast majority of the predominantly red faceted samples also showed orange surface-conformal color zones (figure 36). The few blue Be-diffused sapphires we have examined all showed a thin, colorless surface-conformal layer overlaying typical blue hexagonal zoning.

However, most of the Be-diffused yellow and orange samples were colored throughout, with less than $10 \%$ showing a layer of surface-conformal color. Sapphires of other colors, such as green and

Figure 40. Occasionally Be-diffused corundum shows both surface-conformal color layers and natural color zones that correspond to the crystal structure, as seen in this 1.29 ct briolette. Photomicrograph by Shane F. McClure; immersion, magnified 10×.

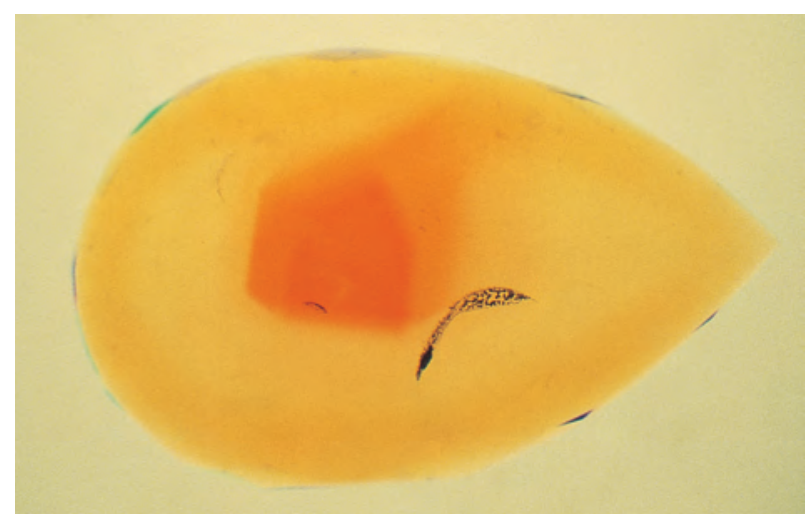

purple, typically revealed orange or yellow surfaceconformal layers overlying purple, green, or blue central colors (figure 37).

The color distribution in an untreated sapphire, or even in a sapphire that has been heated by standard methods, generally will follow the trigonal crystal structure of corundum. Stones cut from such crystals may show angular or straight color banding that conforms to the corundum's crystal morphology and related trace-element distribution, rather than to the shape of the faceted stone (figure 38). In addition, some natural-color stones are faceted to use isolated zones of color in a way that results in an unusual color distribution (e.g., a dark blue zone located in the culet of an otherwise colorless stone or, in the case of a padparadscha sapphire, an orange zone retained along one edge to produce the optimum color). Although we have never observed a natural color zone that conformed to the faceted surface of the polished stone, a Be-diffused piece of pink or red rough also might be cut in such a way that the orange color component does not conform to the facets of the finished stone, but rather merely forms a concentration of orange, for example, along one or several edges (figure 39). The gemologist must develop a keen sense for color distributions that are not completely surface conformal, which will indicate that further testing (such as SIMS) is needed. Therefore, any near-surface concentration of yellow or orange color should be viewed with suspicion.

In several of our samples, the surface-conformal color layer was present in conjunction with natural angular or banded color zones; these even overlapped one another in some cases. In such instances, the two types of zoning were easily distinguished and the relationship of color to faceted 


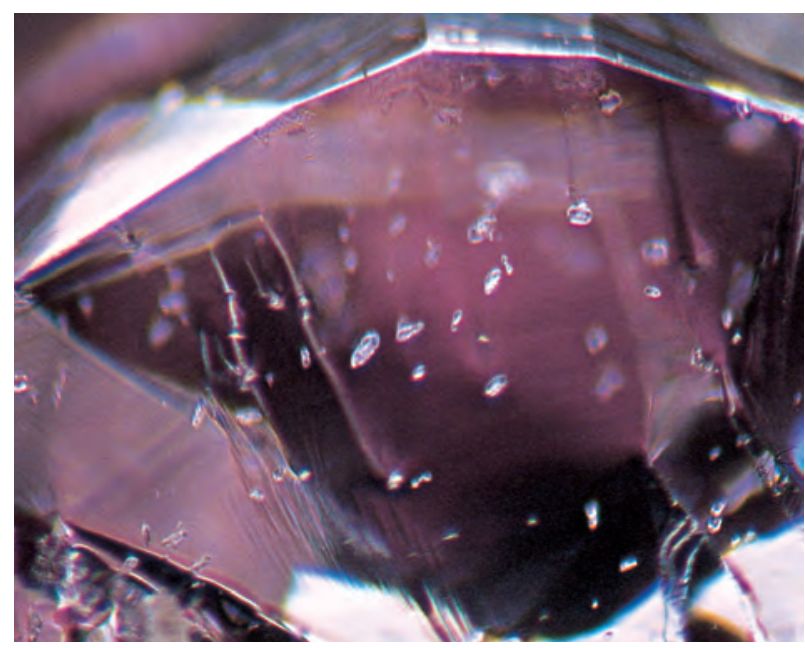

Figure 41. Undamaged zircon inclusions in Madagascar sapphires typically appear as small transparent subhedral (rounded) crystal grains. Photomicrograph by Shane F. McClure; magnified 40x.

shape proved that a color-causing element had been diffused into the stone from an external source (figure 40 and chart figure C-4).

Magnification. Inasmuch as standard gemological tests, other than the observation of a surface-conformal color layer, have not provided proof of Be diffusion, we believed that other evidence obtained from microscopic examination could be critical to identification. We cannot stress strongly enough that the findings represented here indicate changes in inclusions that have occurred due to exposure to extreme heat-heat higher than is typical for what we refer to as standard heat treatment (i.e., above $1780^{\circ} \mathrm{C}$ ). While actual temperature data from Thai treaters is unavailable, we have observed alterations in inclusions that we rarely see with standard heat treatment. Such evidence cannot unequivocally prove beryllium diffusion. However, these types of fea- tures, considered together with the other evidence outlined in this article, can provide a strong indication that a stone has been Be-diffusion treated.

Included Crystals. Almost all of the Madagascar samples contained small crystals of zircon, which is very common in corundum from that locality (see, e.g., Schmetzer, 1999). In all the Be-diffused samples that contained zircon inclusions, we found that those inclusions were always significantly altered. What were once transparent subhedral crystals (rounded grains, as shown in figure 41) were transformed into opaque white irregularly shaped masses, often with a crackled appearance and a gas bubble in the center (figure 42 and chart figure C-7). We have seldom seen the destruction of zircon inclusions in sapphires that have been subjected to typical heat treatments, regardless of their locality of origin. The fact that all such inclusions in Be-diffused stones are significantly altered is important. It means that the temperatures being used for Be diffusion are significantly higher than those used for standard heat treatment. Therefore, if zircon crystals appear to be unaltered, it is unlikely that the sapphire host has been subjected to the high temperatures typically used for Be diffusion (Butterman and Foster, 1967).

Figure 43 shows the Raman spectra of (A) a zircon inclusion inside a natural pink sapphire and (B) a zircon in the same sapphire after Be-diffusion treatment. Spectrum A has strong Raman scattering at 1018, 983, 441, 364, 224, and $200 \mathrm{~cm}^{-1}$. In spectrum B, all these peaks are gone, which indicates that a phase transformation has occurred. It is very likely that the peaks at 192 and $181 \mathrm{~cm}^{-1}$ are from $\mathrm{ZrO}_{2}$ (baddeleyite). None of the other peaks matched any minerals in our database that could
Figure 42. At high temperatures, zircon inclusions become significantly altered. Typically, they are transformed into opaque irregular masses, often with a crackled appearance and a gas bubble in the middle. Photomicrographs by Ken Scarratt; magnified 40x.
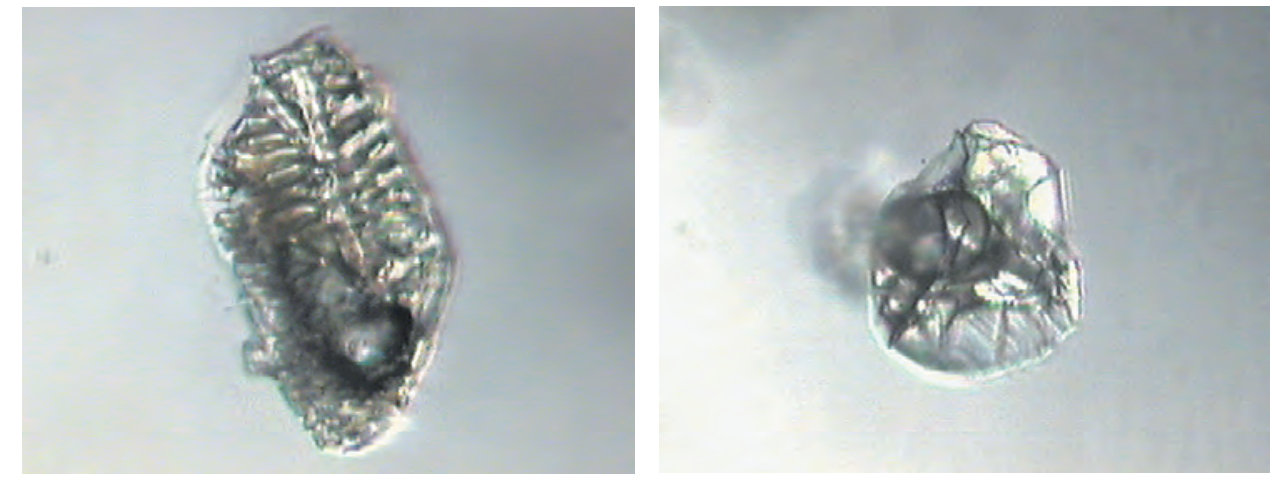


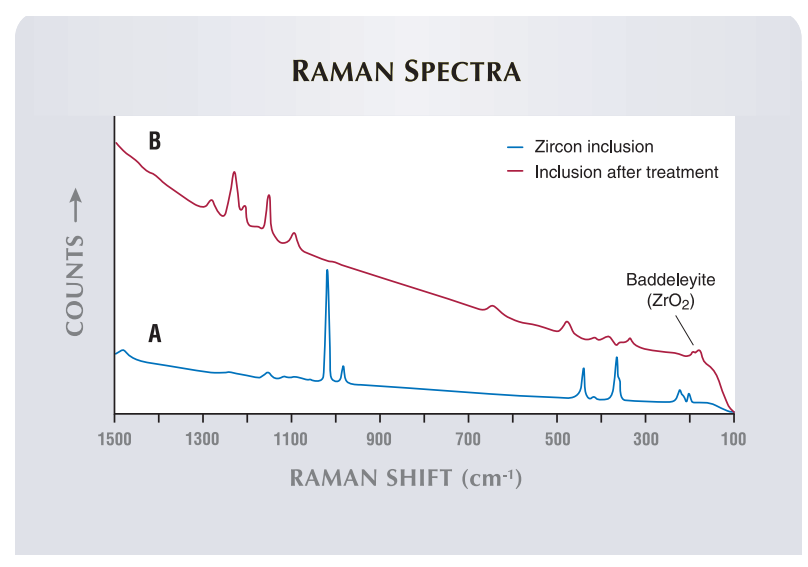

Figure 43. Shown here are the Raman spectra of (A) a zircon inclusion inside a natural pink sapphire, and (B) a similar inclusion in the same sapphire after Bediffusion treatment. Due to partial melting and reaction with the surrounding corundum, the zircon in the Be-diffused sample was transformed to $\mathrm{ZrO}_{2}$ (baddeleyite) and an $\mathrm{Al}_{2} \mathrm{O}_{3}-\mathrm{SiO}_{2}$-rich glass.

crystallize from the partial melt (such as quartz, tridymite, cristobalite, or mullite). These results indicate that the partial melt was cooled rapidly, and the zircon inclusion eventually transformed into $\mathrm{ZrO}_{2}$ and an $\mathrm{Al}_{2} \mathrm{O}_{3}-\mathrm{SiO}_{2}$-rich glass, following the Be-diffusion treatment. These findings are in agreement with those recently published by Rankin and Edwards (2003), who provide an indepth discussion of what happens to zircon crystals at such high temperatures (see also Butterman and Foster, 1967).

Note that the melt created by these highly altered inclusions often flows into the surrounding strain haloes. As it cools within the halo, it forms the phases mentioned above and creates crossing fern-like structures that are reminiscent of the structure of devitrified glass (see chart figure C-10). These recrystallized haloes were seen in many of the Be-diffused stones, but they were particularly common in the orange, yellow, and pink-orange samples. A Raman spectrum of the substance within the halo exactly matched spectrum $B$ in figure 43 , indicating that it, too, was caused by the destruction of zircon.

Other types of crystals were seen in many of the samples tested, but in all cases they were damaged or significantly altered by the treatment, and in most cases they were visually unidentifiable, shapeless white masses (see chart figure C-28). We also saw numerous instances of large gas bubbles that were trapped in internal cavities filled with what appeared to be a transparent glass (figure 44).

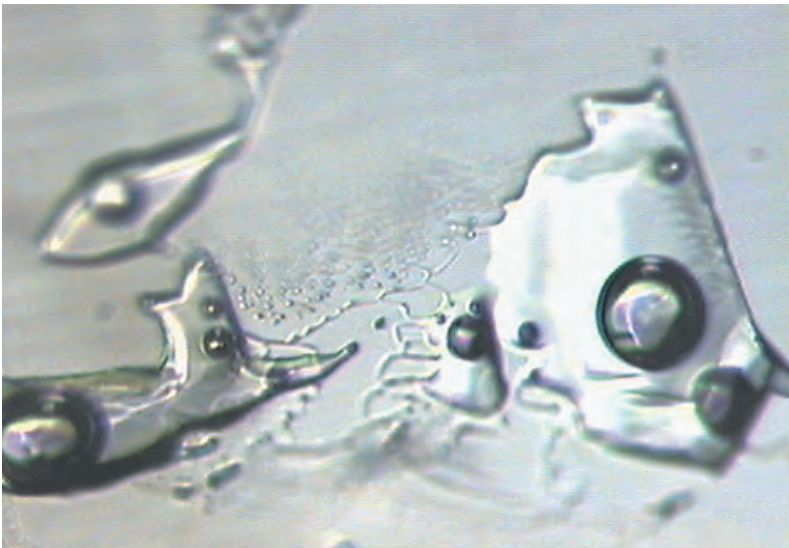

Figure 44. These former mineral inclusions were reduced to a glass-like melt containing gas bubbles after the host sapphire was Be-diffusion treated. Photomicrograph by Ken Scarratt; magnified 40x.

Internal Diffusion. We saw evidence of internal lattice diffusion (i.e., the diffusion of a color-causing agent from an inclusion into the surrounding stone; Koivula, 1987) in many of our study samples, particularly in the orange, yellow, and red colors. This phenomenon generally occurs in association with rutile $\left(\mathrm{TiO}_{2}\right)$, and is extremely common in blue sapphires that have undergone standard heat treatment. At high temperature, rutile inclusions break down and release $\mathrm{Ti}$, which diffuses into the structure of the corundum, reacts with existing $\mathrm{Fe}$, and produces a localized blue coloration (see chart figures $\mathrm{C}-17$ and $\mathrm{C}-18)$.

In many of the untreated Songea rubies and sapphires we examined, the rutile inclusions were in the form of euhedral crystals. In untreated stones from Madagascar, they appeared mostly as needles or clouds of fine, dust-like particles, as are commonly seen in corundum samples from many other localities. However, all of the Be-diffused stones from Songea in this study that contained rutile crystals showed a typical internal diffusion pattern consisting of a hexagonal or irregularly shaped crystal surrounded by a spherical blue halo (figure 45). The blue color contrasted sharply with the yellow, orange, or orangy red bodycolor of the stones. Some of the areas of spotty blue coloration created by rutile silk in Be-diffused stones from Madagascar still contained a visible pinpoint inclusion (chart figure C-19).

The important observation is that although internal diffusion is quite common in heat-treated blue sapphire, it is not at all common in yellow, orange, and red corundum. While it is true that yellow 


\section{Box C: A Practical Guide to Recognizing Beryluium-Diffused Rubies and Sapphires}

The most critical issue for gemologists and the gem trade is how to separate these treated stones from natural-color corundum and corundum that has been heated by "standard" methods, without the addition of external elements. Although our research has shown that all the Bediffused stones can be identified by mass spectroscopy, especially SIMS analysis, this technique is expensive and time consuming. However, we have found many other, more readily obtainable clues that provide either proof or strong indication of Be-diffusion treatment.

This box and the accompanying chart summarize the clues a gemologist can use to help determine if a sapphire or ruby has-or has not-been subjected to Be diffusion. While we believe these indicators to be common to all colors of Be-diffused corundum, to date we have not examined a sufficient number of Be-diffused blue sapphires to draw general conclusions about them. Observations requiring magnification are best seen with a gemological microscope. All numbers in parentheses refer to images on the chart.

\section{DIAGNOSTIC EVIDENCE}

Color Zoning - The only diagnostic evidence of Be-diffusion treatment immediately available to the gemologist is the presence of a color zone that conforms to the external faceted shape of the stone. This color zone may be seen in all types of Be diffusion-treated corundum and can penetrate to any depth, including throughout the gem (figure C-1). The Be-diffused conformal zone is yellow, orange, or occasionally colorless (C-2). It surrounds central cores that are either colorless or some other color, most often pink or red (C-3). It also may be seen to overlay natural zoning (C-4). Observation of this feature requires the use of immersion, with methylene iodide (what gemologists call 3.32 liquid) the best medium.

\section{HIGHLY INDICATIVE EVIDENCE}

The features in this section do not prove that a stone has been Be-diffusion treated. However, they do prove that it was subjected to very high temperatures (i.e., higher than those typically used for the standard heat treatment of corundum) and are a strong indication that Be-diffusion treatment may have occurred. Therefore, observation of one or more of the following features in a ruby or sapphire means that the color origin is highly suspect.

Highly Altered Zircon Inclusions - Zircon crystals in corundum usually survive standard heat treatment, retaining their initial appearance as small transparent angular or rounded grains (C-5). The extreme alteration of such crystals to white, formless masses (C-6) - often containing a gas bubble (C-7)-is an excellent indicator that the stone has been exposed to very high temperatures.

Internal Recrystallization - Several forms of internal recrystallization occur as a result of the extreme tempera- tures used in Be-diffusion treatment. One of these relates to the zircon inclusions mentioned above. Discoid fractures around zircon crystals are commonly created during normal heat treatment as the crystal expands, even when the inclusion itself is not damaged (C-8); the circular fractures around zircons and other crystals are often glassy and reflective (C-9). Such fractures also often occur around zircon crystals during Bediffusion treatment. However, as the zircon is destroyed, the resulting fluid melts and flows into the planar fractures of the discoid. Then, as the stone cools, the melt partially recrystallizes, leaving a characteristic appearance that we had not seen in sapphires prior to this new treatment: a plane of transparent material interwoven with fern-like patterns reminiscent of the structure seen in devitrified glass (C-10), occasionally displaying iridescent colors (C-11). The discoids also may contain areas healed by the regrowth of corundum (C-12), and near their center is always a white mass (usually with a gas bubble) that used to be a zircon crystal (C-13).

The second type of recrystallization involves the mineral boehmite. Recrystallized corundum in the channels left behind by destroyed boehmite inclusions often has a characteristic "roiled" appearance (C-14), particularly in transmitted light. These now-filled channels often contain voids that may be spherical (C-15) or have a bone-like shape (C-16).

Internal Diffusion - Internal lattice diffusion around rutile crystals and "silk" is very common in heat-treated blue sapphires. This typically manifests itself as roughly spherical blue haloes around the crystals (C-17) and spotty blue coloration where the rutile "silk" used to be (C-18). In our experience, however, this phenomenon is extremely rare in rubies and yellow-to-orange sapphires (C-19) since these stones are heated in an oxidizing atmosphere that usually removes blue color. Its presence in these colors can be considered a direct result of exposure to high temperatures. However, since yellow sapphires from some localities (such as Montana) are routinely heatedbut not diffused - at temperatures high enough to cause some spotty blue coloration, these characteristics indicate the possibility—but not proof—of Be diffusion.

Synthetic Overgrowth - Synthetic corundum can grow in any high-temperature treatment environment. However, the appearance of synthetic overgrowth on faceted Be-diffused rubies and sapphires is different from any we have seen before. Specifically, remnants of synthetic overgrowth occasionally have been seen in surface-reaching cavities as tiny platelets, but not covering entire facets. Although this synthetic material is often removed during finishing, portions remain on the surfaces of some stones, particularly those that are yellow to orangy red, providing an important clue to the use of high heat.

The synthetic crystals that grow during Be-diffusion treatment are often randomly oriented, tend to be platy 
and hexagonal in shape (C-20), and are much larger and far more numerous than any typically found on stones heat treated by standard methods. When they grow together, they form a solid layer that often looks like an aggregation of irregular blocks (C-21), sometimes with tiny voids between them and cloud-like inclusions along the crystal interfaces (C-22). This tends to create a roiled appearance in the surface layer (C-23). While this usually can be seen with darkfield illumination, it is even more readily visible with transmitted light (C-24). Cross-polarized light also helps reveal such features, due to the randomness of the crystal growth. Since the orientation of many of the synthetic crystals is different from that of the natural host, in crossed polarizers they may appear light while the host material is dark (C-25).

We have recently noted increased synthetic growth on the surfaces of a number of Mong Hsu rubies, sometimes lining cavities and sometimes having the same appearance as that found on Be-diffused stones (C-26). The cavities exhibited linings of tiny hexagonal platelets and were often filled with glass residues. This indicates that some of these stones are now being treated at higher temperatures than were typically used before. However, we have not seen this type of growth in yellow and orange heat-treated sapphire that has not been subjected to Be-diffusion treatment.

Other Inclusions - Other unidentifiable severely damaged crystals that do not appear to have been zircons have been noted in some Be-diffused corundum (C-27). Although the original form of these white, shapeless masses is unrecognizable, the sheer amount of damage (C-28) is clear evidence of exposure to extreme temperatures. This is also true of internal cavities that are now filled with a transparent glass-like material containing spherical gas bubbles (C-29).

\section{EVIDENCE THAT IS NOT INDICATIVE}

Some features of Be-diffused corundum overlap too much with corundum that has not been treated by this process to help in identification, although they may suggest that a stone is suspect.

Color - The colors produced by Be diffusion are often very saturated and "unnatural" (C-30). Yet all of the colors produced by Be diffusion can occur naturally or as a result of standard heat treatment (C-31). Thus, for any individual stone, color by itself does not indicate Be diffusion, but it can be a reason for further testing.

Be diffusion produces colors in rubies that are often a slightly orangy red, or occasionally even pure red (figure C-32). These colors mimic many iron-rich rubies that are found in Africa and elsewhere.

Healed Fractures - Artificial healing of fractures clearly occurs during the Be-diffusion process (C-33). However, it also commonly occurs during the heating of rubies, particularly from Mong Hsu. Therefore, it cannot be used to identify the presence of Be diffusion.
Dissolution - Dissolution of the surface is very common on Be-diffused stones. Surfaces that have not been repolished often have a melted appearance (C-34). However, this is a common feature on most corundums that have been heated at high temperatures, particularly when fluxes are used, so it is not distinctive of Be diffusion.

\section{INDICATIONS OF NO EXPOSURE TO VERY HIGH TEMPERATURES}

The presence of these inclusions proves that the stone has not been exposed to high heat and therefore could not be Be diffused.

$\mathrm{CO}_{2}$ Inclusions - Internal "voids" that contain water and a bubble of carbon dioxide $\left(\mathrm{CO}_{2}\right)$ are quite common in sapphires from some localities, particularly Sri Lanka (C35). Because $\mathrm{CO}_{2}$ expands when heated, these inclusions cannot survive the very high temperatures necessary for Be diffusion. Therefore, the presence of undamaged inclusions would prove that a stone has not been Be-diffusion treated.

Internal voids filled with other liquids will also not survive high-temperature heat treatment. The presence of undamaged liquid-filled voids of any kind proves that no Be treatment has occurred (C-36).

Included Crystals - As discussed above, the presence of undamaged zircon crystals in a sapphire is a good indication that Be diffusion treatment has not taken place. Likewise, in our experience, it is unlikely that any crystalline inclusion could survive the temperatures required for Be diffusion without being significantly altered. Therefore, the presence of transparent, angular, or rounded solid grains of any mineral would be an excellent indication that Be diffusion has not taken place (C-37 and 38).

Rutile Needles - Needle-like inclusions of rutile, often referred to as "silk," are common in corundum from many localities. These needles usually survive the lower-temperature heat treatments that are performed on some sapphires. However, they typically do not survive the higher-temperature treatments to which most blue sapphires and rubies are subjected, including the very high temperatures necessary for Be-diffusion treatment. The presence of unaltered rutile needles means that a stone has not been exposed to this (or any other) high-temperature treatment (C-39).

\section{SEND IT TO A LABORATORY}

What if you have a sapphire that is colored throughout and does not show any of the indications listed above? These are the most difficult situations. We recommend that you send it to a qualified gemological laboratory and have its chemistry analyzed by the techniques mentioned in this article. We will continue to investigate alternative methods to identify this treatment process. 


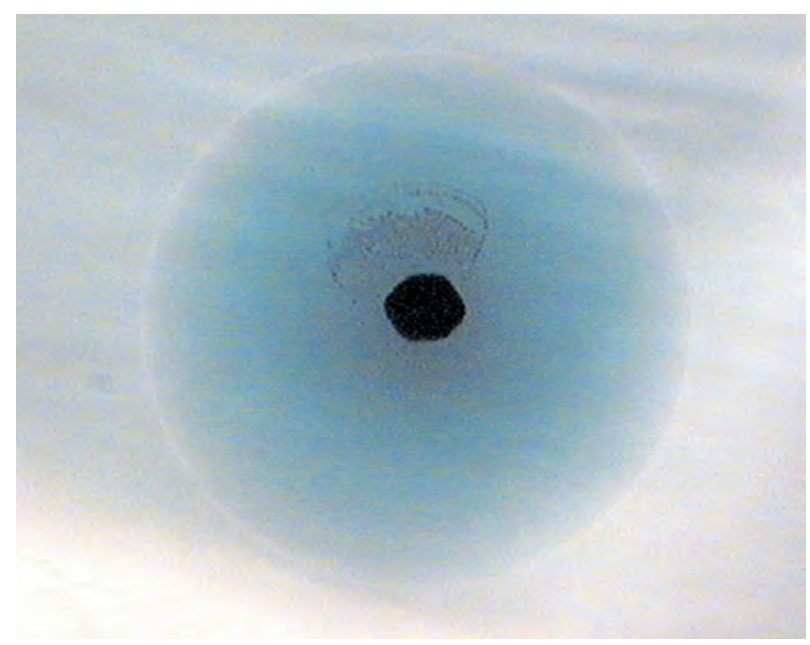

Figure 45. All the Be-diffused sapphires in this study that contained rutile crystals exhibited blue internal diffusion haloes around those crystals, which is very unusual in yellow and orange sapphires. Photomicrograph by Ken Scarratt; magnified 20x.

sapphire from some localities (e.g., Montana) is routinely heated to temperatures high enough (without adding chemicals) to cause such spotty blue coloration, this phenomenon is seen only rarely in heat-treated stones. Its presence does not unequivocally prove beryllium diffusion, but it does provide solid evidence of exposure to very high temperatures.

Flux-Assisted Synthetic Growth. During fluxassisted heat treatment (with or without diffusion), material from the surface of the corundum (as well as the alumina crucible and the boehmite inclusions) will dissolve to some degree into the molten flux (which may itself contain alumina). On cooling, the flux becomes supersaturated in alumina and crystallizes out onto the nearest convenient surface, often on the stones themselves (figure 46 and chart figure C-20).

We noted synthetic corundum overgrowth (identified by Raman spectroscopy and microprobe) on the surfaces of some of the yellow, orange, and orangy red Be diffusion-treated samples in this study. The overgrowth was particularly obvious on rough or preformed samples and often remained after the stones were recut following processing. The extent of this overgrowth ranged from single small areas (usually around the girdle) to numerous large areas covering $10-20 \%$ of the stone's surface. The typical appearance of this overgrowth is depicted in figure 47 (McClure, 2002a; Scarratt, 2002a; Moses et al., 2002). The

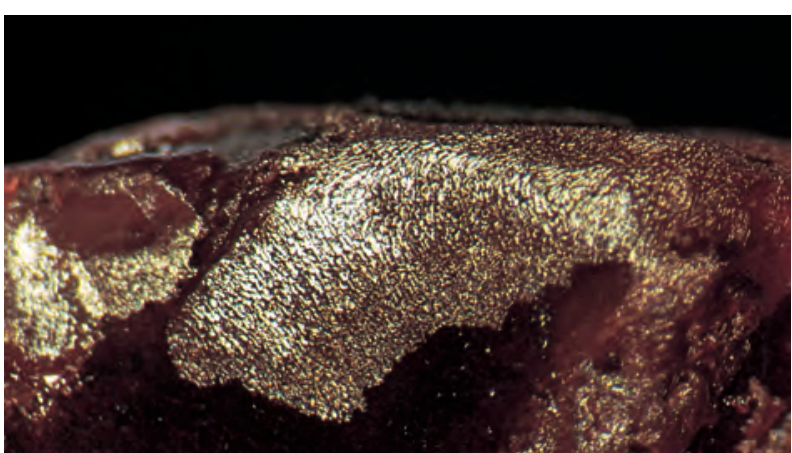

Figure 46. Large areas of platy synthetic corundum crystals were present on the surface of some Be-diffused samples examined for this study. Photomicrograph by Shane F. McClure; magnified 20x.

"blocky" texture may be observed even at lowpower $(10 \times)$ magnification with transmitted light, but it may be missed if only reflected light is used to examine the specimen.

Pre-existing fractures in corundum-as well as those created during Be diffusion-and boehmite channels are often sealed, or "healed," by the same process. The molten flux enters the fracture or channel, and the surfaces of the fracture or channel dissolve into the flux, where the dissolved material is held in solution until the temperature is reduced. On cooling, the alumina then crystallizes out of the flux onto the walls of the fracture or channel, sealing it while at the same time trapping residues such as gas bubbles, flux remains, and glass. This "flux-assisted healing" of fractures was well documented in rubies even before the

Figure 47. Blocky synthetic overgrowth produced during the Be-diffusion process was still present on the surface of some treated stones, even after repolishing. Photomicrograph by Ken Scarratt; transmitted light, magnified 30x.

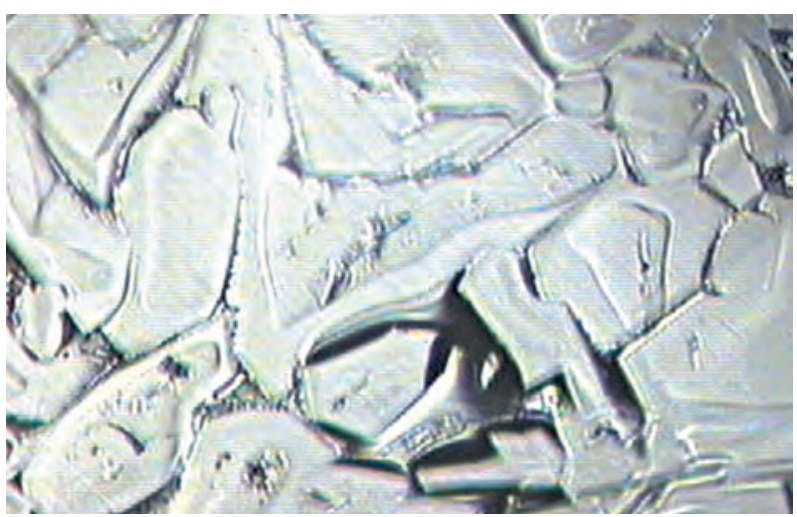


introduction of the new Be-diffusion treatment (Hänni, 2001).

In the Be-diffused stones, the artificially healed fractures (figure 48) often resembled the "fingerprints" or "feathers" seen in flux- or hydrothermally grown synthetic rubies and sapphires. A "roiled" appearance could be seen within the healed boehmite channels, which were aligned with edges of intersecting parting planes. These tubes often contained high-relief internal cavities that varied from spherical to a "dog bone" shape (see chart figures C-15 and C-16).

These observations are not surprising, as the conditions and equipment used to heat treat or lattice diffuse elements into corundum closely resemble those used for corundum synthesis, except that the production of flux-grown synthetic corundum involves lower temperatures (around $1300^{\circ} \mathrm{C}$ ) and the use of platinum crucibles rather than alumina ones (Nassau, 1980).

UV-Vis-NIR Spectroscopy. As discussed earlier, UV-Vis-NIR spectroscopy was used to confirm the trapped-hole nature of color in these Be-diffused stones, but we have not found it useful as an identification method. We have examined the UV and visible-range absorption spectra of dozens of samples, both at room temperature and at liquidnitrogen temperature, but have failed to find a Bediffusion identification criterion. The difficulty is that there appears to be little difference in the spectra of trapped holes caused by naturally occurring magnesium and those induced by beryllium diffusion. This method is therefore of no use in the identification of Be-diffusion treatment.

Infrared Spectroscopy. Much natural corundum contains detectable quantities of hydrogen, which can be present in several forms (Rossman, 1988). Hydrogen can bond with oxygen in the lattice to form $\mathrm{O}-\mathrm{H}$, resulting in sharp absorption bands at $3367,3310,3233$, and $3185 \mathrm{~cm}^{-1}$ (Beran, 1991). Hydrogen can also exist in corundum as $\mathrm{H}_{2} \mathrm{O}$, leading to a broad absorption band at $\sim 3400 \mathrm{~cm}^{-1}$. It can also be present as water within fluid inclusions, and, finally, it can exist as a component of an included solid phase, such as diaspore (Smith, 19951, which is one of the hydroxides of aluminum. Since corundum is transparent from the UV region to $2000 \mathrm{~cm}^{-1}(5000 \mathrm{~nm})$ in the infrared, even trace amounts of hydrogen are detectable using infrared spectroscopy. Some of the variations

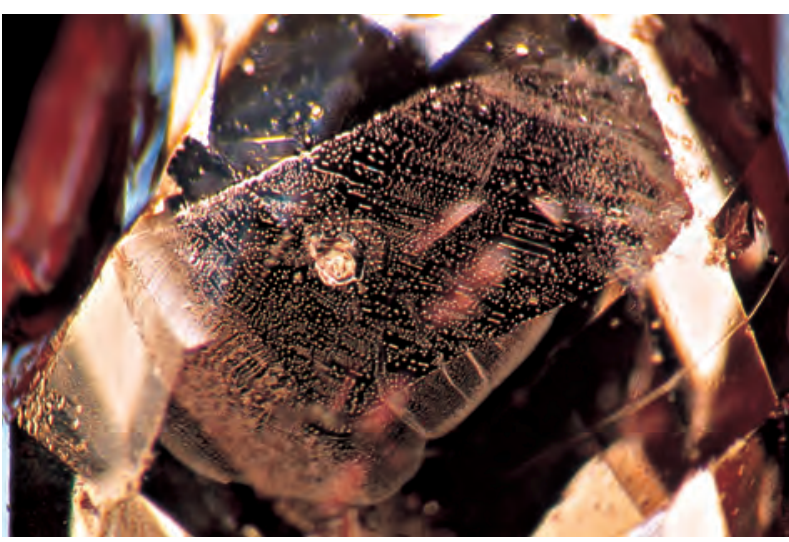

Figure 48. Healed fractures such as these were seen in many of the Be-diffused corundum samples we examined. They often appeared similar to those found in flux- or hydrothermally grown synthetic rubies and sapphires. Photomicrograph by Shane F. McClure; magnified 25×.

observed in the IR spectra of natural sapphires are shown in figure 49.

During the course of this study, we collected IR spectra on 50 Be-diffused sapphires. In none of these spectra did we observe hydrogen-related features. This result was expected, since hydrogen rapidly diffuses out of corundum at high temperatures (e.g., $1800^{\circ} \mathrm{C}$ ) in a hydrogen-free atmosphere (i.e., the oxygen atmosphere used for Be diffusion). An example of this effect is illustrated in figure 50 . The blue spectrum shows the $\mathrm{O}-\mathrm{H}$ absorption of a natural

Figure 49. The $\mathrm{O}-\mathrm{H}$ infrared absorptions in sapphire may vary in appearance, as illustrated by the selection of five spectra shown here. The top four spectra are derived from heat-treated blue sapphires, and the bottom spectrum is from an unheated yellow sapphire.

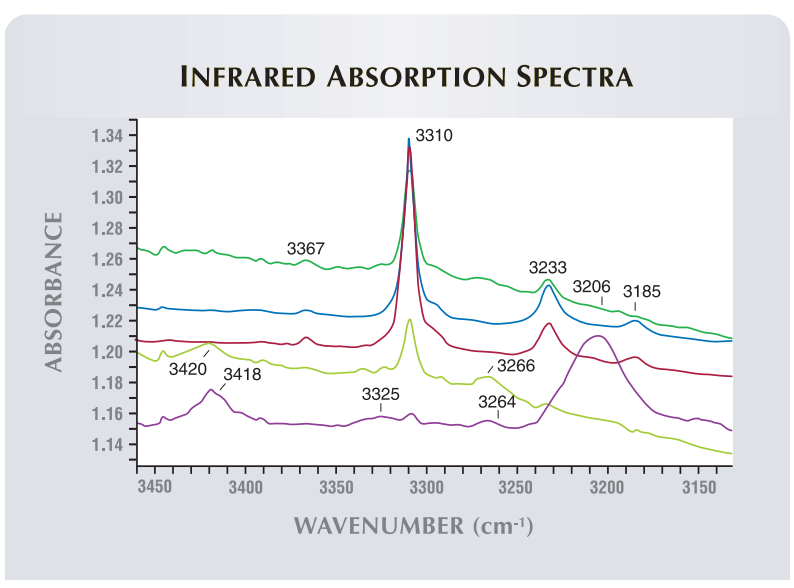


pink sapphire from Vietnam. After Be diffusion at $1800^{\circ} \mathrm{C}$ for 33 hours in an oxygen atmosphere (red spectrum), the O-H absorption features have entirely disappeared. Figure 51 shows the $\mathrm{H}_{2} \mathrm{O}$ absorption band (Rossman, 1988) in a natural light yellow sapphire of unknown origin (blue spectrum). After the same Be diffusion parameters noted above, the $\mathrm{H}_{2} \mathrm{O}$ absorption features are absent (red spectrum).

As shown earlier, some types of dark blue basaltic sapphire can be greatly lightened by a twostep process of Be diffusion followed by normal heat treatment in a reducing environment. Because the reduction heat treatment is carried out in an atmosphere that contains hydrogen, the hydrogen will diffuse back into the crystal and appear in the absorption spectrum as $\mathrm{O}-\mathrm{H}$, with the absorption features enumerated above. Thus, an attractive blue Be-diffused sapphire could exhibit the O-H absorption features of a naturalcolor sapphire or one that has been heat treated without diffusion. Consequently, the presence of $\mathrm{O}-\mathrm{H}$ absorption features in a blue stone is not evidence that it has not been Be diffused. This is only an issue in blue sapphire, since heat treatment of a yellow or orange stone in a reducing atmosphere will remove the Be-induced color.

Our data show that a ruby or a yellow, orange, or orange-pink sapphire that has undergone Be diffusion contains no structurally bonded hydrogen and little if any molecular water. However, this tells us only that the stones have been heated in

Figure 50. The infrared spectrum of a natural-color pink sapphire from Vietnam containing hydrogen as $\mathrm{O}-\mathrm{H}$ (blue) shows strong absorption bands at 3367, 3310, 3233, and $3185 \mathrm{~cm}^{-1}$. After Be diffusion at $1800^{\circ} \mathrm{C}$ for 33 hours in an oxidizing atmosphere, these hydrogen-related bands were eliminated (red).

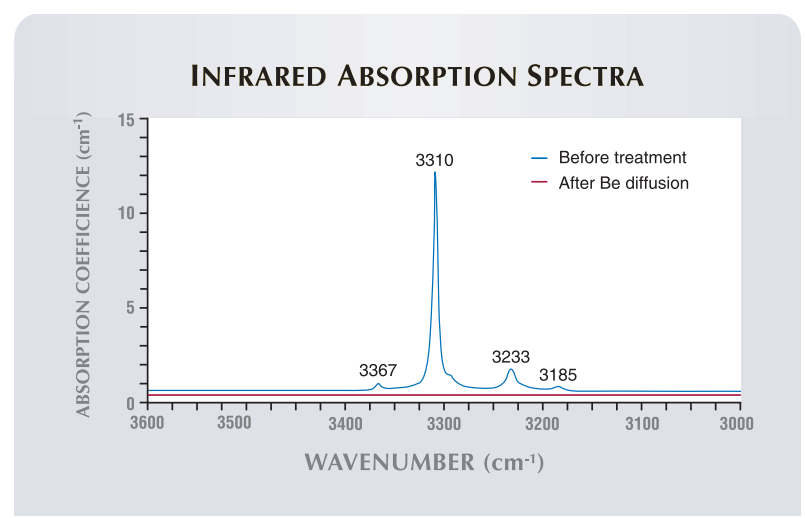

an oxidizing atmosphere, the same atmosphere required for Be-diffusion treatment. It does not necessarily mean that Be diffusion is involved. Still, it can be a helpful piece of data when combined with other factors.

Raman Spectroscopy. No additional peaks were discovered and no changes in the normal corundum spectrum were observed in specimens analyzed before and after Be diffusion treatment.

Raman analysis also proved that the overgrowth seen on some of the samples was indeed (synthetic) corundum. An unexpected result was the identification of a tiny grain of material on the surface of one stone as synthetic cubic zirconia, the feed source of which may have been a zircon inclusion or a flux additive.

Chemistry. EDXRF spectra on stones that were not re-polished following Be diffusion consistently revealed the presence of both $\mathrm{Ca}$ and $\mathrm{Zr}$, elements that are not typically found in corundum. The $\mathrm{Zr}$ may be related to exposed zircon inclusions or to zircons that were accidentally included in the heattreatment process. The $\mathrm{Ca}$ may indicate that calcium borate is a component of the flux mixture (see "Beryllium Diffusion into Corundum: Process and Results" section).

Figure 51. This infrared spectrum of a natural-color yellow sapphire from an unknown source (blue) shows a broad absorption band centered at about 3300 to $3400 \mathrm{~cm}^{-1}$ that is indicative of molecular water $\left(\mathrm{H}_{2} \mathrm{O}\right)$, possibly contained in the stone as an inclusion. After Be diffusion at $1800^{\circ} \mathrm{C}$ for 33 hours in an oxidizing atmosphere, this $\mathrm{H}_{2} \mathrm{O}$-related absorption was removed (red).

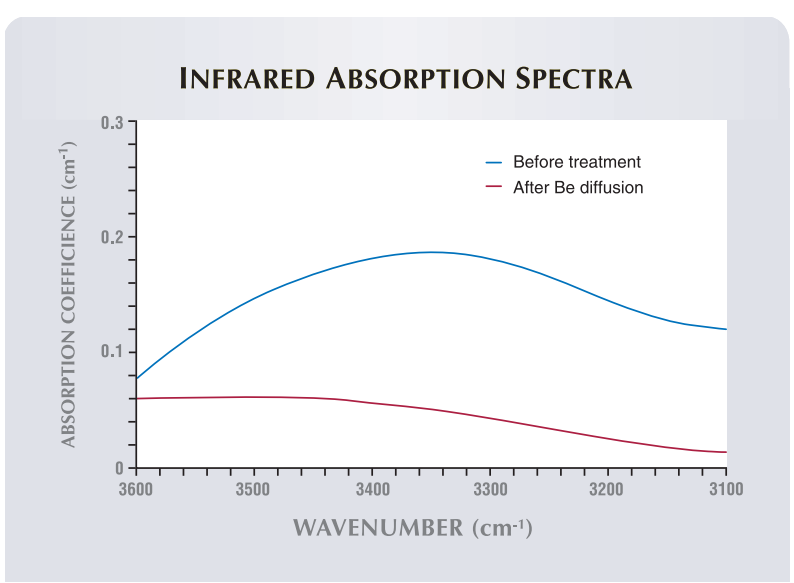




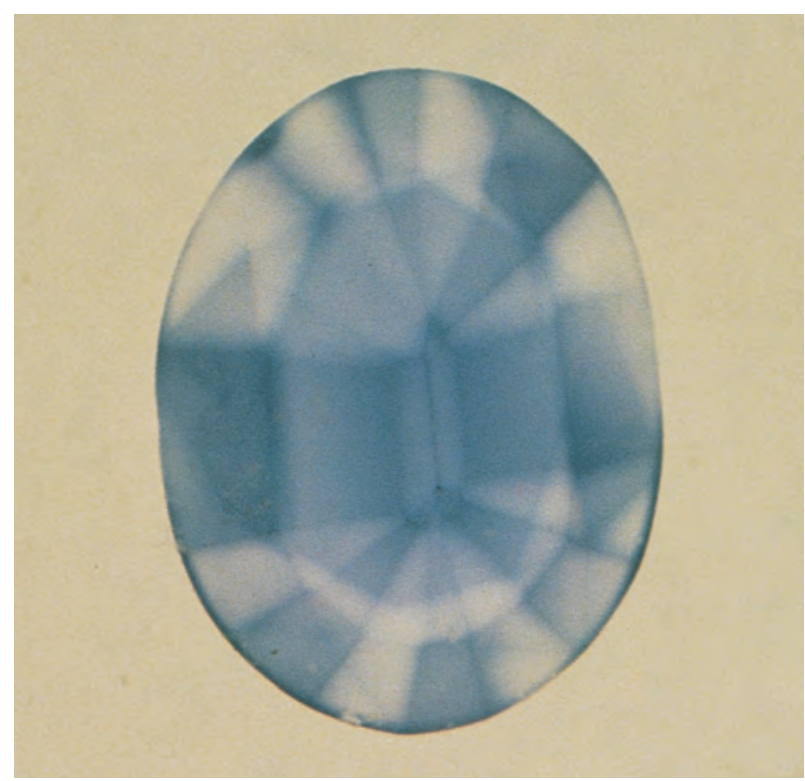

Figure 52. Titanium-diffused sapphires often show patchy surface coloration in immersion, caused by the shallow penetration depth of Ti. This is not seen in Bediffused corundum. Photo by Shane F. McClure.

SIMS analysis readily identified the presence of beryllium at the surface of all the samples of Bediffused rubies and sapphires analyzed. Table 7 shows representative analyses ${ }^{2}$ of a variety of our corundum samples (with full analyses given in the data depository SIMS table). When there is no Be in the stone, the SIMS analysis indicates about 1.5 ppma because of interference from aluminum ions. This sets the lower limit of what can be measured, and thus a measurement of 5 ppma or more gives high confidence that a stone contains beryllium. The Be concentration for this process ranges from approximately 10 to 35 ppma. Consequently, our data confirmed that very little $\mathrm{Be}$ is needed to affect the color of corundum. If measurements are much below 10 ppma, the

${ }^{2}$ The very first analyses were conducted and published (McClure et al., 2002) without the benefit of a Be-in-sapphire analytical standard with which to calibrate the SIMS equipment. Those analyses indicated a Be content roughly 10 times higher than we now know to be correct. An accurate Be-in-sapphire standard was then prepared by one of the authors ( $\mathrm{SN}$ ) and analyzed at Evans East, which allowed the previous data to be recalculated (see, e.g., Wang and Green, 2002a) Although the precise concentrations changed for all the samples reported, the ratio of beryllium content between known treated stones and known natural-color stones remained the same. Thus, the original correlation of elevated Be content to color modification in treated stones was correct, though the absolute Be concentration was not. Since April 2002, all analyses have been run with the Be-in-sapphire standard. All other elements in the table are also calibrated by element-in-sapphire standards.

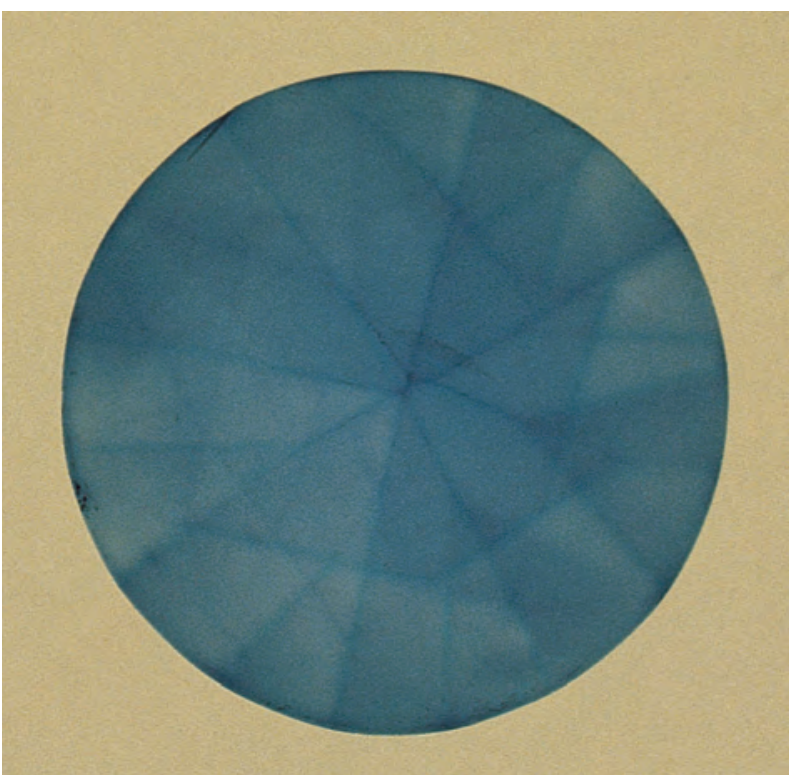

Figure 53. The facet junctions of this $1.77 \mathrm{ct}$ Ti-diffused sapphire appear darker blue when seen in immersion. This phenomenon is not seen in Be-diffused corundum. Photo by Shane F. McClure.

sample should be re-measured on another facet. Overall, these analyses demonstrate a clear correlation between color modification and elevated Be content.

\section{Comparison to Ti Diffusion Treatment}

There are definite differences in diagnostic features between sapphires that have been diffusion treated with titanium (see, e.g., Kane et al., 1990) and those that have been diffused with beryllium. In the earlier diffusion-treated stones, the colorcausing elements (mainly Ti to produce blue) had limited penetration into the surface of the treated stone (again, see figure 16). However, Be diffuses much faster than Ti (see Appendix), so the depth of the color layer produced can vary greatly, even extending throughout the stone.

Ti-diffused corundum will typically show patchy surface coloration with immersion (figure 52 ), since the very shallow color layer is often cut through during repolishing. Immersion will also reveal color concentrations at facet junctions and high relief (figure 53), as well as "bleeding" of color into the stone from the surfaces of cavities, fractures, and fingerprints (figure 54). None of these features has been seen in stones that have been diffused with Be. In contrast, the layer of color conforming to the outside shape of the stone is usually not visible in faceted Ti-diffused sapphires, even with immersion. However, this surface-conformal 


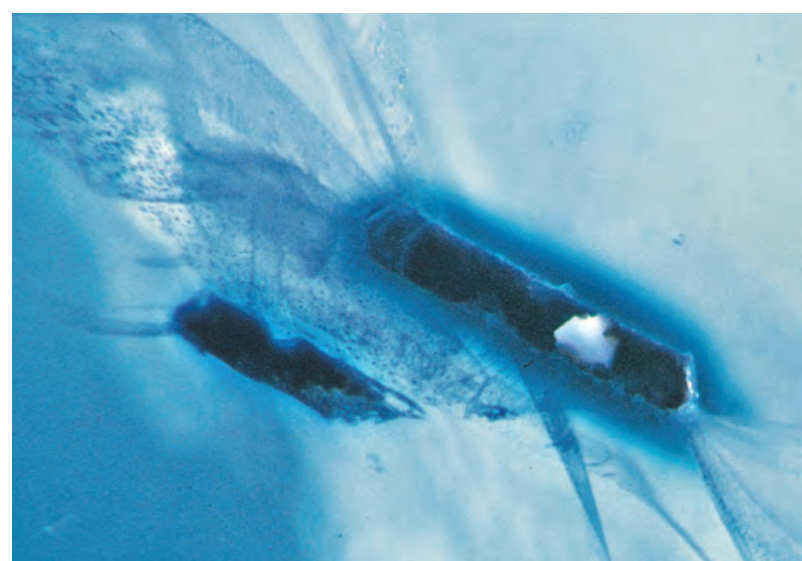

Figure 54. "Bleeding" of color into surface-reaching fractures and cavities is often visible in sapphires that have been diffused with Ti. This was not seen in any of the Be-diffused samples examined in this study. Photomicrograph by John Koivula; magnified 15x.

layer is easily visible-when present-in stones that have been Be diffused (figure 55).

\section{WHERE DO WE GO FROM HERE?}

We have been investigating other nontraditional methods of Be detection with the goal of developing a low-cost screening methodology for these treated stones. We have no solution yet, but out-

Figure 55. The actual surface-conformal color zone that is produced by Ti diffusion is usually not visible, even in immersion, as seen with the stone on the right in this image. This is distinctly different from the Be-diffused stones, in which the surfacerelated color layer (if present) is often easily seen with immersion (left). Photomicrograph by Shane F. McClure; magnified 10x.

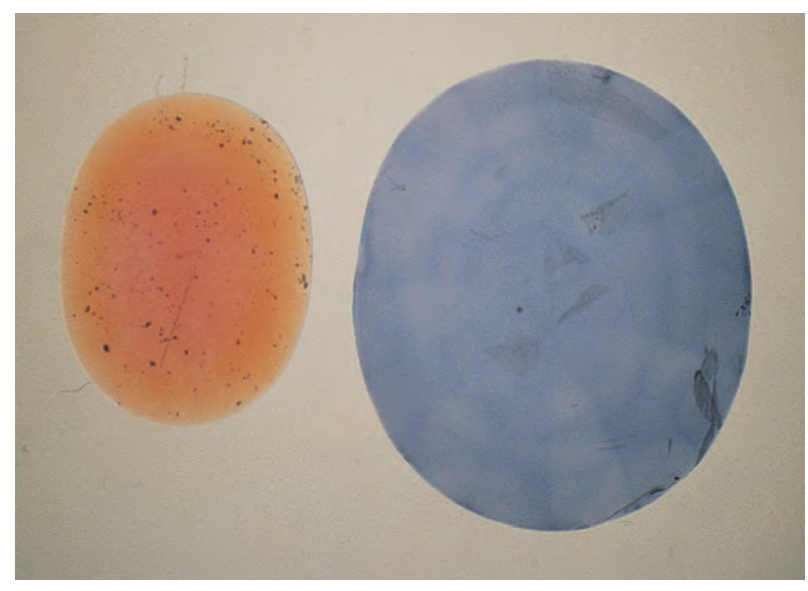

line below a number of possibilities that are being studied. We hope that this discussion will stimulate gemologists around the world to focus their creative talents on this problem.

Electrical Conductivity. Magnesium at 15-40 ppma in corundum gives rise to measurable electrical conductivity as the temperature is raised moderately above room temperature (Ramírez et al., 2001; Tardío et al., 2001a,b,c). A similar effect should be produced by beryllium. The trapped holes induced by $\mathrm{Mg}^{2+}$ (and potentially by $\mathrm{Be}^{2+}$, which are responsible for color formation in corundum, also give rise to electrical conductivity when the stones are heated. One of the authors (OB) performed initial experiments on a Be-diffused cube of Czochralski-grown sapphire using electrically conductive epoxy for electrodes. Be-diffused synthetic sapphire was chosen to eliminate possible interference with other impurities. Measurable conductivity was achieved at about $160^{\circ} \mathrm{C}$ over a range of 500 to 3,000 volts, similar to what was observed by Tardío et al. (2001a,c).

Measurements were then made on two natural faceted sapphires-a $1.6 \mathrm{ct}$ Be-diffused yellow, and a 5.46 ct heat-treated but not Be-diffused yellow. The Be-diffused sample showed conductivity of two to three orders of magnitude higher than the non-Be-diffused sapphire, providing some indication that this method has potential.

There are many issues that will have to be addressed before the value of this technique can be determined. It will be necessary to prove that the conductivity measured is a bulk conductivity and not surface conductivity that would only be dependent on stone finish and the size of the stone. A practical method of applying electrical contacts will have to be developed. A significant amount of data will have to be acquired on the effects of geometry and beryllium concentration to prove that Be can be identified independently from naturally occurring $\mathrm{Mg}$, and to delineate regions of validity and regions of uncertainty. In principle, though, it is a technique that could be automated.

Low-Temperature Heating. During discussions of the Be-diffusion problem with Thomas R. Anthony of General Electric Co. (pers. comm., 2002), he suggested that the Be-induced color modification may not be stable at temperatures in the range of $400^{\circ}-600^{\circ} \mathrm{C}$. It is known that the absorption due to the $\mathrm{Fe}^{2+}-\mathrm{Ti}^{4+}$ pair is substantially 


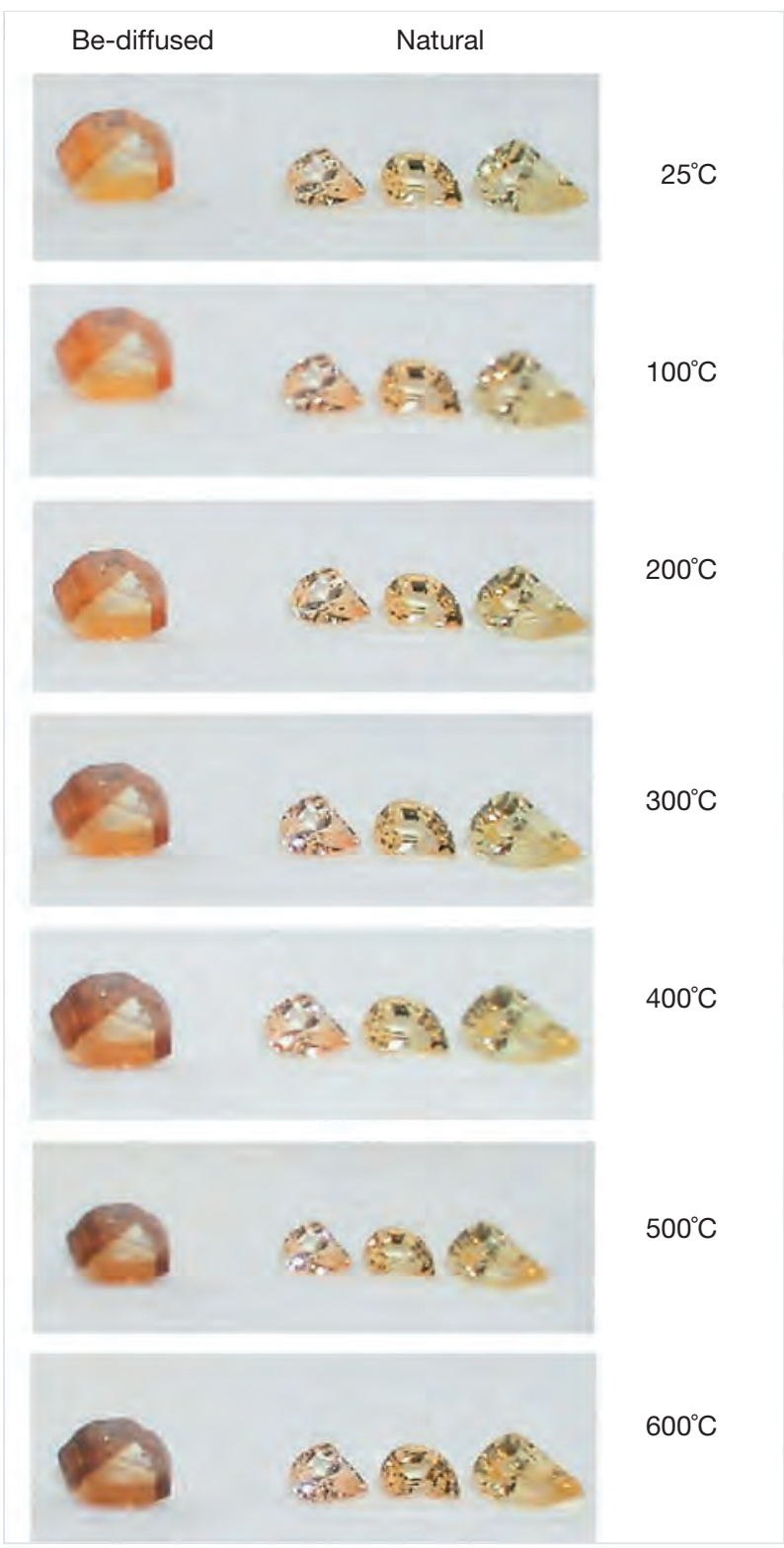

Figure 56. These photos show a Be-diffused sapphire on the left $(0.95 \mathrm{ct}$ ) and three non-diffused (Fe-colored) sapphires on the right $(0.28-0.33 \mathrm{ct})$. Note that at about $400^{\circ} \mathrm{C}$, the Be-diffused sapphire took on a distinct brown coloration, whereas the natural sapphires did not show any change. Photos by Wuyi Wang.

reduced at temperatures of $500^{\circ} \mathrm{C}$ and above, and the Be-induced trapped-hole coloration could exhibit similar, useful color alterations with temperature. These "thermochromic" effects are a common property of minerals. With increasing temperature, absorption bands become broader and shift to a lower energy (i.e., higher wavelength).

The Be trapped-hole center causes selective absorption from $600 \mathrm{~nm}$ to the high-energy side, producing additional yellow coloration. However, color appearance varies depending on the color center involved, so this yellow color differs in tone from that typically caused by Fe in natural corundum. Because of the different natures of these two absorbing centers (Burns, 1993), they could react differently to heat. Therefore, heating Be-diffused sapphires and natural sapphires with similar (or even identical) colors could reveal a temperature range within which the colors of treated and untreated corundum temporarily become very different, possibly yielding a useful method of identification.

To test this idea, a natural colorless corundum was Be diffused at $1800^{\circ} \mathrm{C}$ for 33 hours at a high oxygen partial pressure. It turned intense yellow due to formation of Be trapped-hole centers. It was then heated to $600^{\circ} \mathrm{C}$ with three other natural yellow sapphires colored by Fe. The Be-diffused yellow sapphire began to exhibit a strong brown coloration starting at about $400^{\circ} \mathrm{C}$ (figure 56). Figure 57 shows the changes in its absorption spectrum over the range from room temperature to $600^{\circ} \mathrm{C}$. The shift in coloration from yellow to brown is a result of the increasing absorption in the red region of the spectrum. The original color was restored after cooling. The three naturally Fe-colored sapphires showed no visual changes in color when heated.

Figure 57. The absorption spectrum of the Be-diffused yellow sapphire in figure 56 changed as the temperature increased. The increased absorption in the red at high temperature is responsible for the brown coloration.

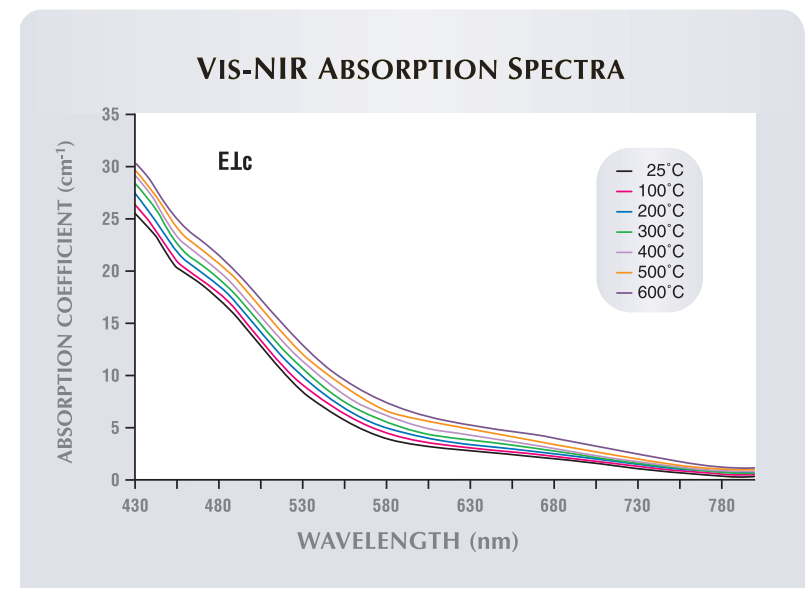


More than 30 pinkish orange Be-diffused sapphires also were tested for visual color change on heating, and all exhibited a strong brown coloration at $\sim 500^{\circ} \mathrm{C}$. Hughes $(1987 \mathrm{~b}, 1988)$ noted that heat-treated yellow sapphires from Sri Lanka $\left(\mathrm{Mg}^{2+}\right.$ trapped-hole coloration) shift to a darker, browner color when heated to moderate temperatures. Thus it remains to be determined if this heating process can distinguish the yellow Beinduced coloration from the yellow $\mathrm{Mg}$-induced coloration of heat-treated yellow sapphire.

It is important to note that this procedure also requires several caveats, and may not apply across the full range of colors and types of corundum being treated by the new diffusion process. However, if applicable, it may provide a means to rapidly identify large groups of treated sapphiresboth loose and mounted in jewelry, since the temperature range being used would not affect the metals used in jewelry.

Luminescence to Ultraviolet Radiation. Recent work outlined in Fritsch et al. (2003) has noted differences in luminescence to ultraviolet radiation that may provide helpful indications for identifying Be-diffusion treatment, particularly using a specialized microscope for viewing this property that was designed by Franck Notari of GemTechLab in Geneva. Junko Shida, of the Gemmological Association of All Japan, recently presented useful fluorescence observations to members of the Laboratory Manual Harmonization Committee that she and her staff had made when examining Be-diffused corundum using laser tomography. They found that, with this technique, the Be-diffused areas fluoresced a distinctive orange (J. Shida, pers. comm., 2003).

\section{DURABILITY AND STABILITY OF THE TREATMENT}

One of the first questions most jewelers and gemologists ask about a gemstone enhancement is: Is the process permanent and stable when subjected to typical jewelry cleaning and repair procedures? To address this question, we tested three faceted Be diffusion-treated orange to pinkish orange sapphires (all of which had been treated in Thailand) to determine the durability and stability of this process under a wide range of conditions to which sapphires might be subjected during jewelry manufacturing or routine cleaning and repair. The samples used were: (1) a 1.12 ct medium dark pinkish orange oval mixed-cut, (2) a 0.43 ct dark orange oval mixed-cut, and (3) a 0.83 ct intense reddish orange princess cut. All three sapphires were mounted in $14 \mathrm{k}$ gold rings (the first in a fourprong white head, the second in a six-prong yellow head, and the third in a four-prong yellow head) before the durability testing began. Details on the tests used and the results observed are provided in the durability table of the $G \uplus G$ Data Depository (http://www.gia.edu/GemsandGemology).

Given the low concentrations of Be required to change the color of corundum, we did not expect these diffused stones to behave any differently from natural-color or heat-treated samples. Indeed, Be-diffusion treatment did not appear to have any impact on the durability or stability of the three samples tested when exposed to routine cleaning and jewelry repair procedures. Neither ultrasonic nor steam cleaning produced any damage in the treated stones, which were examined with magnification both before and after the cleaning procedure.

In addition, these three Be-diffused stones showed little or no surface etching as a result of retipping. However, it is well known that the use of borax-containing chemicals (both fire coat and flux) contributes to moderate to severe surface etching of corundum, so other researchers may find different results using a different flux or higher temperatures. The best way to avoid this potential problem is to unmount the stone for any repair procedure that would expose it to heat.

If etching due to exposure to borax-containing compounds is severe enough, the stone might have to be repolished. Of particular importance for diffusion-treated stones with shallow color layers is the fact that repolishing or recutting could remove some or all of the diffused layer, resulting in a significant change in the appearance of the stone (figure 58). This precaution is especially pertinent to Be diffusion-treated stones in the orangy pink color range, which may have a shallow color penetration. Therefore, we recommend great caution in repolishing or recutting Be diffusion-treated stones.

\section{LABORATORY NOMENCLATURE AND TRADE DISCLOSURE RECOMMENDATIONS}

As with other gem treatments, a clear declaration of the lattice diffusion process is necessary, 

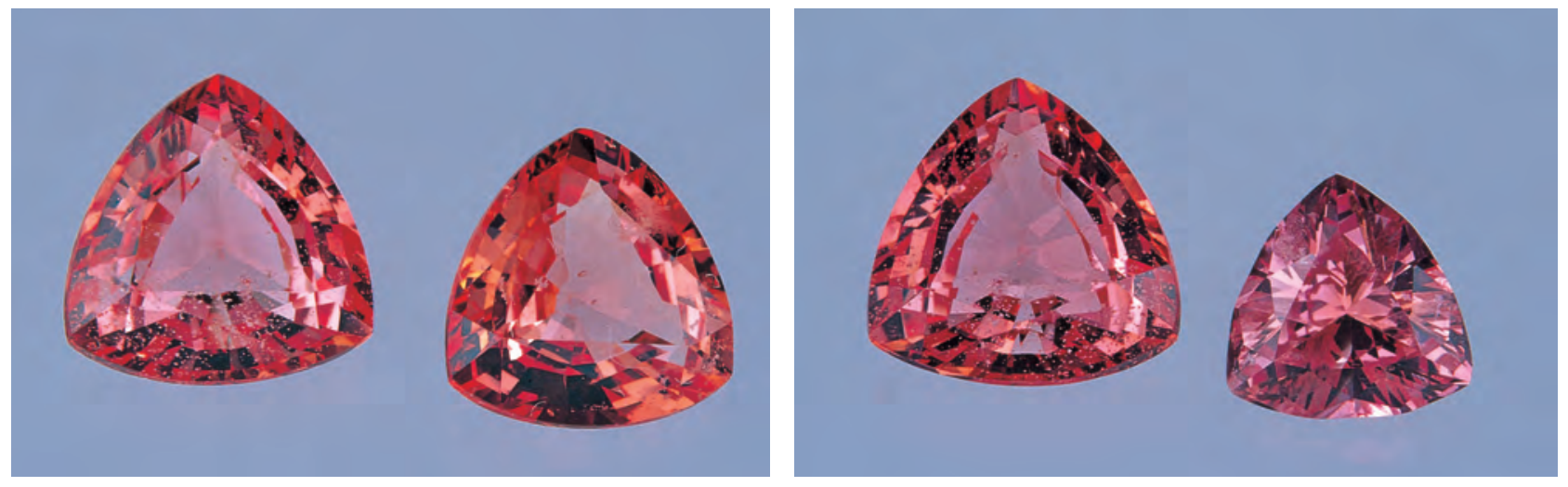

Figure 58. To illustrate the consequences of recutting incompletely Be-diffused stones, we took one of these two closely matched treated sapphires and had it recut as if it had been chipped and needed significant repair. The $0.71 \mathrm{ct}$ stone on the right side of the pair was recut to $0.40 \mathrm{ct}$, and clearly has lost most of its orange component. Photos by Maha Tannous.

whether Be or Ti is involved, to insure trade stability and to maintain consumer confidence in gems. In the case of the two gemological laboratories represented by authors of this article, GIA and AGTA, laboratory reports indicate the exposure of a gem to a treatment process such as lattice diffusion, and note if synthetic corundum is present on the surface. This is consistent with the nomenclature adopted by the Laboratory Manual Harmonization Committee (LMHC), of which our two labs are members. For lattice diffusion, the LMHC conclusion states that the stone shows: ". . . indications of heating, color induced by lattice diffusion from an external source." For the flux-assisted healing of fractures, a quantitative descriptor (such as minor, moderate or significant) is applied, as is commonly used for heat-treated rubies.

It is also important that synthetic overgrowths on corundum are properly characterized and declared on laboratory reports. The reasons for this closely parallel those for clearly describing the filling of cavities and fractures with glass on reports and, as a consequence, within the industry (Kane, 1984; Scarratt and Harding, 1984; Scarratt et al., 1986; Hughes, 1987a; Scarratt, 1988, 2000; "Glass filled rubies . . .," 1994; "Glass filling . . .," 1994; Robinson, 1995). Specifically, synthetic overgrowths created during the Be-diffusion process: (1) are created artificially and, therefore, are unnatural additions to the stone; and (2) unnaturally increase the weight of a finished stone by both adding the weight of the synthetic material and allowing a larger stone to be cut than would otherwise be possible.

Gem dealers and retailers often need more descriptive terminology to communicate with the consumer. In some instances, one could say that beryllium was introduced into the stone to create colors that are otherwise very rare in nature. A simple and accurate description might be "artificially colored with beryllium." Additional disclosure information is needed for those stones where repolishing may affect the color or where synthetic material may be present on the surface.

\section{SUMMARY AND CONCLUSIONS}

We have shown that the "new process" from Thailand is the diffusion of beryllium into ruby and sapphire at very high temperatures in an oxygen atmosphere. Unlike the much older titanium diffusion process, which produced a thin blue layer under the surface, Be diffusion can penetrate deeply, sometimes coloring the entire volume of the stone. We have shown that beryllium diffused into corundum, at high temperature, is the sole cause of the color modifications observed. A wide variety of colors are produced by this process, depending on how the Be trapped-hole pair interacts with the internal chemistry of the stone. Thus far, the colors produced or modified by this process are predominantly yellow, yellowish orange, orangy pink to pinkish orange, orange, and orangered to red (ruby). Many are very attractive, and have excellent commercial potential (figure 59). We have also shown that some types of dark blue basaltic sapphire can be lightened very significantly by Be diffusion. Thus, the majority of sapphire colors in the marketplace could potentially be products of the Be-diffusion process.

However, color modifications are not the only important consequences of this process. We have 


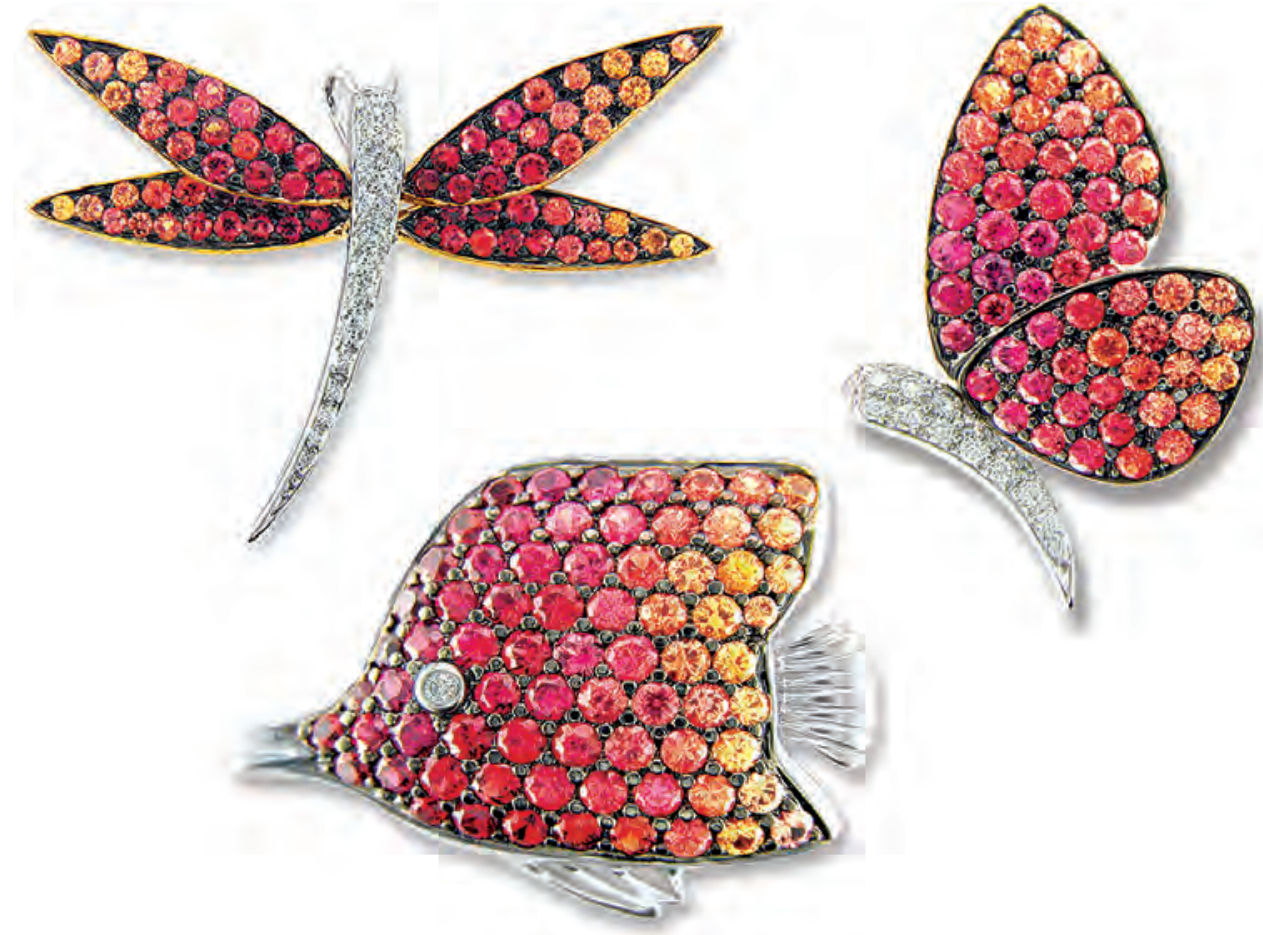

Figure 59. As shown by this attractive jewelry, Be-diffused sapphires clearly have significant commercial potential, as long as they are properly disclosed. Photo by Myriam Naftule Whitney; courtesy of Nafco Gems.

noted significant amounts of synthetic corundum overgrowth on many of these stones, much of which may remain after re-cutting. Some faceted stones have shown $10-20 \%$ of the surface covered with this synthetic material, raising questions concerning just how "natural" such a stone is. In addition, fractures and boehmite channels are often sealed or "healed" by this process

Identification of Be diffusion-processed stones ranges from very simple observations to quite complex chemical analyses. Standard gemological properties are not changed by Be diffusion, nor does the durability of the stone appear to be affected. If the diffusion layer penetrates only a portion of the radius of the stone, it may be seen easily by immersion in a high R.I. liquid with diffuse background illumination. Observation of a three-dimensional surface-conformal color layer is considered proof that the stone has been diffused. If there is only a portion of a color layer, however, because the stone was recut or originally diffused in the rough, care must be taken not to confuse Be-diffusion treatment with natural color zoning.

In some sapphires, diffusion fully penetrates the stone-and identification becomes substantially more difficult. However, the inclusion scene may provide important indicators of the high heat required for Be-diffusion treatment. Careful examination with magnification and diffuse reflected light may reveal synthetic growth on surfaces and in healed fractures and channels. Highly altered zircon inclusions are also indicative of the very high temperatures used in this process, as is the replacement of boehmite with synthetic material. Internal diffusion, in the form of blue halos around rutile crystals in yellow and red corundum, is another important indicator. Although these features do not prove Be diffusion, they do indicate that the stone should be subjected to additional testing.

SIMS and LA-ICP-MS can both unequivocally identify the presence of beryllium in color-altering concentrations (5-30 ppma). While these are expensive tests, they are necessary for potentially high-value stones that do not exhibit a surfaceconformal color layer.

As a part of the study of this process we have decided to replace the term surface diffusion, which has been used by gemologists and some laboratories for years, with lattice diffusion to be consistent with the usage in other scientific disciplines. In their official reports, both the GIA laboratory and AGTA-GTC describe Ti- and Be-diffused stones with the wording ". . indications of heating, color induced by lattice diffusion from an external source." Thus, both the earlier titanium blue diffusion and the new beryllium diffusion are described the same way, as they are exactly the same process, just different diffusing elements.

The implications of Be diffusion to the entire gem community (from miner to consumer) are 
quite far reaching. It appears that virtually any color of ruby and sapphire can be reproduced by the Be-diffusion process. Transparent corundum actually is a common commodity. Only corundum in attractive colors and color saturation levels is rare. There are large deposits of sapphire that can produce large stones in unmarketable colors. Conventional heat treatment can improve only a very small percentage of such material. However, it appears that much, if not most, of this material can be Be diffused to produce attractive colors (figure 60). We have observed that Be diffusion beneficially affects $50-95 \%$ of mine run material, not just a small portion. Thus, if we cannot develop a simple low-cost detection method, gem sapphire will become as common as blue topaz, supply will exceed demand, and prices will fall radically, damaging the entire gem trade. Today, there is no simple, low-cost alternative to SIMS or LA-ICPMS, but we are working on the problem and strongly encourage others to do so as well.

Technology will always advance, and attempting to slow or stop it is as rewarding as trying to sweep back the sea with a broom. However, as a community we need to come together to understand each new process as it is developed, and bring it to the gem market with full disclosure, allowing an informed marketplace to determine value. Only in

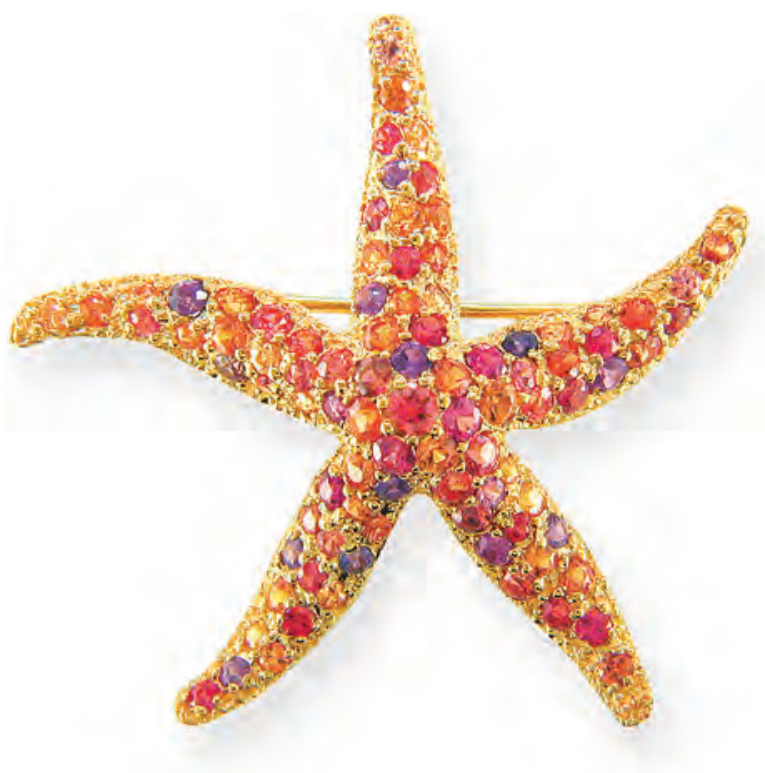

Figure 60. Many attractive sapphire colors that were previously very rare will now be made abundant with Be diffusion, opening up uses in jewelry designs that were previously not available. The total weight of the Be-diffused sapphires in this pin is $3.50 \mathrm{ct}$. Photo by Myriam Naftule Whitney; courtesy of Nafco Gems.

this way can our miners, treaters, dealers, and jewelers prosper. Only in this way will the consumer show us the trust and support we have enjoyed in the past.

\section{ABOUT THE AUTHORS}

Dr. Emmett (jlemmett@earthlink.net) is a principal of Crystal Chemistry, Brush Prairie, Washington; Mr. Scarratt is laboratory director, AGTA Gemological Testing Center, New York; Mr. McClure is director of Identification Services, GIA Gem Laboratory, Carlsbad, California; Mr. Moses is vice president for Identification and Research, GIA Gem Laboratory, New York; Mr. Douthit is a principal of Crystal Chemistry, Los Altos, California; Mr. Hughes is the author of Ruby \& Sapphire and webmaster at Palagems.com, based in Fallbrook, California; Dr. Novak is manager of Dynamic SIMS Services, Evans East, East Windsor, New Jersey; Dr. Shigley is director of GIA Research in Carlsbad; Dr. Wang is a research scientist, GIA Gem Laboratory, New York; Mr. Bordelon is a gem merchant and designer/manufacturer of gemological instruments in New Orleans, Louisiana; and Mr. Kane is president, Fine Gems International, Helena, Montana.

ACKNOWLEDGMENTS: The authors thank gem dealers Terry Coldham, Mark Smith, Joe Belmont, Tom Cushman, Rudi Wobito, Hans-Georg Wild, Markus Wild, Bill Larson, Eric Braunwart, Santpal Sinchawla, Jeff Bilgore, and Roland
Naftule for graciously supplying stones and other materials for these experiments. They thank Junko Shida for details on the Gemological Association of All Japan's experience with laser tomography and supply of, and information concerning, Be-diffused blue sapphires. A number of stimulating conversations with Professor George Rossman of the Division of Geological and Planetary Sciences at the California Institute of Technology, Pasadena, California, are also greatly appreciated, as are conversations with Milan Kokta and Jennifer Stone-Sundberg of Sant-Gobain Crystals and Detectors, Washougal, Washington. Yianni Melas provided invaluable assistance in the early stages of this research. Dr. Thomas $R$. Anthony of the General Electric Company, Schenectady, New York, is also thanked for his assistance. Garth Billings and Dave Witter are thanked for their support of the experiments. Don and Corey Johnson of Eaton-Turner Jewelry, Helena, Montana, kindly provided assistance with the durability testing. Thomas Moses, Shane McClure, and Kenneth Scarratt acknowledge with thanks the aid of their laboratory staff members. John Emmett, Troy Douthit, and Owen Bordelon express their appreciation to the AGTA for partial financial support of their work. 


\section{APPENDIX: WhAT IS DIFFUSION?}

The motion of atoms through solids is fundamental to our technological society. The heat treatment and case hardening of steels, the doping of semiconductors for integrated circuits, and the production of padparadscha-like colored sapphires from pink ones all rely on the transport of atoms through solids. The mechanism by which atoms or ions move through solids is known as diffusion.

How actually does an atom move through a solid that is, after all, solid? It turns out that even the most perfect crystal has places in its lattice where atoms are missing. These holes are termed "vacancies." In the case of corundum, which is made up of aluminum and oxygen atoms, even the most perfect crystal sample will have missing aluminum and oxygen atoms, and the higher the temperature the more missing atoms there will be. A foreign ion can move through solid corundum by jumping from one vacancy to the next. Since the vacancies are randomly distributed, the diffusing ion will "random walk" through the crystal, sometimes moving forward or back, up or down, or right or left. Averaged over a large number of jumps, the ion always moves away from regions of high concentration of diffusing ions to regions of low concentration. Jumping requires energy, which is supplied by heat, so an ion makes more jumps per second at high temperatures than at low temperatures. Thus, diffusion rates increase dramatically with temperature due to the increase in the number of both vacancies and jumps per second.

All types of heat treatment of corundum involve some type of diffusion process. It is the movement of preexisting ions that makes heat treatment work. For example, the dissolution of rutile needles into the host corundum crystal is simply titanium diffusing into corundum (and aluminum diffusing into rutile) at high temperature. In this case, the diffusion involves ions that are already in the host corundum (Koivula, 1987). In this article, however, we are primarily concerned with the diffusion of a foreign element (Be) into corundum from an outside source. Thus, diffusion is the physical process, and diffusion treatment-the term we use to describe the enhancement method in this article-refers to artificially coloring a gem.

How fast does diffusion occur? In corundum it depends on the size (ionic radius) of the diffusing ion relative to the size of the vacancy, the ionic charge of the diffusing ions, the temperature during treatment, and a variety of other less important factors. Because of the "random walk" nature of diffusion, the depth of penetration does not increase linearly with time. Rather, it increases with the square root of time. This means that if the penetration depth of a given ion at a given temperature is $1.0 \mathrm{~mm}$ in one hour, it will be $3.16 \mathrm{~mm}$ in 10 hours, and $10 \mathrm{~mm}$ in 100 hours. Thus at a particular temperature we can say that the diffusion depth $x$ (in $\mathrm{cm})$ is related to time by

$$
\mathbf{x}=\sqrt{D t}
$$

where $D$ is the diffusion coefficient in units of $\mathrm{cm}^{2} / \mathrm{sec}$, and $t$ is the time in seconds over which the diffusion is conducted. The diffusion coefficient $D$ is a measure of the ease with which an ion moves through the corundum lattice. At $1750^{\circ} \mathrm{C}$, for example, the diffusion coefficients for the following ions are approximately: $\mathrm{H}^{+} \sim 10^{-5}, \mathrm{Be}^{2+} \sim 10^{-7}, \mathrm{Ti}^{4+} \sim 10^{-9}$, and $\mathrm{Cr}^{3+} \sim 10^{-13} \mathrm{~cm}^{2} / \mathrm{sec}$. Diffusion coefficients increase exponentially with temperature.

Figure Ap-1 shows the concentration profiles at three different times for beryllium (assuming $D=$ $10^{-7} \mathrm{~cm}^{2} / \mathrm{sec}$ at $1750^{\circ} \mathrm{C}$ ). The shape of these curves is typical of the diffusion process. If we wish to fully saturate a stone with a foreign ion, we need to know how long it will require. Figure Ap-2 is a plot of the average concentration in a spherical sample as a function of time $t$, the diffusion coefficient $D$, and the diameter $d$, of the stone. Continuing our example, if we assume $D$ to be $10^{-7} \mathrm{~cm}^{2} / \mathrm{sec}$, then it will require 97 hours to completely saturate a 5mm-diameter spherical sample of corundum, but $75 \%$ of complete saturation can be achieved in about 16 hours, which is one-sixth of the time for complete saturation.

What determines the magnitude of the diffusion coefficients, which, as we have noted, can vary over many orders of magnitude from element to element? At a given temperature, aliovalent ions (see "Color in Corundum" section) exhibit diffusion coefficients in relatively pure corundum that are between 1,000 and 10,000 times those of isovalent ions. As discussed above, a diffusing ion requires vacancies into which to jump in order to move. In pure corundum, or corundum containing only isovalent impurities, vacancies occur only from heating the lattice. These thermally induced vacancies exist only in extremely low concentrations, even at very high temperatures. Thus the diffusion of isovalent ions is very slow. In contrast, aliovalent ions make their own vacancies and do not have to rely on thermally induced vacancies. This is due to the fact that aliovalent ions must be charge compensated to dissolve into 


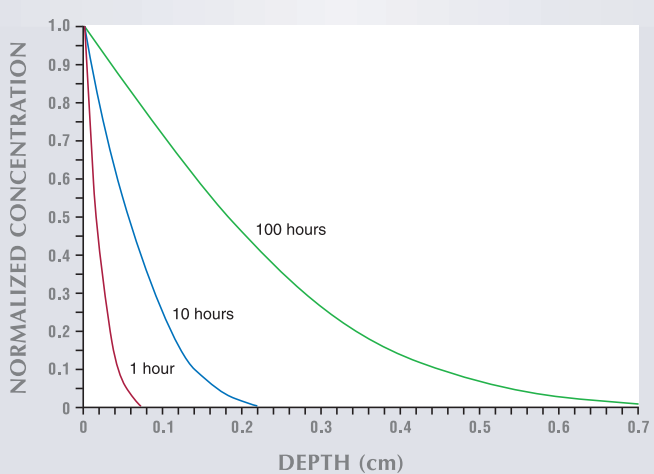

Figure Ap-1. The depth of beryllium diffusion into sapphire is shown here calculated for three different processing times-1 hour, 10 hours, 100 hours. Diffusion depth does not increase linearly with time, but with the square root of time.

the corundum lattice (see "Color in Corundum" section). In diffusion situations, this charge compensation is usually accomplished by the formation of vacancies. For example, to place three $\mathrm{Ti}^{4+}$ ions in the corundum lattice requires the formation of one aluminum vacancy to charge compensate them. At any measurable $\mathrm{Ti}^{4+}$ concentration, therefore, the concentrations of these vacancies exceeds by orders of magnitude the concentration of thermally induced vacancies. Thus the aliovalent ion can diffuse orders of magnitude faster than isovalent ions.

Ion size, or the effective "radius" of an ion, has a strong effect on the diffusion coefficient. The effective radius (Shannon, 1976) of the $\mathrm{Al}^{3+}$ site in corundum is 53 picometers ( $1 \mathrm{pm}=10^{-12}$ meters). $\mathrm{Be}^{2+}$ on this site, at $45 \mathrm{pm}$, is much smaller. $\mathrm{Mg}^{2+}$ on this site, at $72 \mathrm{pm}$, is much larger. Ando (1987) determined that the diffusion coefficient of $\mathrm{Mg}^{2+}$ in sapphire-at low concentrations and at $1800^{\circ} \mathrm{C}$-is about $2.5 \times 10^{-10} \mathrm{~cm}^{2} / \mathrm{sec}$. Our estimate of the $\mathrm{Be}^{2+}$ diffusion coefficient (see "Beryllium Diffusion into Corundum: Process and Results" section) at the same temperature, based on the depth of the color boundary, is roughly $10^{-7} \mathrm{~cm}^{2} / \mathrm{sec}-400$ times greater than that of $\mathrm{Mg}^{2+}$. Recently there has been concern in the gemological community about the possibility that boron or lithium might be diffused into sapphire (see, e.g., Shor, 2003). Diffusion coefficients for $\mathrm{B}^{3+}$ and $\mathrm{Li}^{+}$in corundum have not been measured, but boron is both isovalent and very small (27 pm), so its diffusion coefficient is hard to estimate but is expected to be smaller than that of titanium or magnesium

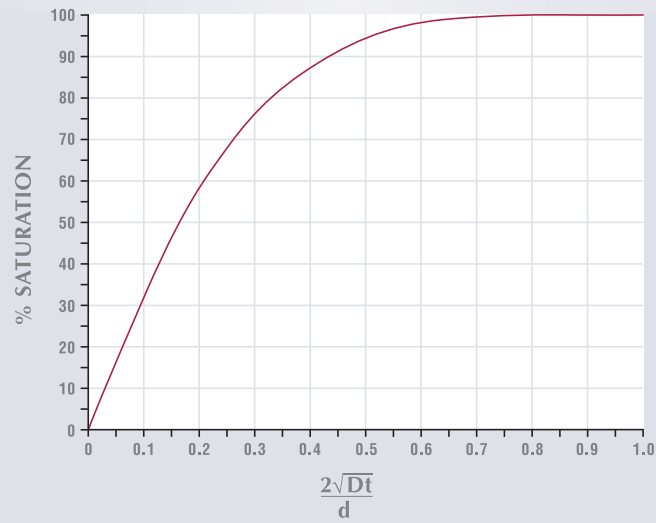

Figure Ap-2. This diagram shows the time required to saturate, by diffusion, a sphere of material of diameter $\mathrm{d}$ in $\mathrm{cm}$. D is the diffusion coefficient in units of $\mathrm{cm}^{2} / \mathrm{sec}$, and $\mathrm{t}$ is the diffusion time in seconds. Note that to achieve $100 \%$ saturation requires approximately six times as long as to achieve $75 \%$ saturation. An example of how to use this graph is as follows: Suppose that we wish to determine the degree of Be saturation (and thus color saturation) that will be achieved in a 5mm-diameter sapphire that we will Be diffuse for 25 hours at $1750^{\circ} \mathrm{C}$. Thus $\mathrm{d}=5 \mathrm{~mm}$ (or $0.5 \mathrm{~cm}$ ), $\mathrm{t}=25$ hours (or 90,000 seconds), and $\mathrm{D}=10^{-7} \mathrm{~cm}^{2} / \mathrm{sec}$ (or $\left.0.0000001 \mathrm{~cm}^{2} / \mathrm{sec}\right)$. Putting these numbers into the relation on the horizontal axis, $2 \sqrt{D t} / d$, we get 0.375 . A value of 0.375 on the horizontal axis corresponds to about $85 \%$ saturation. Note that the curve is very general in that it applies to any ion at any temperature diffusing into any spherical host, as long as the diffusion coefficient is known at the temperature of interest.

because it is isovalent. Thus $\mathrm{Be}^{3+}$ would diffuse much more slowly than $\mathrm{Be}^{2+}$. Lithium is both large $(76 \mathrm{pm}$; very close to the size of $\mathrm{Mg}^{2+}$ ) and aliovalent and could be expected to diffuse somewhat like magnesium or titanium.

In most diffusion situations, the concentration of the diffusing ion is much higher in the flux or other carrier outside the crystal, than just inside the crystal. The concentration just inside the crystal is not determined by the concentration outside, but by the solubility of the foreign ion in corundum. The solubility of foreign ions in corundum also increases with temperature. Solubilities vary widely; for example, at $1750^{\circ} \mathrm{C}$, titanium solubility is a several hundred ppma while that of beryllium is a few tens of ppma.

A good overall reference on diffusion is Borg and Dienes (1988). 


\section{REFERENCES}

Ando K. (1987) Magnesium-impurity diffusion in $\mathrm{Al}_{2} \mathrm{O}_{3}$ single crystals. Nonstoichiometric compounds. In C.R.A. Catlow and W.C. Mackrodt, Eds., Advances in Ceramics, Vol. 23, American Ceramic Society, Westerville, OH, pp. 149-158.

Beesley C.R. (1982) The alchemy of blue sapphire. Jewelers' CircularKeystone, Vol. 153, No. 8, pp. 102-103.

Beran A. (1991) Trace hydrogen in Verneuil-grown corundum and its colour varieties: An IR spectroscopic study. European Journal of Mineralogy, Vol. 3, No. 6, pp. 971-975.

Boiko B.B., Shkadarevich A.P., Zhdanov É.A., Kalosha I., Koptev V.G., Demidovich A.A. (1987) Lasing due to color centers in an $\mathrm{Al}_{2} \mathrm{O}_{3}: \mathrm{Mg}$ crystal. Soviet Journal of Quantum Electronics, Vol. 17, No. 5, pp. 581-582.

Borg R.J., Dienes G.J. (1988) An Introduction to Solid State Diffusion. Academic Press, San Diego, CA, 360 pp.

Bube R.H. (1992) Electrons in Solids, 3rd ed. Academic Press, San Diego, CA, $329 \mathrm{pp}$.

Burns R.G. (1981) Intervalence transitions in mixed-valence minerals of iron and titanium. Annual Review of Earth and Planetary Sciences, Vol. 9, pp. 345-383.

Burns R.G. (1993) Mineralogical Applications of Crystal Field Theory. Cambridge University Press, Cambridge, UK.

Butterman W.C., Foster W.R. (1967) Zircon stability and the $\mathrm{ZrO}_{2}-\mathrm{SiO}_{2}$ phase diagram. American Mineralogist, Vol. 52, No. 5/6, pp. 880-885.

Carr R.R., Nisevich S.D. (1975) Altering the appearance of sapphire crystals. U.S. patent $3,897,529$, issued July 29.

Carr R.R., Nisevich S.D. (1976) Altering the appearance of corundum crystals. U.S. patent 3,950,596, issued April 13.

Carr R.R., Nisevich S.D. (1977) Altering the appearance of corundum crystals. U.S. patent 4,039,726, issued August 2.

CGA (2003) Chanthaburi gem traders and heaters agree to disclose beryllium treatment, CGA Press Release, February 20.

Chiang Y.-M., Birnie D.P. III, Kingery W.D. (1997) Physical Ceramics. John Wiley \& Sons, New York, 522 pp.

Coldham T. (2002) Orange sapphires or just lemons? Australian Gemmologist, Vol. 22, No. 7, pp. 288-293.

Crowningshield R. (1966) Developments and highlights at GIA's Lab in New York: Unusual items encountered. Gems $\oplus$ Gemology, Vol. 12 , No. 3, p. 73

Crowningshield G.R. (1970) Developments and highlights at GIA's Lab in New York: Unusual fluorescence [sapphire with unusual fluorescence]. Gems « Gemology, Vol. 13, No. 4, pp. 120-122.

Crowningshield R. (1979) Developments and highlights at GIA's Lab in New York: Treated blue sapphires. Gems ↔ Gemology, Vol. 16, No. 5, p. 147.

Crowningshield R., Nassau K. (1981) The heat and diffusion treatment of natural and synthetic sapphires. Journal of Gemmology, Vol. 17, No. 8, pp. 528-541.

Dodd D.M., Wood D.L., Barns R.L. (1964) Spectrophotometric determination of chromium concentration in ruby. Journal of Applied Physics, Vol. 35, No. 4, pp. 1183-1186.

Dutt B.V., Kröger F.A. (1975) High-temperature defect structure of irondoped $\alpha$-Alumina. Journal of the American Ceramic Society, Vol. 58, No. 11/12, pp. 474-476.

Eigenmann K., Kurtz K., Günthard H.H. (1972) The optical spectrum of $\alpha-\mathrm{Al}_{2} \mathrm{O}_{3}: \mathrm{Fe}^{3+}$. Chemical Physics Letters, Vol. 13, No. 1, pp. 54-57.

El-Aiat M.M., Kröger F.A. (1982) Hydrogen donors in $\alpha-\mathrm{Al}_{2} \mathrm{O}_{3}$. Journal of Applied Physics, Vol. 53, No. 5, pp. 3658-3667.

Emmett J.L., Douthit T.R. (1993) Heat treating the sapphires of Rock Creek, Montana. Gems «) Gemology, Vol. 29, No. 4, pp. 250-272.

Emmett J.L. (1999) Fluxes and the heat treatment of ruby and sapphire. Gems «) Gemology, Vol. 35, No. 3, pp. 90-92.

Emmett J.L., Douthit T.R. (2002a) Beryllium diffusion coloration of sapphire: A summary of ongoing experiments. American Gem Trade Association, http://agta.org/consumer/gtclab/treatedsapps04.htm.

Emmett J.L., Douthit T.R. (2002b) Understanding the new treated pink-orange sapphires. Pala International, http://palagems.com/ treated_sapphire_emmett.htm.

Ferguson J., Fielding P.E. (1971) The origins of the colours of yellow, green and blue sapphires. Chemical Physics Letters, Vol. 10, No. 3, pp. $262-265$.

Ferguson J., Fielding P.E. (1972) The origins of the colours of natural yel- low, blue, and green sapphires. Australian Journal of Chemistry, Vol. 25 , pp. 1371-85.

Fritsch E., Chalain J.-P., Hänni H., Devouard B., Chazot G., Giuliani G., Schwarz D., Rollion-Bard C., Garnier V., Barda S. Ohnenstetter D., Notari F., Maitrallet P. (2003) Le nouveau traitement produisant des couleurs orange à jaune dans les saphirs (French with English abstract). Revue de Gemmologie, No. 147, pp. 11-23.

Fritsch E., Rossman G.R. (1987) An update on color in gems. Part 1 : Introduction and colors caused by dispersed metal ions. Gems Gemology, Vol. 23, No. 3, pp. 126-139.

Fritsch E., Rossman G.R. (1988) An update on color in gems. Part 2 Colors involving multiple atoms and color centers. Gems et Gemology, Vol. 24, No. 1, pp. 3-15.

GIT (2002) GIT information on heat-enhanced orange-pink (padparadscha-like) sapphires from Madagascar. Gem and Jewelry Institute of Thailand, http://www.git.or.th (document no longer available online; hard copy on file with authors.

Glass filled rubies increasing (1994) Jewellery News Asia, No. 119, pp. 66-70

Glass filling in ruby from Burma (1994) Indian Gemmologist, Vol. 4 No. 1, pp. 1, 24.

Häger T. (1992) Farbgebende und "farbhemmende" Spurenelemente in blauen Saphiren. Berichte der Deutschen Mineralogischen Gesellschaft, Beihefte zum European Journal of Mineralogy, Vol. 4, p. 109.

Häger T. (1993) Stabilisierung der Farbzentren von gelben natürlichen Saphiren. Berichte der Deutschen Mineralogischen Gesellschaft, Beihefte zum European Journal of Mineralogy, Vol. 5, p. 188

Häger T. (1996) Farbrelevante Wechselwirkungen von Spurenelementen in Korund. Dissertation, Universität Mainz, Mainz, Germany.

Häger T. (2001) High temperature treatment of natural corundum. International Workshop on Material Characterization by Solid State Spectroscopy: The Minerals of Vietnam, April 4-10, Institute of Materials Science, Hanoi.

Hänni H.A. (2001) Beobachtungen an hitzesehandeltem Rubin mit künstlicher Rissheilung. Zeitschrift der Deutschen Gemmologischen Gesellschaft, Vol. 50, No. 3, pp. 123-136.

Hänni H.A. (2002) Orange treated sapphire-towards finding a name for a new product. Journal of the Gemmological Association of Hong Kong, Vol. 23, pp. 23-28

Hänni H.A., Pettke T. (2002) Eine neue Diffusionsbehandlung liefert orangefarbene und gelbe Saphire. Zeitschrift der Deutschen Gemmologischen Gesellschaft, Vol. 51, No. 4, pp. 137-152.

Hervig R.L. (2002) Beryllium analysis by secondary ion mass spectrometry. In E.S. Grew, Ed., Beryllium: Mineralogy, Petrology, and Geochemistry, Reviews in Mineralogy and Geochemistry, Vol. 50, Mineralogical Society of America, Washington, DC, pp. 319-332.

Hughes R.W. (1987) Glass infilling of cracks in ruby. ICA Lab Alert, Vol. 4, p. 1

Hughes R.W. (1988) Identifying yellow sapphires-two important techniques. Journal of Gemmology, Vol. 21, No. 1, pp. 23-25.

Hughes R.W. (1991a) Thailand taking the heat. JewelSiam, Vol. 2, No. 2, pp. $42-48$.

Hughes R.W. (1991b) There's a rumble in the jungle-The sapphire facelift face-off. Gemological Digest, Vol. 3, No. 2, pp. 17-31.

Hughes R.W. (1997) Ruby «) Sapphire. RWH Publishing, Boulder, CO, $511 \mathrm{pp}$.

Hughes R.W. (2002) The skin game: Orange sapphire treatment raises controversy. The Guide, Vol. 21, No. 2, pp. 3-7.

Kane R.E. (1984) Natural rubies with glass-filled cavities. Gems $\oplus$ Gemology, Vol. 20, No. 4, pp. 187-199.

Kane R.E., Kammerling R.C., Koivula J.I., Shigley J.E., Fritsch E. (1990) The identification of blue diffusion-treated sapphires. Gems $\oplus$ Gemology, Vol. 26, No. 2, pp. 115-133.

Keller P.C. (1982) The Chanthaburi-Trat gem field, Thailand. Gems $\Perp$ Gemology, Vol. 18, No. 4, pp. 186-196.

Khattak C.P., Schmid F. (1984) Growth of large-diameter crystals by heat exchanger method for optical and laser applications. In $S$. Musikant, Ed., Proceedings of the SPIE Conference on Advances in Optical Materials, $260 \mathrm{pp}$

Khattak C.P., Scoville A.N., Schmid F. (1986) Recent developments in sapphire growth by heat exchanger method (HEM). In R.W Schwartz, Ed., Proceedings of the SPIE Conference on Infrared and Optical Transmitting Materials, $181 \mathrm{pp}$. 
Kingery W.D., Bowen H.K., Uhlmann D.R. (1976) Introduction to Ceramics. John Wiley \& Sons, New York, 1032 pp.

Kizilyalli M., Corish J., Metselaar R. (1999) Definitions of terms for diffusion in the solid state. Pure and Applied Chemistry, Vol. 71, No. 7, pp. 1307-1325.

Koivula J.I. (1987) Internal diffusion. Journal of Gemmology, Vol. 20, No. $7 / 8$, pp. 474-477.

Koripella C.R., Kröger F.A. (1986) Electrical conductivity of $\mathrm{Al}_{2} \mathrm{O}_{3}: \mathrm{Fe}+$ Y. Journal of the American Ceramic Society, Vol. 69, No. 12, pp. 888-896.

Krebs J.J., Maisch W.G. (1971) Exchange effects in the optical-absorption spectrum of $\mathrm{Fe}^{3+}$ in $\mathrm{Al}_{2} \mathrm{O}_{3}$. Physical Review B, Vol. 4, No. 3, pp. 757-769.

Kröger F.A. (1974) The Chemistry of Imperfect Crystals. North-Holland Publishing Co., Amsterdam, The Netherlands, $988 \mathrm{pp}$.

Kröger F.A. (1984) Defect related properties of doped alumina. Solid State Ionics, Vol. 12, pp. 189-199.

Kvapil J., Perner B., Sulovsky I., Kvapil J. (1973) Colour centre formation in corundum doped with divalent ions. Kristall und Technik, Vol. 8 , No. $1 / 3$, pp. $247-251$

Lee C.H., Kröger F.A. (1985) Electrical conductivity of polycrystalline $\mathrm{Al}_{2} \mathrm{O}_{3}$ doped with silicon. Journal of the American Ceramic Society, Vol. 68, No. 2, pp. 92-99.

Leta D.P., Morrison G.H. (1980) Ion implantation for in-situ quantitative ion microprobe analysis. Analytical Chemistry, Vol. 52, pp. 277-280.

McClure D.S. (1962) Optical spectra of transition-metal ions in corundum. Journal of Chemical Physics, Vol. 36, No. 10, pp. 2757-2779.

McClure S.F. (2002a) Gem Trade Lab Notes: Bulk-diffusion treated sapphire with synthetic overgrowth. Gems $巴$ Gemology, Vol. 38, No. 3 , pp. 255-256.

McClure S.F. (2002b) Swarovski scientists identify possible source of beryllium in new treated sapphires. GIA Insider, May 3, 2002, http://www.gia.edu/newsroom/issue/2798/1046/insider_newsletter_ details.cfm\#3.

McClure S.F., Kammerling R.C., Fritsch E. (1993) Update on diffusiontreated corundum: Red and other colors. Gems ↔) Gemology, Vol. 29 , No. 1, pp. 16-28.

McClure S.F., Moses T., Wang W., Hall M., Koivula J.I. (2002) Gem News International: A new corundum treatment from Thailand. Gems « Gemology, Vol. 38, No. 1, pp. 86-90.

Mohapatra S.K., Kröger F.A. (1977) Defect structure of $\alpha-\mathrm{Al}_{2} \mathrm{O}_{3}$ doped with magnesium. Journal of the American Ceramic Society, Vol. 60, No. 3/4, pp. 141-148.

Moon A.R., Phillips M.R. (1994) Defect clustering and color in Fe, Ti: $\alpha$ $\mathrm{Al}_{2} \mathrm{O}_{3}$. Journal of the American Ceramic Society, Vol. 77, No. 2, pp. 356-357.

Moses T.M., Hall M., Wang W. (2002) Gem Trade Lab Notes: More bulk diffusion-rubies and orange sapphires. Gems 巴) Gemology, Vol. 38, No. 4, pp. 342-344.

Nassau K. (1980) Gems Made by Man. Chilton Book Co., Radnor, PA.

Nassau K. (1983) The Physics and Chemistry of Color. John Wiley \& Sons, New York, 454 pp.

Nelson D.F., Sturge M.D. (1965) Relation between absorption and emission in the region of the R lines of ruby. Physical Review, Vol. 137, No. 4A, pp. 1117-1130.

Pauling L. (1956) General Chemistry. W. H. Freeman and Co., San Francisco, CA, $710 \mathrm{pp}$.

Peretti A., Günther D. (2002) The color enhancement of fancy sapphires with a new heat-treatment technique (Part A). Contributions to Gemology, Vol. 1, pp. 1-48.

Pisutha-Arnond V., Häger T., Wathanakul P., Atichat W. (2002) Lab News: A brief summary on a cause of colour in pink-orange, orange and yellow sapphires produced by the new heating technique. Gem and Jewelry Institute of Thailand Gem Testing Lab, http://www.git.or.th/eng/eng_lab/eng_lab_news/eng_news_on 22_november_2002.htm.

Proust M.A. (2002) New sapphire treatment still a mystery. Colored Stone, Vol. 15, No. 2, pp. 12-13.

Qi L., Yuan X., Lin S., Wang Z. (2002) Colouring mechanism of hightemperature heat-treated orange sapphire in Madagascar [in Chinesel. Journal of Gems «) Gemology, Vol. 4, No. 4, pp. 1-5.

Ramírez R., Tardío M., González R., Kokta M.R., Chen Y. (2001) Electroluminescence in magnesium-doped $\mathrm{Al}_{2} \mathrm{O}_{3}$ crystals. Radiation Effects $\nrightarrow$ Defects in Solids, Vol. 154, pp. 295-299.

Rankin A., Edwards W. (2003) Some effects of extreme heat treatment on zircon inclusions in corundum. Journal of Gemmology, Vol. 28, No. 5, pp. $257-264$

Robinson N.L. (1995) Thais get burned by glass fillings. Colored Stone, Vol. 8, No. 4, pp. 1, 6

Rossman G.R. (1988) Vibrational spectroscopy of hydrous components. In Hawthorne F.C., Ed., Spectroscopic Methods in Mineralogy, Reviews in Mineralogy, Vol. 18, Mineralogical Society of America, Washington, DC, pp. 193-206.

Scarratt K. (1983) Notes from the Laboratory: Diffusion treated corundum. Journal of Gemmology, Vol. 18, No. 6, pp. 523-530.

Scarratt K. (1988) Notes from the laboratory: Glass filled feathers and cavities in ruby. Journal of Gemmology, Vol. 21, No. 3, pp. 131-139.

Scarratt K. (2000) Gem News: Heat-treated rubies: Glass or not glass? Gems \&) Gemology, Vol. 36, No. 1, pp. 75-76.

Scarratt K. (2002a) Is it pink or is it padparadscha? Rapaport Diamond Report, Vol. 25, No. 5, pp. 103, 105, 109.

Scarratt K. (2002b) Orange-pink sapphire alert. American Gem Trade Association, http://www.agta.org/consumer/gtclab/orangesapphirealert.htm.

Scarratt K., Harding R.R. (1984) Glass infilling of cavities in natural ruby. Journal of Gemmology, Vol. 19, No. 4, pp. 293-297.

Scarratt K., Harding R.R., Din V.K. (1986) Glass fillings in sapphire. Journal of Gemmology, Vol. 20, No. 4, pp. 203-207.

Schmetzer K. (1981) The colour of natural corundum. Neues Jahrbuch für Mineralogie, Monatshefte, No. 2, pp. 59-68.

Schmetzer K. (1999) Ruby and variously colored sapphires from Ilakaka. Australian Gemmologist, Vol. 20, No. 7, pp. 82-84.

Schmetzer K., Bosshart G., Hänni H.A. (1983) Naturally-coloured and treated yellow and orange-brown sapphires. Journal of Gemmology, Vol. 18, No. 7, pp. 607-622.

Shannon R.D. (1976) Revised effective ionic radii and systematic studies of interatomic distances in halides and chalcogenides. Acto Crystallographica, Vol. A32, pp. 751-767.

Shor R. (2003) Gem News International: AGTA corundum panel. Gems «) Gemology, Vol. 39, No. 1, pp. 58-59.

Smith C.P. (1995) A contribution to understanding the infrared spectra of rubies from Mong Hsu, Myanmar. Journal of Gemmology, Vol. 24, No. 5, pp. 321-335.

Smith G., Strens R.G.J. (1976) Intervalence-transfer absorption in some silicate, oxide and phosphate minerals. In R.G.J. Strens, Ed., Physical Chemistry of Rocks $\oplus$ Minerals, John Wiley \& Sons, New York, pp. 584-612.

Smyth D.M. (2000) The Defect Chemistry of Metal Oxides. Oxford University Press, New York.

Tardío M., Ramírez R., González R., Chen Y., Kokta M.R. (2001a Electrical conductivity in magnesium-doped $\mathrm{Al}_{2} \mathrm{O}_{3}$ crystals at moderate temperatures. Radiation Effects $\uplus$ Defects in Solids, Vol. 155 pp. 409-413.

Tardío M., Ramírez R., González R., Chen Y., Kokta M.R. (2001b) Enhancement of electrical conductivity in $\alpha-\mathrm{Al}_{2} \mathrm{O}_{3}$ crystals doped with magnesium. Journal of Applied Physics, Vol. 90, No. 8, pp. 3942-3951.

Tardío M., Ramírez R., González R., Chen Y., Kokta M.R. (2001c) High temperature semiconducting characteristics of magnesium-doped $\alpha$ $\mathrm{Al}_{2} \mathrm{O}_{3}$ single crystals. Applied Physics Letters, Vol. 79, No. 2, pp. 206-208.

Thailand stands by thermal enhancement claim (2002) Jewellery News Asia, No. 220, pp. 80-90

Themelis T. (1992) The Heat Treatment of Ruby and Sapphire. Gemlab Inc., Clearwater, FL, 236 pp.

Themelis T. (2003) Beryllium-Treated Rubies $\Theta$ Sapphires. Ted Themelis, Bangkok, Thailand, $48 \mathrm{pp}$.

Townsend M.G. (1968) Visible charge transfer band in blue sapphire. Solid State Communications, Vol. 6, pp. 81-83.

Treated Songea sapphires hit the market (2002) Jewellery News Asia, No. 209, p. 62.

Wang H.A., Lee C.H., Kröger F.A., Cox R.T. (1983) Point defects in $\alpha$ $\mathrm{Al}_{2} \mathrm{O}_{3}: \mathrm{Mg}$ studied by electrical conductivity, optical absorption, and ESR. Physical Review B, Vol. 27, No. 6, pp. 3821-3841.

Wang W., Green B. (2002a) Gem News International: Update on Be-diffused corundum. Gems $\oplus$ ) Gemology, Vol. 38, No. 4, pp. 363-364.

Wang W., Green B. (2002b) An update on treated natural corundum. GIA Insider, December 20, 2002, http://www.gia.edu/newsroom/ issue/2798/1482/insider_newsletter_details.cfm\#2.

Weldon R. (2002) Corundum conundrum. Professional Jeweler, Vol. 5 No. 3, pp. 36-37. 